مجلة كلية التربية ـ جامعة الإسكندرية المجلد السادس والعشرون (العدد الرابع) لسنة 17 ب ب

فاعلية برنامج معلوماتي قائم على استخدام بعض الأنثطة الموسيقية

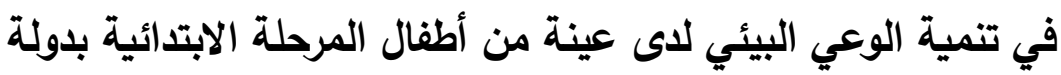
الكويت

د. سميرة علي حسن المذكوري

د. تمحم حمد السعيد

"د. ناصر عبد العزيز العسعوسي

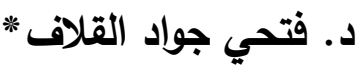

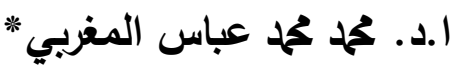

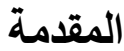

هناك تفاعل مستمر بين الإنسان وبين البيئة التي يعيش فيها منذ

أن خلقه الله تعالي، فالإنسان يحاول السيطرة على البيئة والتغيير من عواملها بما يتوافق مع رغباته ومع ظروفه، ونتيجة لسعيه الدائم نحو إشباع حاجاته البيئية ازدادت الضغوط على البيئة وازدادت مشكلاتها من رعن نقص في الغذاء مع محدودية في مصادر الطاقة وتزايد السكان بدرجة كبيرة.

ولذلك تعد القضايا البيئية واحدة من أهم المجالات الرئيسية التي تشغل بال جميع الدول المتقدمة والدول النامية على حد سواء، حيث شهدت الفترات الأخيرة زيادة في المشكلات البيئية والمرتبطة بتدهور الموارد الطبيعية، وارتفاع مستويات التلوث في الهواء والماء، بالإضافة إلى استتزاف الموارد الطبيعية من خلال الاستخدام المفرط لتلك الموارد، مع ندرة الماء العذب على نطاق العالم، والنقص في مساحة الرقعة

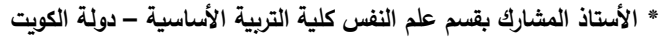

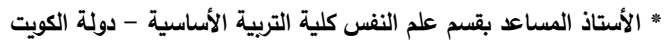

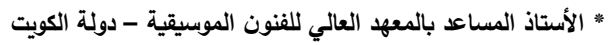

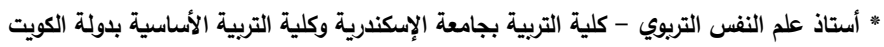


الخضراء، واستتزاف التربة، واختلال التتوع البيولوجي، حيث صارت تلك

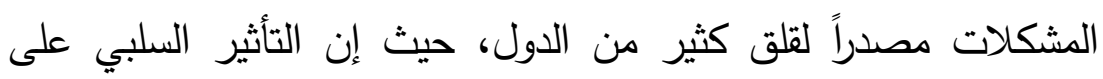
البيئة يؤثر في جميع مجالات النمو والتتمية المستدامة على المدى البعيد،

يذهب إلى تهديد النمو والتتمية المستدامة على المدى البعيد، بل يذهب إلى تهديد واسع النطاق على الإنسان. ومع تقدم الزمن تضاعف تأثير الإنسان على هذه البيئة، حيث النقان

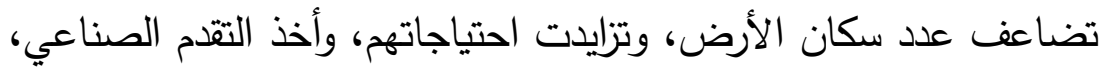
والتطور العلمي، والقوة التكنولوجية تفرض نفسها وتوسع من دائرة نشاط ولاط

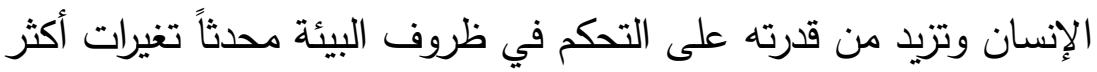
Klein, )

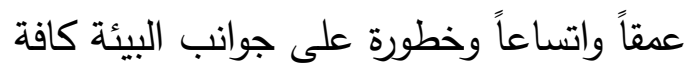
.(E. and Messitt, A. 2014 لاللك تعالت الأصوات التي نادت بضرورة العمل على الحد من هذه المشكلات، مع ضرورة تضافر الجهود التي تحاول التصدي لها، نظراً

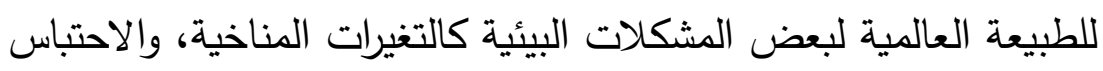
الحراري، واستنفاد طبقة الأوزون، بالإضافة إلى تشابه أغلب المشكلات Krishnamara, V. )

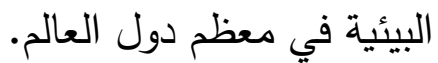
.(and Reddy, G.2005 ومن تلك المشكلات أيضاً كذلك التوسع في استخدام الطاقة الملوثة للبيئة في كافة مناحي الحياة كالأغراض المنزلية والخدمات العامة، ونتيجة لذلك تدهورت النظم البيئية في كثير من دول العالم، وقد ظهرت محاولات متعددة للتغلب على تلك المشكلات منها وضع القوانين المتعددة، وعقد الكثير من اللقاءات والمؤتمرات، ولكن كل هذه المحاولات لم تأتي بالثمار من عقدها ولم تحقق الغرض منها بدرجة كافية، وربما 
يرجع ذلك إلى قلة وعي الأفراد ببيئاتهم وبالمشكلات والمخاطر التي تحيط بها.

ولقد سلم المجتمع الدولي بأهمية اتخاذ خطوات عملية للحد من تدخل الإنسان سلبياً في البيئة، والعمل على نشر الوعي البيهئي بين مختلف قطاعات المجتمع، ولقد عقد مؤتمر عالمي في ستوكهولم عام

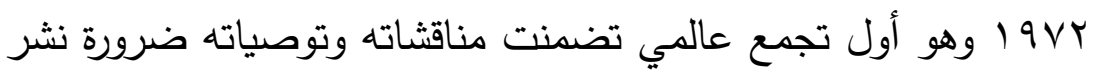

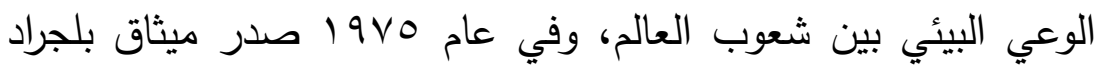

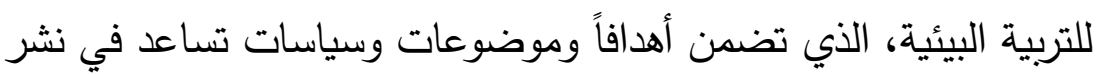
الوعي البيئي بين سكان العالم

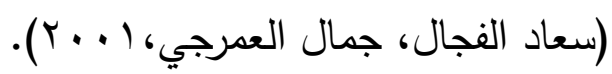

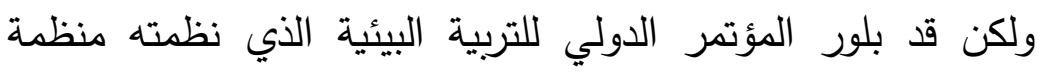
اليونسكو وبرنامج الأمم المتحدة الإنمائي في الاتحاد السوفيتي السابق

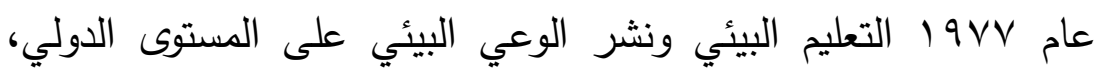

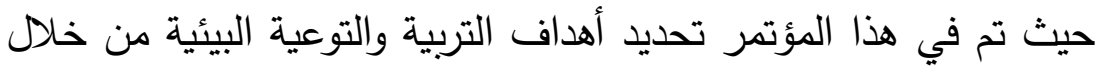

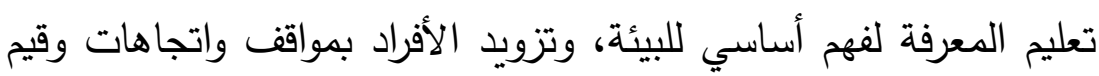
ايجابية نحو البيئة، وتوليد أنماط جديدة من السلوك تجاه البيئة بهدف ولئه خلق وعي بيئي لدى جميع قطاعات المجتمع، والتركيز على التدريس في المدارس والكليات (Malhotra, T.2012). والذي يمكن ملاحظته أن المؤتمر الدولي للتربية البيئية الذي عقد عام I9VV في ثلاثة أبعاد هي البعد المعرفي، والبعد القيمي (الاتجاهات)، والبعد السلوكي (المهاري).

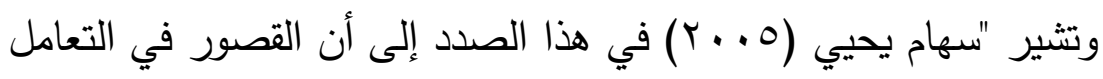
مع المشكلات البيئية يكون نابعاً من قصور الوعي البيئي عند الأفراد،

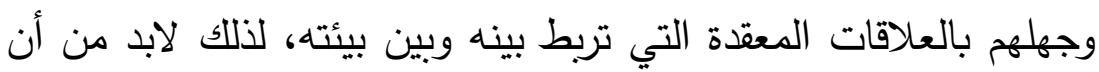


تراعي عملية نشر الوعي البيئي إكساب الفرد الخلفية المعرفية حول

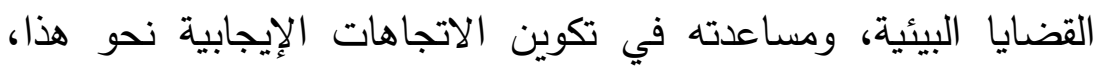

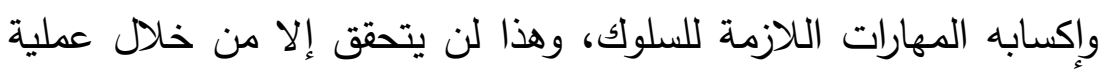
مدنهجة ومتكاملة في العملية التعليمية.

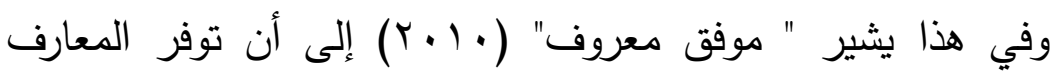

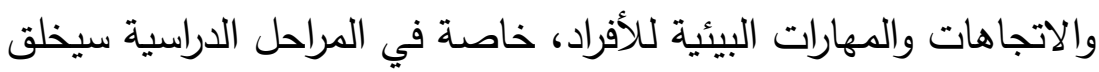
جيلاً قادراً على رعاية بيئية وتلافي أخطارها وسيضع الحلول المناسبة لمشكلاتها، بما يجعله يتكيف بشكل صحيح معها. وعملية نشر الوعي البيئي يجب أن تتم على نطاق واسع في المجتمعات المختلفة من خلال المناهج الدراسية وفي سياسة المعلمين أثناء تعاملهم لئه

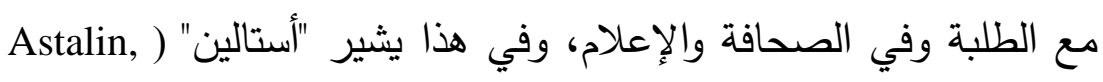

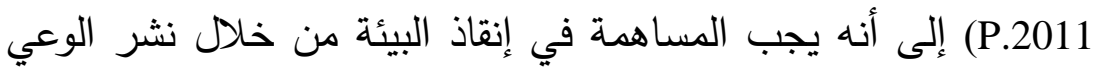
البيئي بين الطلبة من خلال المناهج الدراسية، ومن خلال المعلم القادر على إكساب الطلبة المعارف البيئية وتوليد القيم والاتجاهات البيئية لدي

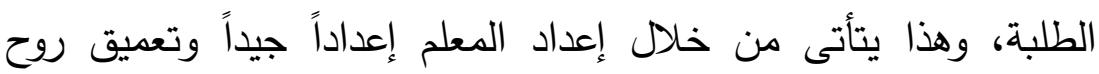

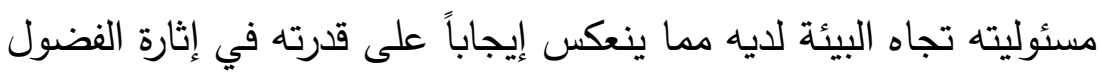

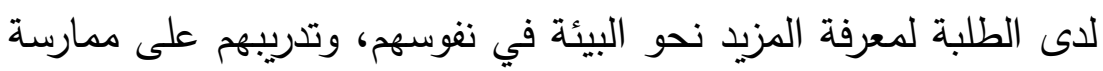
سلوكيات صديقه للبيئة، والقيام بدور فعال في حماية بيئاتهم.

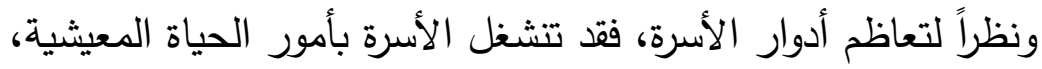

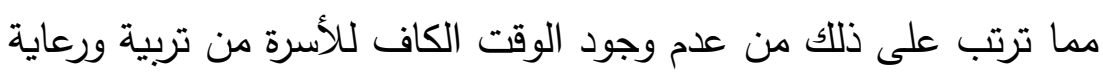
أبنائها، لذلك أكدت جميع المصادر الموثوق بها من أهمية دور المدرسة

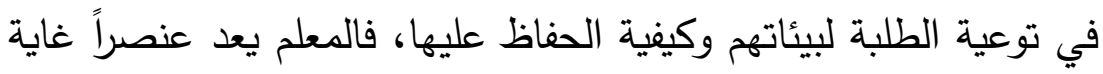
في الأهمية في مجال نشر الوعي البيئي، فما زال يمثل أحد مدخلات

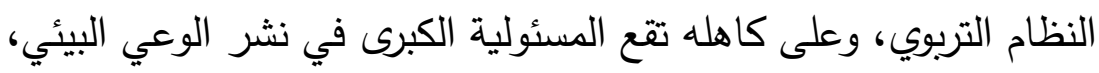

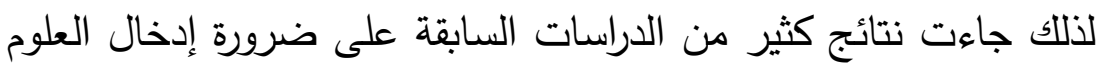


البيئية والتربوية البيئية في مناهج إعداد المعلمين قبل الخدمة، وأن تتخذ

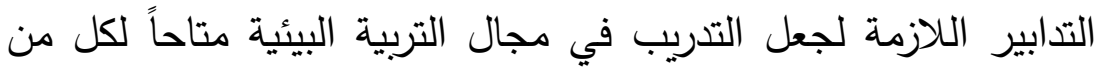
يحتاج إليه من المعلمين أثناء الخدمة من أجل رفع مستوى الوعي البيئي لديهم.

ولقد دللت كثير من الدراسات على أن لا تترك التربية البيئية للصدفة، ولكن يجب أن تحتل مكانة عالية وراقية في السياسات والخطط والبرامج التعليمية، كما وتعتبر المدرسة أولى المؤسسات المسئولة عن ون ذلك في مجال التربية، وقد أدى ذلك إلى تطوير برامج الإعداد والتدريب،

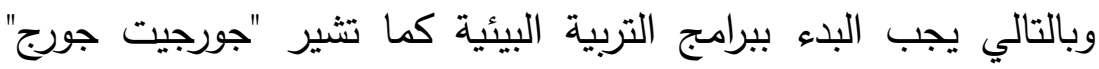

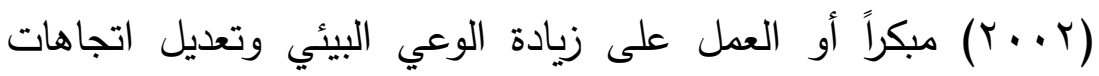
الطلبة نحو البيئة.

إن قضية تتمية الوعي بالبيئة والإحساس بها، تعد قضية هامة لجميع أفراد أي مجتمع، واستجابة للاتجاهات العالمية التي تحض على ضلى ضرورة وجود بيئة خصبة للتعليم ومحاولة الحفاظ عليها أصبحت محوراً أساسياً في جميع المجتعات، فلقد أصبحت كثير من المنظمات والمؤسسات العمل على إدخال التكنولوجيا الحديثة والبرامج المتطورة لتنمية الإحساس بالبيئة والتعامل مع التكنولوجيا المتطورة والاستفادة منها في تكوين وتتمية

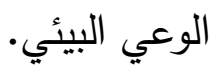

ونتيجة لمواكبة الاهتمام العالمي بنشر الوعي البيئي بين قطاعات

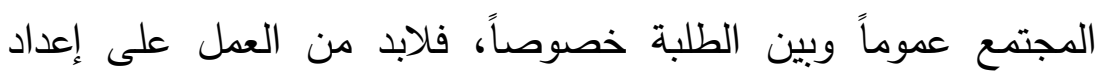

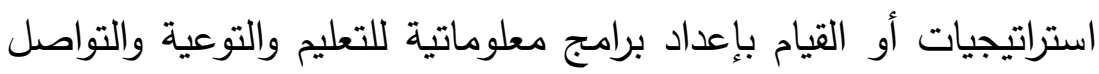
البيئي ولإدخال قضايا البيئة والاهتمام بها في العملية التعلمية، والعمل على وضع إجراءات عملية لضمان نشر الوعي البيئي بين الطلبة من ونان خلال تقديم مقررات تعليمية بيئية للمعلمين قبل الخدمة، وتتمية الاتجاهات التي تؤكد دور المدرسة في تتمية الوعي البيئي لدى الطلبة 
من خلال توظيف عدد من البرامج التي تعتمد على الطرق العلاجية للقضايا البيئية والعمل على إكساب المعلمين أنماط تدريس جديدة، وتوجيه برامج التعليم البيئي إلى تعديل سلوك الطلبة وإكسابهم ممارسات فعلية تؤدي إلى تتمية الحس والوعي البيئي.

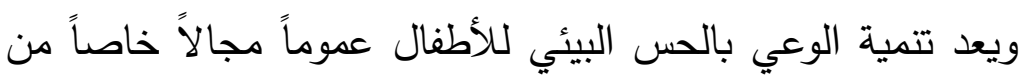
مجالات الاهتمام به، ويمكن تتمية الوعي البيئي من خلال برامج بيئية

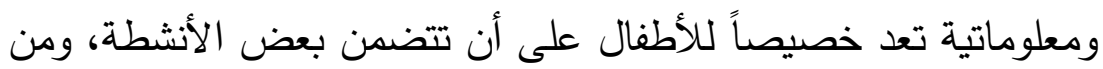
هنا جاءت فكرة البحث الحالي والتي تدور حول كيفية إعداد برنامج معلوماتي قائم على استخدام بعض الأنشطة الموسيقية وقياس فاعليته في

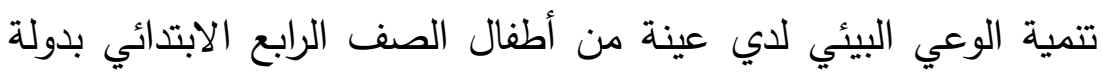
الكويت.

\section{مشكلة البحث}

رغم الاهتمام المتزايد بالتربية البيئية، إلا أن المشكلات البيئية في تزايد مستمر نتيجة للاستغلال الجائر للموارد البيئية، أو لنقص الوعي من

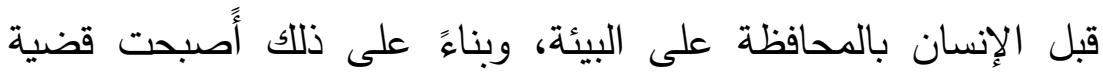
البيئة وحمايتها والمحافظة عليها من مختلف أنواع التلوثات من أهم

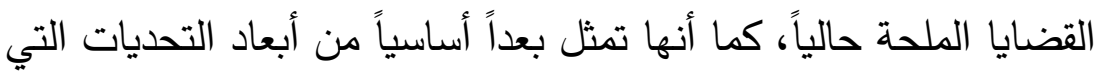
تدور حول أثر المخاطر البيئية في المستقبل. ومن جانب آخر فإن البيئة هي الإطار الذي يمارس الإنسان فيه

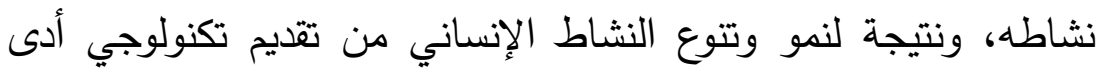

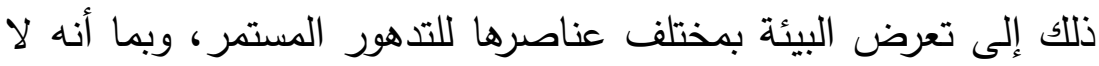
يمكن التعرض للتتمية والتطور والتقدم التكنولوجي بالإيقاف من أجل بيئة

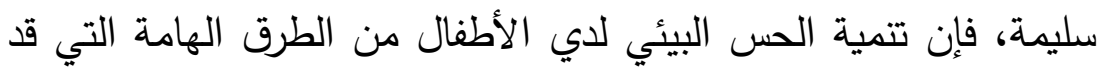
تساعد في الحد من مقدار التلوث والتدهور البيئي. 
إزاء هذا أصبحت القضايا البيئية من القضايا الأساسية والمحورية التي تتحدى التنمية الاقتصادية والبشرية، ومعالجة ذلك التلوث يعني تخفيف لهن التيه

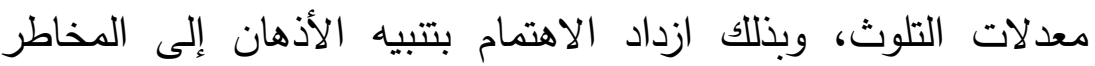
المترتبة على عدم الوعي بالبيئة التي تحيط بنا وبالأجيال القادمة. من هنا نرى أن ثمة إقرار من الجميع بالحاجة الماسة لخلق تربية بيئية ووعي بيئي وثقافة بيئية لاى الجميع وعلى وجه الخصوص الخد الأطفال

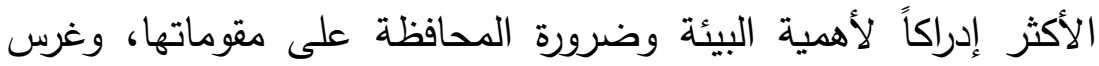
السلوك الإنساني السليم بوصفه العامل الرئيسي الذي يحدد أسلوب الئه وطريقة تعامل الإنسان معها، واستغلال مواردها حتى يمكن التحكم في المحافظة على القوانين التي تنظم مكونات البيئة الطبيعية، وتشكل التربية البيئية والوعي البيئي بوجه عام محاولة محكمة للتخلص من الكثير من

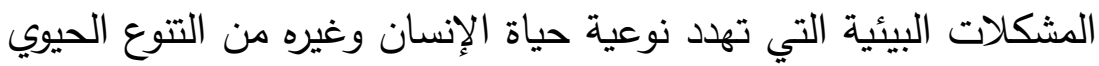
أو الأحياء الأخرى على الأرض عن طريق توضيح المفاهيم والحقائق والعلاقات التي تربط الإنسان ببيئته وتساعده على التعرف على مشكلاتها

$$
\text { وتلاقي هذه المشكلات وحلها. }
$$

والوعي البيئي المرتبط بالتربية البيئية يمثل أحد وسائل تخفيف حماية البيئة وأهدافها لأنهما يعملان على غرس السلوك الإيجابي وتتميته تجاه البيئة، ويسعيان إلى إيجاد وعي وطني بأهمية البيئة لمتطلبات التنمية بأهدافها.

ومن هنا تأتي ضرورة تتمية الوعي البيئي عند الفرد خلال تربيته بيئياً، والعمل على وضع القوانين والتشريعات البيئية التي تحكم العلاقة بين الفرد وبيئته، وعلى وجه الخصوص فإن تتمية الوعي البيئي عند الأطفال يعد مجالاً هاماً، ويمكن تنميته لديهم من خلال إعداد برامج التربية البيئية في المدارس والتي تتضمن بعض الأنشطة الموسيقية، وتتمية الوعي البيئي في المراحل المبكرة من الطفولة تؤدي إلى تتمية 
اتجاهاتهم ومفاهيمهم وقيمه وسلوكياتهم بما ينعكس بالإيجاب على بيئاتهم المباشرة بما يحقق نوع من العلاقة المتوازنة التي تحقق الأمان

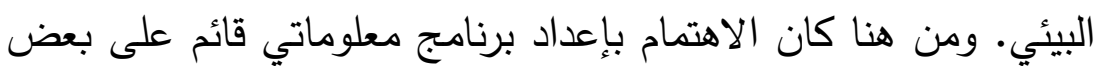

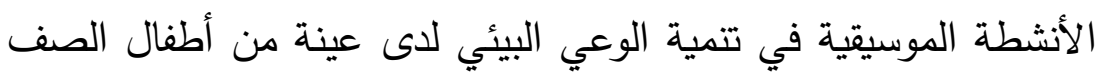

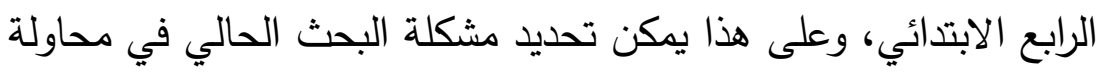

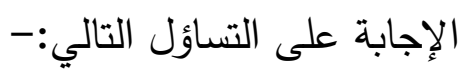

ما فاعلية البرنامج المعلوماتي القائم على استخدام بعض التصالئ الأنشطة

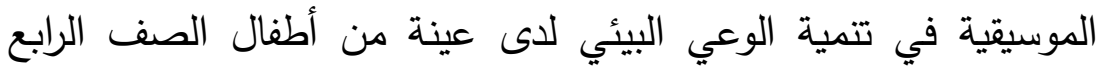

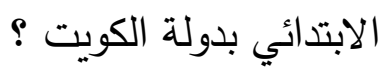
ولإجابة على هذا التساؤل، تم الالتزام بالإجابة عن التساؤلات الفرعية

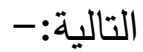

1- هل توجد فروق دالة إحصائياً بين متوسطي درجات أطفال المجموعة التجريبية وأطفال المجموعة الضابطة في القياس القبلي على مقياس الوعي البيئي بأبعاده لأطفال الصف الرابع الابتدائي ؟

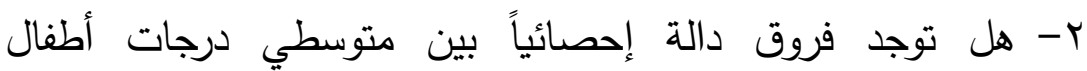
المجموعة التجريبية وأطفال المجموعة الضابطة في القياس البعدي لهي

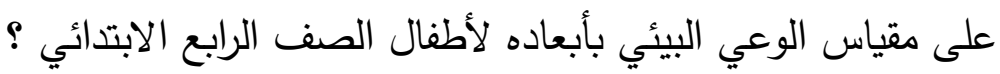

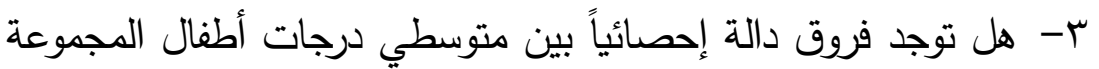
التجريبية في القياسين القبلي والبعدي على مقياس الوعي البيئي بأبعاده

$$
\text { لأطفال الصف الرابع الابتدائي؟ }
$$

ع- هل توجد فروق دالة إحصائياً بين متوسطي درجات أطفال

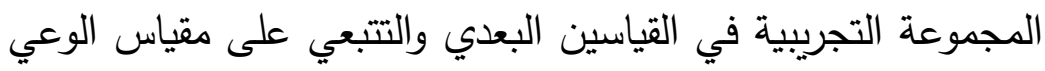
البيئي بأبعاده لأطفال الصف الرابع الابتدائي ؟ 
Information Program البرنامج المعلوماتي مجموعة من الإجراءات والأنشطة التي يقوم بها الطفل بكل حماس وفي شكل تعاوني لتحقيق أهداف تربوية محددة تتمثل في اكتساب المعارف

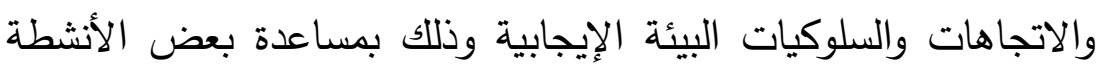
الغنائية والموسيقية المستمدة من البيئة المحيطة، على أن يتعلم الطفل كيف يحل المشكلات البيئية التي تواجهه من خلال الاندماج في أنشطة كل خطوة من خطوات البرنامج.

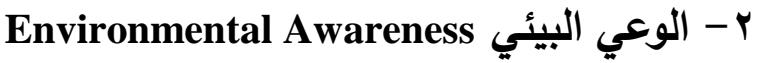
إدراك الطفل لدوره في التعامل مع البيئة ومواجهتها، وحسن استغلال مواردها الطبيعية، وإدراكه للمشكلات البيئية، وقدرته على التوصل لأنسب الحلول لمواجهة هذه المشكلات، ويقاس الوعي البيئي في البحث ولهث

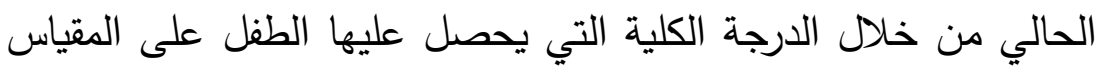
المعد لللك بأبعاده الثلاثة (المعرفة البيئية، الاتجاهات البيئية، المهارات

البيئية).

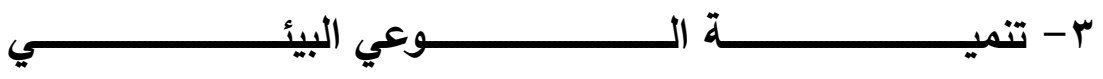

Development of Environmental Awareness توعية الطفل وتتمية إدراكاته واتجاهاته ومهارات في التعامل مع البيئة ومواجتها وحسن استغلال مواردها بما يعود بالنفع على حمايتها والمحافظة عليها.

$$
\text { צ - مكونات الوعي البيئي }
$$

أ - المعرفة البيئية: وتتمثل في تزويد الأفراد بالمعلومات البيئية التي تمكنهم من معرفة بيئتهم وعلاقتهم معها. ب- الاتجاهات البيئية:- وتتمثل في تكوين اتجاهات إيجابية نحو البيئة، وأهمية المحافظة عليها. 
ج- المهارات البيئية: وتتمثل في إكساب الأفراد المهارات التي تمكنهم من المساهمة في حل المشكلات البيئية.

$$
\text { أهمية البحث }
$$

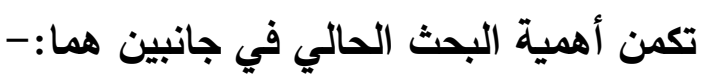

\section{الأهمية النظرية الهمن الهمبة}

\section{تنبع الأهمية النظرية للبحث الحالي من التالي:-}

1- يعتبر هذا البحث استكمالاً للجهود التي بذلت استجابة لما أوصت التهية

به القرارات والمؤتمرات التي عنيت بضرورة الاهتمام بالتربية البيئية

$$
\text { وإيجاد وعي بيئي لاى الأفراد. }
$$

r- يعتبر هذا البحث استكمالاً للدراسات والبحوث التي اهتمت الترات

بضرورة نشر الوعي البيئي لاى الأفراد.

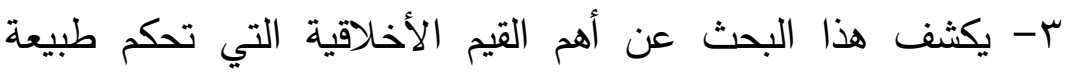
العلاقة بين الإنسان وبيئته فضلاً عن توصيف للإجراءات والأساليب

التي يمكن بها تتمية الوعي البيئي لدى أطفال المرحلة الابتدائية.

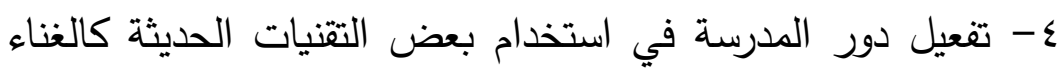
والموسيقى في تنمية الحس البيئي للأطفال.

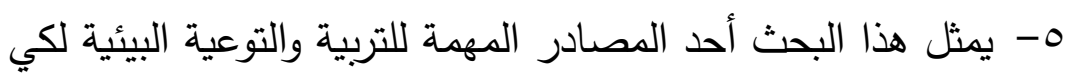
يسلك الأطفال سلوكاً قويماً تجاه البيئة التي يعيشون فيها، معتمدين في ذلك على خلفية معرفية ووجدانية تمثل أساساً كبيراً يوجه سلوكياتهم في الاتجاهات السليمة بوعي وحكمة. צ- يساعد هذا البحث في تقديم مصادر لتتشئة أفراد يدركون أبعاد الششكلات البيئية ويعملون على تفاديها، فتكون الطفولة هي البداية الحقيقية لتحقيق ذلك.

V- الاسهام في تحقيق التراكم المعرفي والبحثي الذي سوف يفتح الآمال أمام بحوث مستقبلية تتناول عينات من مستويات تعليمية 
مجلة كلية التربية ـ جامعة الإسكندرية المجلد السادس والعشرون (العدد الرابع) لسنة 17 ب ب

مختلفة من أجل تتمية الحس البيئي لهم تفادياً الوقوع في مشكلات مع البيئة.

\section{الأهمية التطبيقية التهانية}

\section{تكمن الأهمية التطبيقية للبحث الحالي في التالي:-}

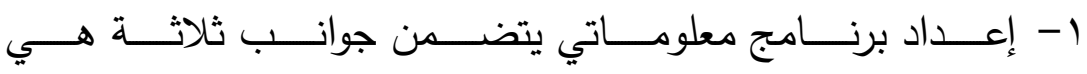

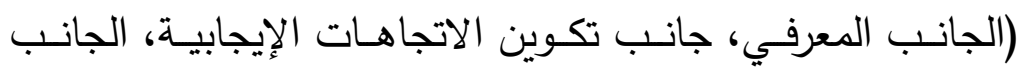

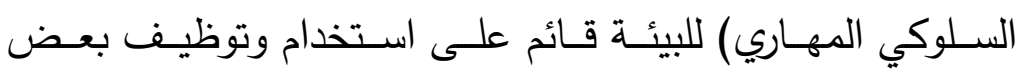

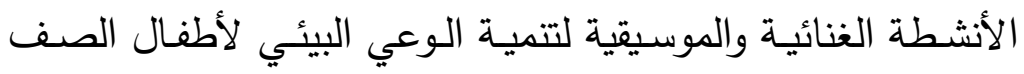

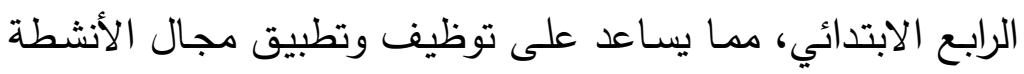
المدرسية المختلفة لتكوين علاقات متوازنة بين الأفراد والبيئة.

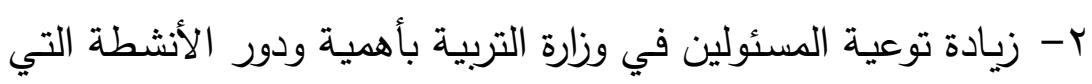
تساعد في تتمية الوعي البيئي لأطفال المرحلة الابتدائية.

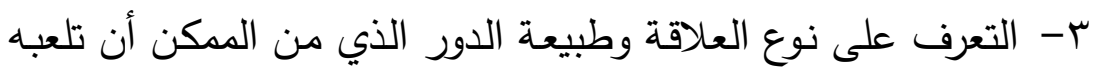

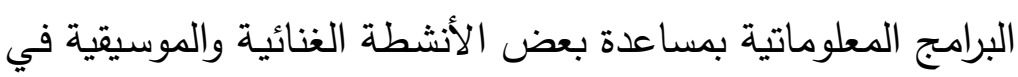
تتمية الوعي البيئي لدى الأطفال. أهداف البحث

\section{هدف البحث الحالي إلى تحقيق ما يلي:-}

ـ - إعداد برنامج معلوماتي قائم على استخدام بعض الأنشطة الغنائية

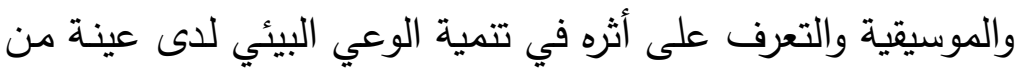
الأطفال الأكور بالصف الرابع الابتدائي. 0- إعداد مقياس لقياس الوعي البيئي لأطفال الصف الابني الرابع الابتدائي. 


\section{الحدود المكانية}

الأطفال الذكور بالصف الرابع الابتدائي بمدرسة علي بن أبي طالب الابتدائية للبنين بمنطقة حولي التعليمية بدولة الكويت. بالصفي الابتي بدرنه الحدود الزمنية

حددت الفترة الزمنية لإجراء هذا البحث بالفصل الدراسي الثاني من العام $\cdot 17 / r \cdot 10$ الإطار النظري يتناول الإطار النظري للبحث كل من المتغيرات التالية:- مفهوم البيئة، التربية البيئية (أهداف التربية البيئية، مستويات التربية البيئية)، التلوث

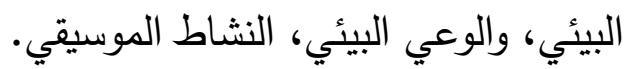

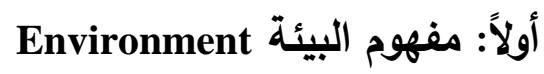
يمكن النظر إلى البيئة على أنها مجموعة الظروف الطبيعية للمكان من هواء وماء وأرض، والكائنات الحية المحيطة بالإنسان، وعلى ضوء لهيه ذلك

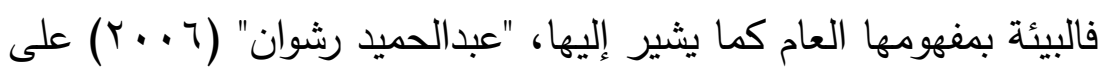
أنها الوسط أو المجال المكاني أو الإطار الذي يعيش فيشيله فيه الإنسان،

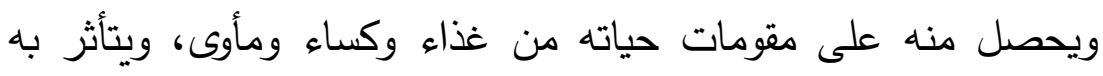
ويؤثر فيه - فالبيئة هي المحيط الذي يعيش فيه الإنسان ويقوم فيه بعملية الإنتاج، وتحتوي على مواد حية وغير حية وتتحكم فيها العوامل الاجتماعية والاقتصادية والطبيعية. فالبيئة عاملاً مهماً في تتمية قدرات الأفراد العقلية والنفسية والجسمية، ولمية، دافية كما تمثل دافعاً للإبداع الإنساني من حيث طبيعتها ومكوناتها الجغرافية، ومع تطور الصناعات المختلفة ووسائل التكنولوجيا الحديثة بدأت التأثيرات السلبية على البيئة، مما دعا الباحثين دراسة البيئة والاهتمام بها، واقتراح سبل للمحافظة عليها من الملوثات المختلفة. 
ومن هنا فقد بدأت المؤسسـات التربوية الاهتمام بنشر الوعي البيئي بين

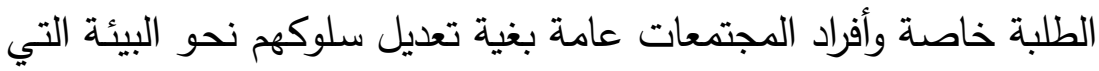
يعيشون فيها، فالتربية قادرة على إحداث تغيرات إيجابية في سلوك الأفراد

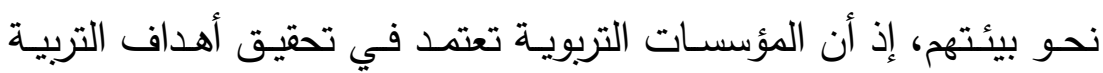

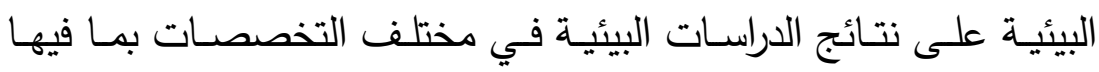
تصحيح المفاهيم البيئية لدى الأفراد، ونشر الوعي البيئي لليهم باستخدام

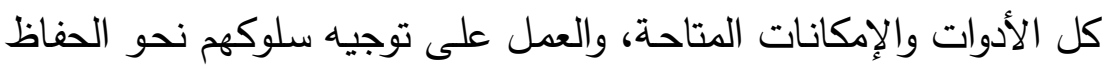

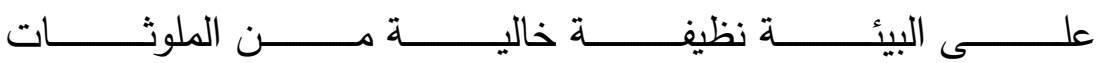

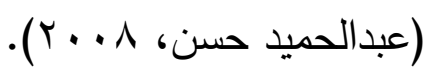

وفي ظل هذه المقدمات، فإن المؤسسات التربوية عليها دور هام في التربية البيئية ونشر الوعي البيئي بما يضمن تعديل وتوجيه السلوك

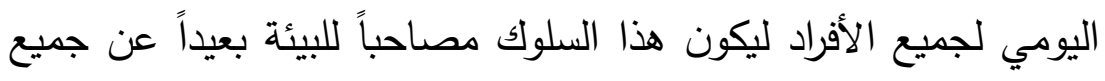
الممارسات المعادية للبيئة. لذا على المؤسسات التربوية عامة، والمدارس بصفة خاصة القيام بدور أساسي في تتمية الوعي البيئي من خلال المقررات الدراسية أو من خلال البرامج المعلوماتية المختلفة، ويتعاظم هذا الدور ويزداد أهمية لئية وخاصة للممارسات الكثيرة التي تقوم بها الدول من تدمير للبيئة بفعل ولئل

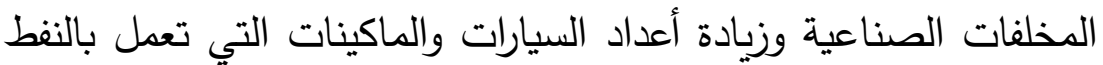

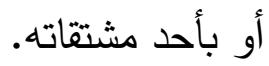

وتزداد دور المدارس أهمية في التربية البيئية ونشر الوعي البيئي

في دولة الكويت بتحديد دورها في إيجاد الطالب الواعي بأهمية البيئة والمنتمي للمجتمع الذي يعيش فيه من خلال تتاغم وتكامل لدور المناهج الدراسية ومدخلات العمليات التربوية الأخرى. 
وتزداد أهمية تتمية الوعي البيئي عند الأطفال من خلال التربية البيئية،

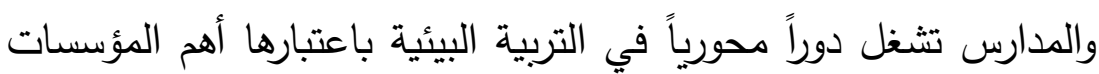
التربوية والاجتماعية القادرة على التأثير في وعي وسلوك الأطفال. ثانياً : الوعي البيئي الواعيه هناك شبه إجماع بين الباحثين على تعريف الوعي البيئي، فالوعي بداية

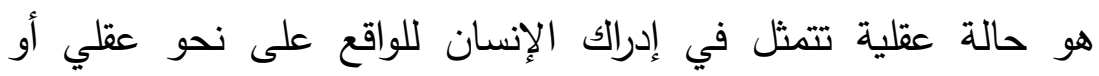
وجداني يساعده في التصرف بطريقة صحيحة.

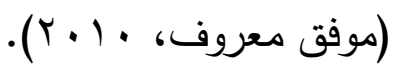

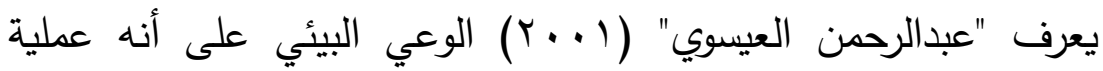
إدرالك ومدى معرفة المشكلات البيئة، وكيفية التغلب عليها، ومدى لئى لئي الوصول إلى الحل الأفضل وإظهار البيئة بشكل صحي ومنظم.

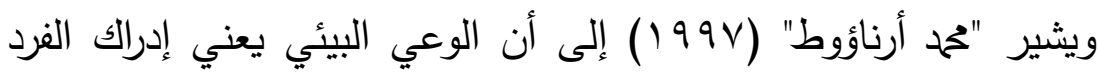

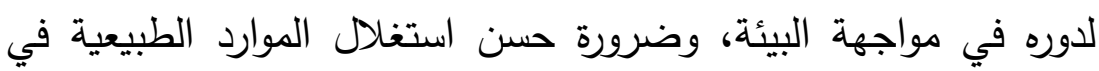
البيئة، مع إدراك المشكلات البيئية واقتراح أنسب الأساليب لمواجهة هذهة الئه المشكلات.

كما يعرف "سعيد الحفار" (9941) الوعي البيئي على أنه يتمثل في توضيح المفاهيم ومعرفة القيم التي تهدف إلى تتمية المهارات اللازمة لفهم وتقدير العلاقات التي تربط بين الإنسان وبيئته الطبيعية الحيوية.

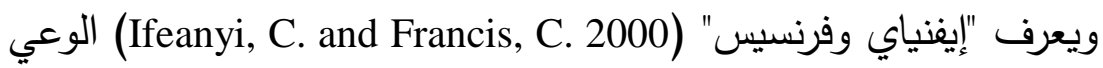
البيئي بأنه اكتساب الأفراد المعارف الكافية بمكونات وقضايا ومشكلات البيئة، وفهم العلاقة بين الإنسان والبيئة، وتقدير قيمة مكونات البيئة والمحافظة عليها، والتدريب على حل المشكلات البيئية والحد من حدوثها مستقبلاً. 
ويعرف ديسنجر" (Disinger, j. 2001) الوعي البيئي بأنه إدراك الفرد للبيئـة القـائم علـى المعرفــة والثــعور الـداخلي نحـو عناصـر البيئـة ومشكلاتها.

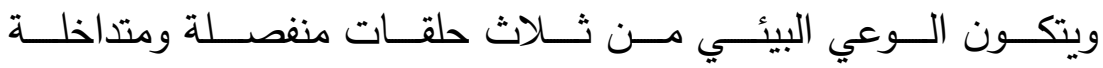
(Rider, T. 2005) - التربية والتعليم البئي

ويبدأ بالتعليم من رياض الأطفال ويستمر خلال مراحل التعليم العام إلى الى التعليم الجامعي، بشرط أساسي وهو وجود تكامل لأهداف البرامج التعليمية والتربوية. r- r - r الثقافة البيئية تبدأ من توفير مصادر المعلومات من كتب ونشرات وإشراك المثقغين البيئيين في الحوارات والنقاشات المذاعة والمنشورات، وفي الحوادث

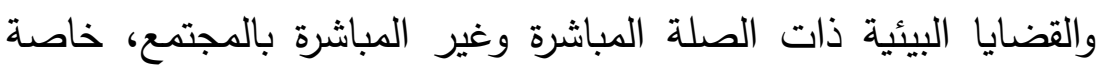

$$
\text { ذات المردود الإعلامي. الإعلامي البيئي }
$$

هو أحد أهم أجنحة التوعية البيئية وهو أداة إذا أحسن استثمارها كان لهائ مردود إيجابي للرقي بالوعي البيئي، ونشر الإدراك السليم للقضايا البيئية، ويعمل الإعلام البيئي في تفسير وفهم وإدراك المتلقي لقضايا البيئة

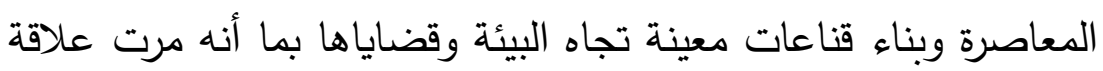
الإنسان بالبيئة كما هو معروف بمراحل عديدة عكست على نحوها ظهور

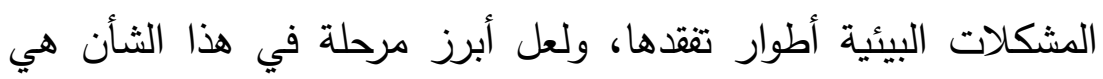

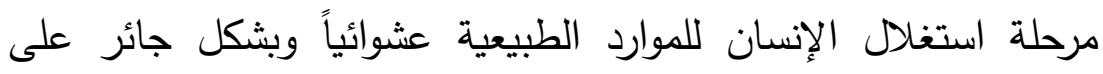
حساب التوازن البيئي ودون الاهتمام لاحتياجات الأجيال التالية،

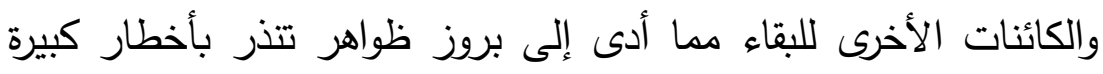

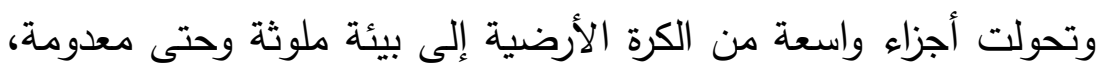


بلغت في مناطق عديدة عدم صلاحيتها لحياة الكائنات الحية، وقد دفع الإنسان بدوافع عديدة أغلبها غير مشروع أن يخرب ويدمر الإطار الذي

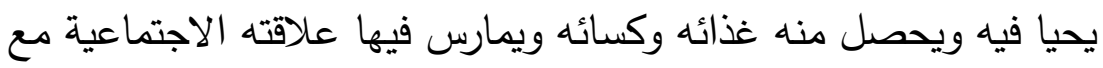
أقرانه من بني البشر، وبذلك ظهرت حركة مناوئة للأعمال المخربة للبيئة واليوم لا تقتصر مشكلة البيئة فقط على التلوث بل يتعداه ليشمل باقي

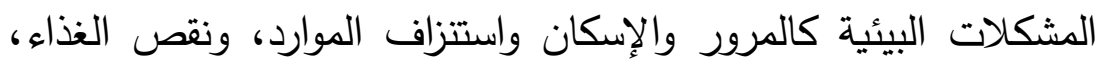
وتدهور التربة، والتصحر وزيادة السكان، وغيرها من المشاكل البيئية

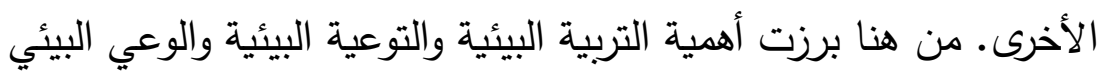
المطلوب للمواجهة التي نتجت عن ممارسات الإنسان الخاطئة، الناجمة عن انعدام أو نقص الوعي البيئي لايه، وتفاقتت المشكلات البيئية طردياً

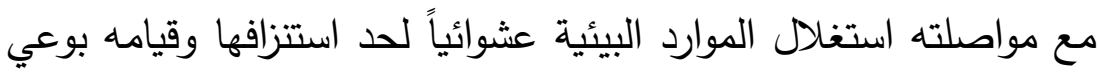
أو دون وعي بتدمير الأنظمة البيئية حتى هددت حياته، وبذلك برزت البرايه الحاجة لتوعية الإنسان وإفهامه كي يدرك مخاطر سلوكياته الخاطئة تجاه بيئته، وحتم ذلك ضرورة أن يربى الإنسان منذ نشأته تربية بيئية صحيحة تبدأها الأم مع رضيعها حتى يصل إلى سن المدرسة بمشاركة الأسرة بدءاً

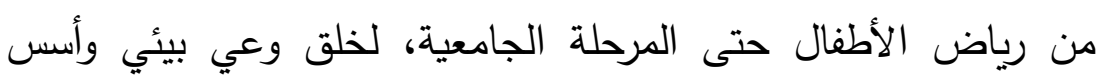
تربوية تجاه البيئة لكي يفهم حقيقة البيئة ويتعامل مع المكونات الحية وغير الحية بشكل صحيح. يمكن ملاحظة أن مفهوم الوعي البيئي لا يكون موجهاً إلى الذاكرة أو أو الو

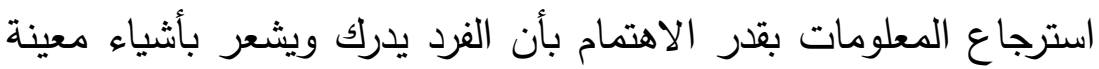
نحو الموقف أو نحو الظاهرة البيئية، ومن ثم يمكن استخلاص أبعاد الوعي البيئي من خلال التعاريف الواردة، كما يلي:-

1- المعرفة البيئية: تتمثل في تزويد الأفراد بالمعلومات البيئية التي تمكنهم من معرفة بيئتهم وعلاقتهم معها. 
r- الاتجاهات: وتتمثل في تكوين الاتجاهات البيئية نحو البيئة، وأهمية المحافظة عليها.

r- السلوك : ويتمثل في إكساب الأفراد المهارات التي تمكنهم من

$$
\text { المساهمة في حل المشكلات البيئية. }
$$

وتحتل المدرسة مكانة هامة في مجال تتمية الوعي البيئي بحيث تعكس لهن

الحاجات الاجتماعية للبيئة، وتحاول إكساب الأطفال والطلبة العادات

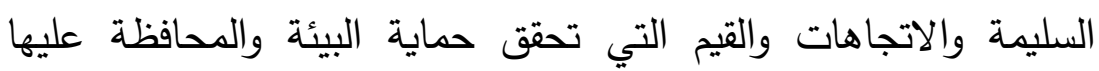

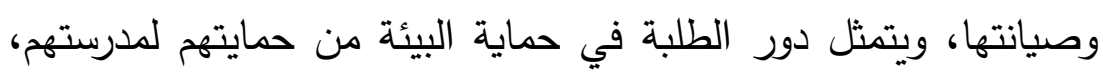
ما يتطلب مجموعة من الممارسات اليومية مثل المحافظة على نظافة

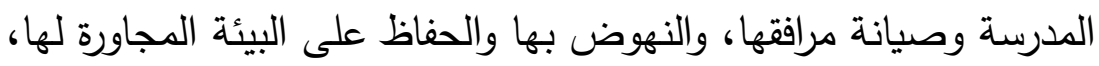
وفي هذه الحالات جميعها ينبغي أن يكون تعليم المعرفة والمهارات والاتجاهات عملية متكاملة، وينبغي أن تسهم المدرسة في تزويد الطلبة لندية الأساليب التي يحتاجون إليها في دراستهم البينية، وتعلمهم كيفية اتخاذ قرارات مناسبة بشأنها، وذلك عن طريق اشتراك المعلمين والطلبة في عملية تحليل البيئة التي يعيشون فيها، وتحليل الاتجاهات الاجتماعية

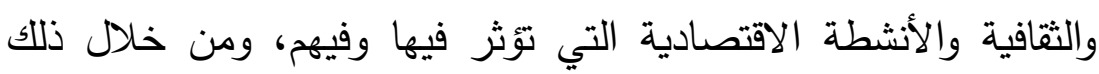

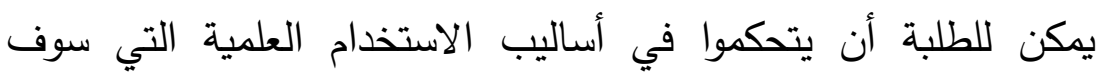
يمارسونها أو يحتاجون إليها من أجل تحسين طبيعة البيئة التي يعيشون فيها.

ويعد المعلم بمثابة العامل الأساسي في نجاح التربية البيئية وتحقيقها لأهدافها، ونموذجاً بسلوكه لتلاميذه يقتدون به، ويقلدونه في أثناء تفاعلهم

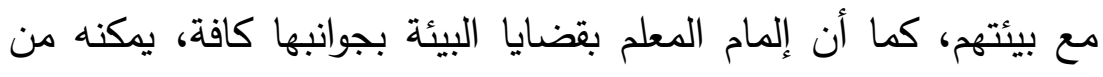

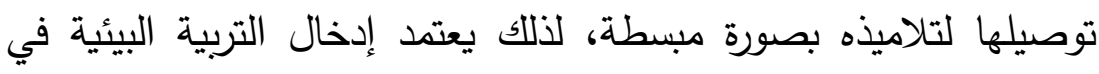

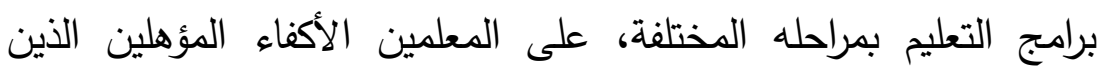
يمكنهم من تتفيذ هذه البرامج. 
ويمكن للأطفال أن يقوموا بدور في حماية البيئة من خلال التعليم البيئي

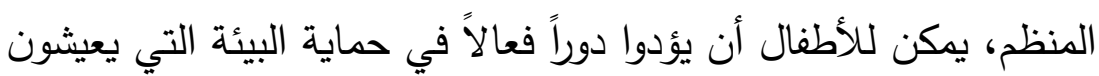

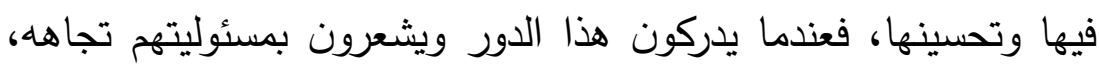

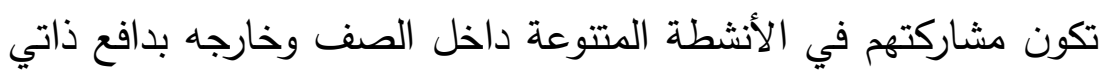

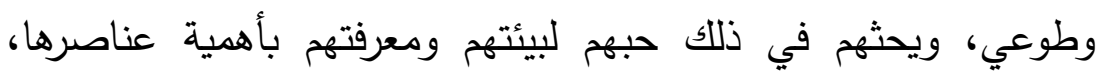

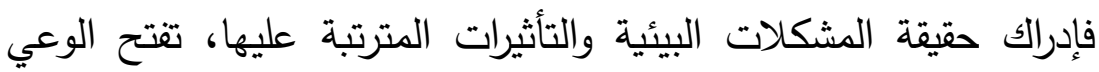
على ضرورة المساهمة في حلها، وتدفع الطفل على معرفة والقيام بدوره في المحافظة على بيئته وسلامتها، ويتمثل هذا الدور في المشاكل الفعالة في تتفيذ المهام الفردية والجماعية، كما يتمثل في السلوك اليومي للطفل (Reason, P. 2005) وتعتبر التوعية البيئية أهم أحد الجوانب الأساسية للمحافظة على البيئة،

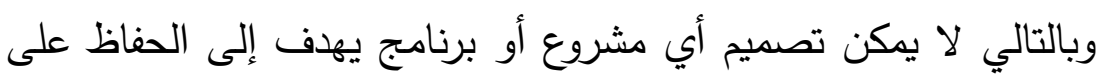
البيئة دون الأخذ في الاعتبار المكون البشري الذي هو أساس العملية التنموية. وهناك أطراف كثيرين مسئولين عن حماية البيئة، فهناك الطرف الرسمي والمتمثل في الحكومة، والطرف غير الرسمي (غير الحكومي) والذي يجب أن يساند الطرف الرسمي عن طريق الأفراد الذين يشتركون مع بعض في اعير واني سبيل تتمية المجتمع وتغييره (Disinger, j. 2001). ولذلك يعد إدراك الفرد لدوره من أهم الأسس التي تقوم عليها التنمية

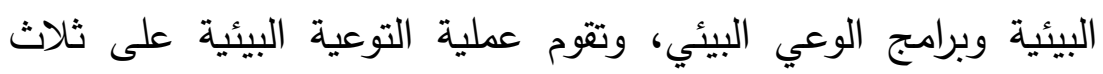
محاور رئيسية هي:-

- - توعية الأفراد من خلال تتمية إدراكهم عن البيئة.

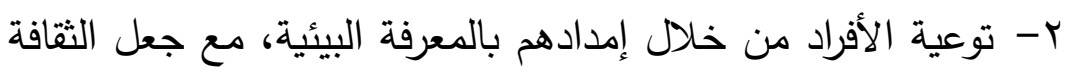
البيئية كوسيلة من وسائل التكيف البيئي. 
r- توعية الأفراد على أنهم يعيشون في بيئة معينة، تحتاج منهم

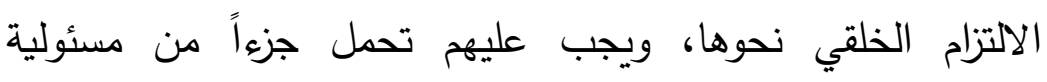
مشكلات البيئة وإيجاد حلول لها.

وهذه المحاور تعتمد على بعضها البعض، حيث إنها متفاعلة، ففي

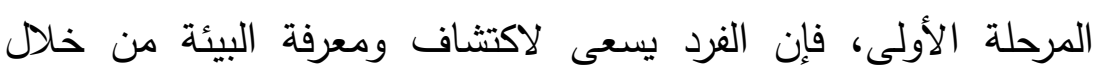

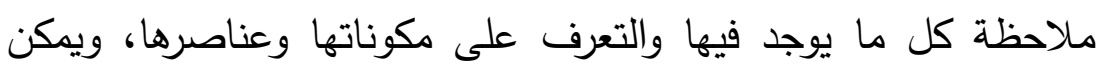
الإشارة هنا إلى أن هذه المرحلة متضمنة في البرنامج المعد في هذا ولها البحث من خلال إمداد الأطفال بالمعلومات المرتبطة بالبيئة، وفي المرحلة الثانية، فإن الأطفال يركزون على تثثيف وتعليم أنفسهم باستخدام

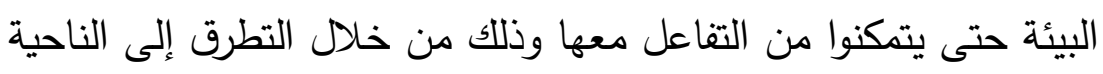

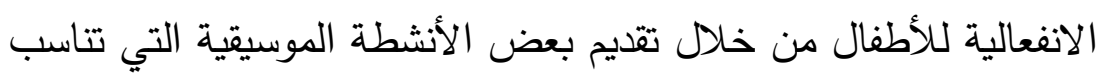
وأعمارهم الزمنية، وهي مرتبطة ببيئتهم الواقعية، والمرحلة الثالثة فإنها

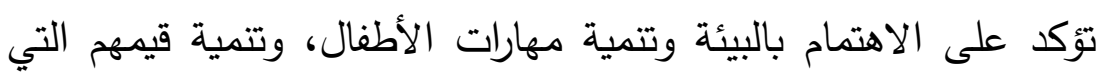
تكون سلوكهم بهدف تتمية الاتجاهات التي تؤدي غلى خلق وتكوين أخلاق بيئية إيجابية تجعل من الفرد أكبر مشاركاً للتفاعل مع البيئة واقتراح الحلول المكنة لمشكلات البيئة. وهناك مصطلحات كثيرة تعبر عن وجود نوع من الوعي لدى الأفراد نتيجة ارتباطهم بالبيئة والتفاعل معها، ومن هذه المصطلحات، التربية

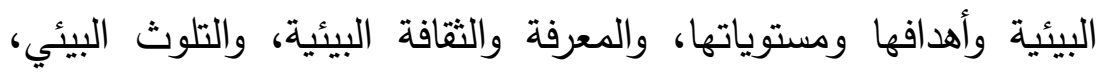

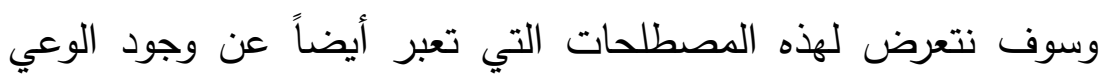
البيئي.

\section{1- التربية البيئية Environmental Education}


فالتربية البيئية تمثل نمطاً من التربية يهدف إلى معرفة القيم وتوضيح

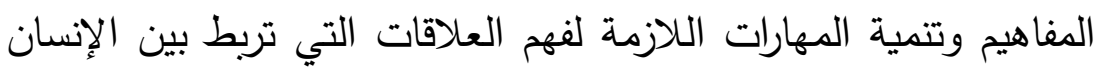
وثقافته وبيئته. فالتربيـة البيئيـة هي عملية إعداد الطفل للتفاعل الناجح مـع بيئته بمـا تشمله من موارد مختلفة، ويتطلب هذا الإعداد إكسابه المعارف والمفاهيم البيئية التي تساعد على فهم العلاقات المتبادلة بين الإنسان وعناصر

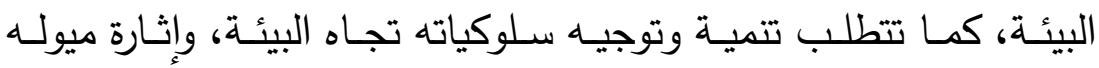

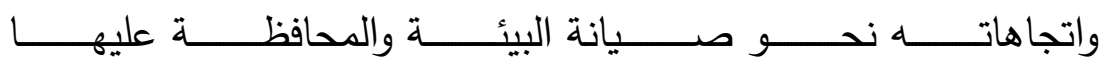

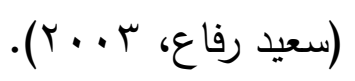

فالطفل يحتاج إلى تعلم كل ما يتعلق ببيئته، لأن حياته تتوقف على هذه

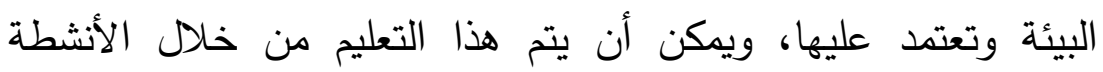

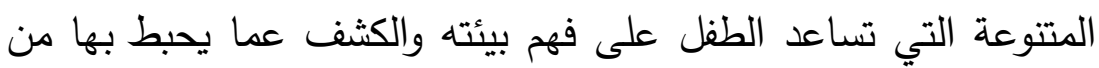
ظواهر طبيعية أو من صنع الإنسان، والتعرف على مشكلاتها، وبناء التقة في مقدرة الطفل على التفاعل البناء مع البيئة والتعاون على حلى ولى ولى مشكلاتها.

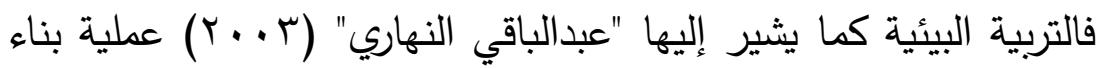
شاملة، وتتمية للاتجاهات والمفاهيم والمهارات والقدرات والقيم عند الأفراد لتحقيق الأهداف المخططة، فالتربية البيئية تعمل على تحقيق نجاح للإنسان في حياته على كوكب الأرض في إطار تفاعل بناء بين الإنسان

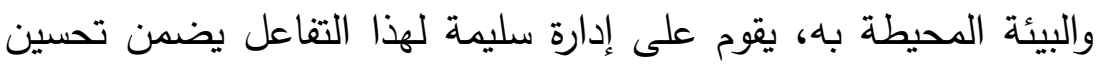
العلاقات بين الإنسان وبيئته بشكل شامل، بما فيها استخدام التقنيات

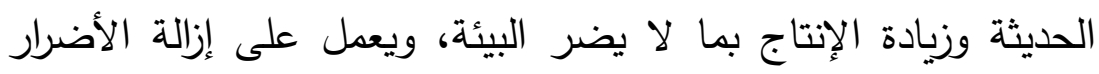

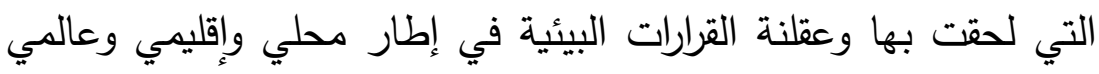
بهدف الحفاظ على الحياة البشرية. r - أهداف التربية البيئية 
بدأ الاهتمام حديثاً بالتربية البيئية من خلال تضمين المفاهيم البيئية في

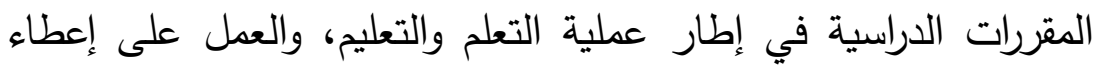
الأولوية بالاهتمام بالمشكلات التي تتعلق بحماية الموارد الطبيعية والحياة النباتية والحيوانية والمحافظة على التتوع البيئي، وعلى هذا فإن التربية

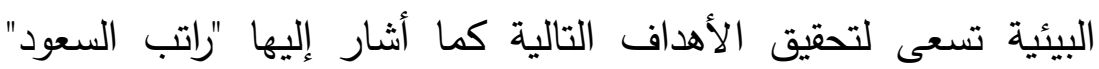

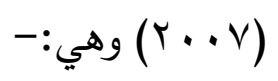

1- الاهتمام بالمشكلات البيئية من خلال المجالات المعرفية المختلفة في إطار محلي وإقليمي ودولي حتى يدرك الفرد حجم المشكلات البيئية ويقتنع بخطورتها، بما يضمن تطوير المفاهيم البيئية لدى لهى لهني المجتمعات الإنسانية، وتعديل السلوك الفردي نحو البيئة التي يعيش فيها.

r- العمل على الحفاظ على التوازن البيئي الذي يتكون من طبيعة معقدة وجوانب بيولوجية وفيزيائية واجتماعية وثقافية واقتصادية من خلال توضيح علاقة التكافل والتكامل التي تربط بين هذه العناصر المختلفة.

r- خلق الوعي الوطني بأهمية البيئة في الجهود الرامية للتمية في

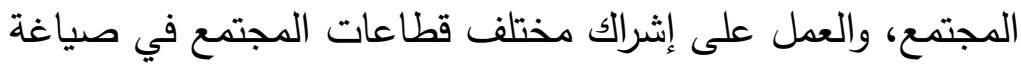
القرارات التي تتطوي على مساس بنوعية ومكونات البيئة التي يعيشون فيها والعمل على ضمان تتفيذها. ع- تتمية روح المسئولية والتضامن بين دول العالم المتخلفة والمتقدمة على السواء لتكون أساساً لنظام يضمن حماية البيئة وتطويرها وتحسينها، بما يشمل تطوير العملية التربوية لنشر المعارف والقيم وإحداث تغيير في السلوك الإنساني تجاه البيئة. 0- العمل على إيجاد كفايات وتقنية عملية لكافة أفراد المجتمع تسهل القيام بأنشطة رشيدة في مجال البيئة، وهذا يضمن إتاحة الفرصة 
لاكتساب الكفايات اللازمة للحصول على المعارف التي تتوافر في

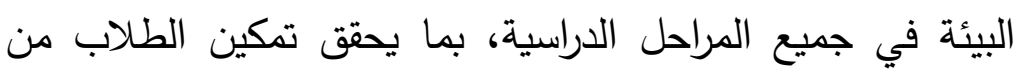
إيجاد حلول تطبيقية للمشكلات البيئية وتحليلها وتتييمها. צ- تعزيز الوعي والاهتمام بترابط المسائل الاقتصادية والاجتماعية والسياسية والبيئية في المناطق الريفية والمدنية.

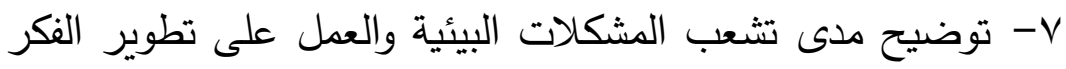
الناقد والمهارات التي تتعلق بالتعامل مع المشكلات البيئية بما فيها تشخيص أعراض المشكلات البيئية وأسبابها وطرق معالجتها. r- مستويات التربية البيئية يمكن تمييز خمسـة مستويات للتربيـة البيئية التي ينبغي لبرامج التربية

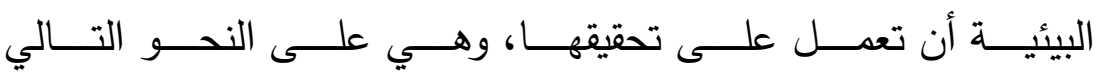
.(Jeronen, E, et al. 2009) أولاً: مستوى الوعي بالقضايا ومشكلات البيئة: تتضمن تنمية وعي الأطفال بالموضوعات التالية: 1- مدى تأثير الأنشطة الإنسانية على حالة البيئة بصورة إيجابية أو

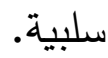
r- مدى تأثير السلوك الفردي للإنسان (مثل حرق المخلفات/

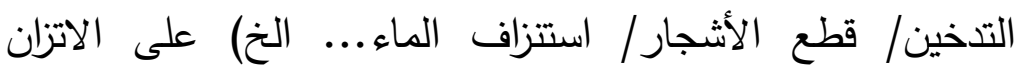
الطبيعي في البيئة. r- أهمية تضافر الجهود الفردية والمحلية والدولية لحل المشكلات البيئية.

ع- ارتباط المشكلات البيئية المحلية مع المشكلات البيئية الإقليمي

والعالمية وضرورة التعاون بين الثعوب لحل هذه المشكلات.

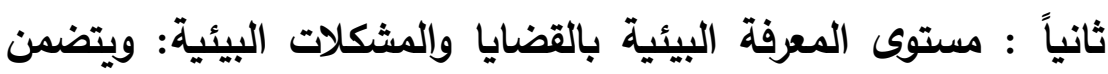

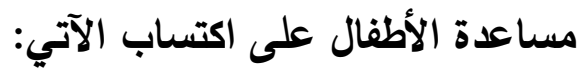




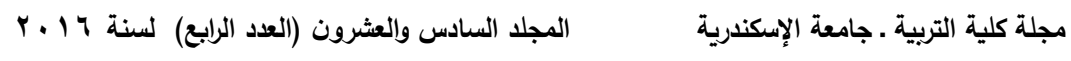

1 - تحليـل المعلومـات والمعـارف اللازمــة للتعـرف علـى أبعـاد

المشكلات البيئية التي تؤثر على الإنسان والبيئة.

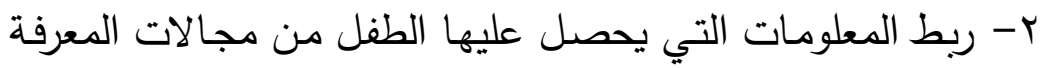

المختلفة بمجال دراسة المشكلات البيئية.

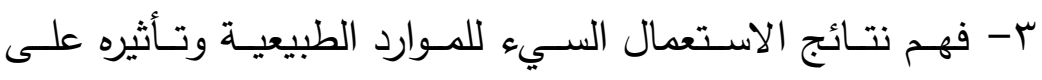

$$
\text { استنزاف هذه الموارد ونفادها. }
$$

ع - التعرف على الخلفية التاريخية التي تقف وراء المشكلات البيئية

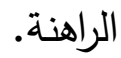

0- التعرف على الجهود المحلية والإقليمية والدولية لحمايـة البيئة

والمحافظة عليها.

ثالثاً: مستوى الميول والاتجاهات والقيم البيئية: وتتضمن تزويا الأطفال بالفرص المناسبة التي تساعد على الآتي:

1- تتمية الميول الإيجابية المناسبة لتحسين البيئة والحفاظ عليها. r- تكوين الاتجاهات المناسبة نحو مناهضة مشكلات البيئة والحفاظ

على مواردها وحمايتها مما يهددها من أخطار بيئية. r-تتمية الإحساس بالمسئولية الفردية والجماعية في حماية البيئة

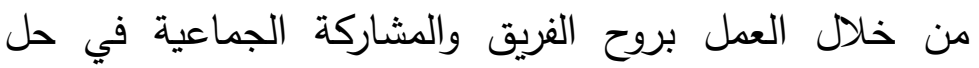
المشكلات البيئية.

ع - بناء الأخلاق والقيم البيئية الهادفة مثل احترام حق الاستمرار لكل

البيئات واحترام الملكيات الخاصة والعامة بشكل يوجه سلوك

التلاميذ نحو الالتزام بمسئوليتهم البيئية والالتزام بها.

0-تقدير عظمة الخالق سبحانه وتعالى في خلق بيئة صحية ومتوازنة للإنسان في الأرض واستخلافه فيها.

رابعاً: مستوى المهارات البيئية: ويتضمن مساعدة الأطفال على تنمية

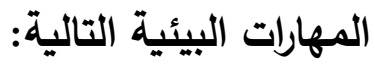


1 - جمع البيانات والمعلومات البيئية من المصادر البحثية والتجارب

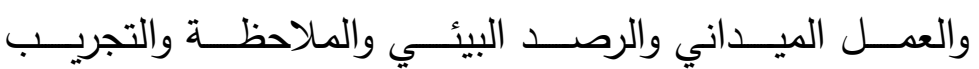

والاستقصاء.

r- تنظيم البيانات وتصنيفها وتمثيلها وتحليلها واستعمال الوسائل

$$
\text { المختلفة للبحث والاستقصاء والعرض. }
$$

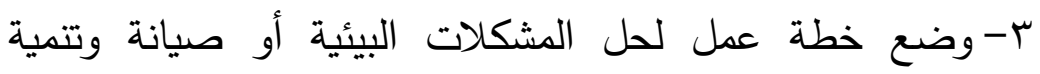

الموارد الطبيعية أو ترشيد استهلاكها وحمايتها من الاستنزاف

والاستهلاك، بحيث تتضمن هذه الخطة إجراءات العمل ونوعيتها

$$
\text { مع جدولته زمنياً ومكانياً. }
$$

ع - استقراء الحقائق من دراسة المشكلات البيئية ثم صياغة نماذجا،

$$
\text { أو تعميمات أو قوانين حولها. }
$$

0- تنظيم دراسات في الرصد البيئي والتجارب البيئية وبناء مشاريع

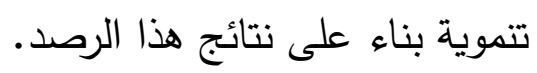

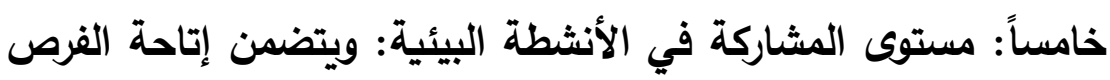

$$
\text { المناسبة للأطفال للمساهمة في الآتي: }
$$

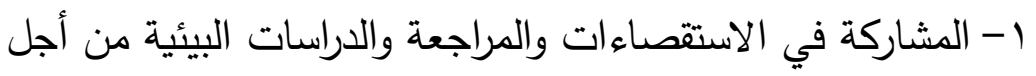

$$
\text { اقتراح الحلول لهذه المشكلات. }
$$

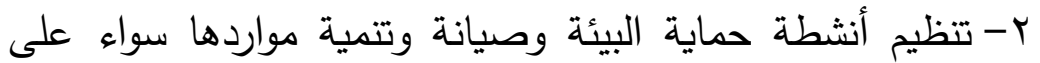

$$
\text { المستوى الفردي أم على مستوى المجموعة. }
$$

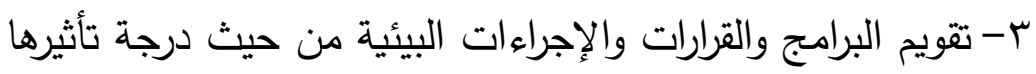
على مستوى التوازن بين متطلبات الحية الإنسانية ومتطلبات

$$
\text { الحفاظ على البيئة. }
$$

ع - المشاركة في الأنشطة والمشاريع والحملات البيئية الوطنية

$$
\text { والإقليمية والعالمية. }
$$

ـ - المعرفة والثقافة البيئية 
يمكن ملاحظة أن هناك تثابهاً بين مفهومي المعرفة البيئية والثقافة

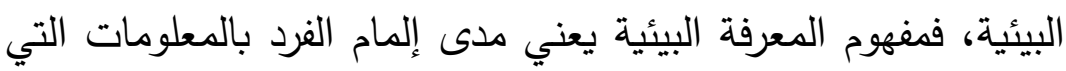
تخص البيئة التي يعيش فيها، ولا يمكن أن يصل إلى هذه المعلومات إلا من خلال مشاركته وتعاونه دع الآخرين لبحث المشكلات البيئية

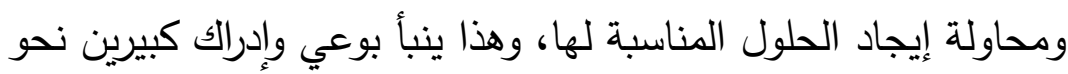

البيئة.

وفي هذا يعرف "دي فال وزينت" (Duvall, J. and Zint, M. 2007) المعرفة البيئية على أنها تتمثل في إعداد الأفراد للقيام بأدوارهم في مواكبة التغيرات البيئية التي تحدث على مستوى العالم واكتسابها حتى لهى يقوموا بالمشاركة في مواجهة المشكلات البيئية والتوصل إلى حلول لهيرل مناسبة وإيجابية. كما يعرف "أدارا" (Adara, O. 2010) المعرفة البيئية على أنها مفهوم يعمل على تزويد الأفراد بالمهارات والاتجاهات البيئية المرغوب فيها، حتى يستطيعون من التعايش مع بيئته ومحاولة الحفاظ عليها. ويمكن توضيح أن المعرفة البيئية التي يحصل عليها لئها الأفراد تؤدي دوراً

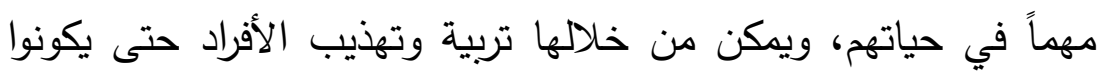
مواطنين قادرين على استيعاب كل ما هو موجود في البيئة ومحاولة التفكير في حل مشكلات البيئة والمجتمع بالطريقة التي تحقق نوعاً من من فوردئ

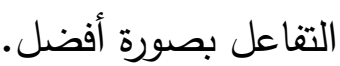
في حين يشير مفهوم الثقافة البيئية عن كيفية اكتساب الفرد للمكونات المعرفية والانفعالية والسلوكية من خلال تفاعله المستمر مع البيئة، والتي تسهم في تشكيل جيد للسلوك، والذي يجعل الفرد قادراً على التفاعل بشكل إيجابي مع بيئته، كما يكون قادراً على نقل هذا السلوك للآخرين

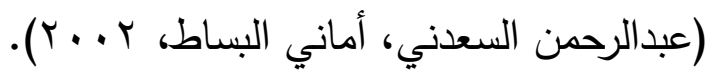


وللمدرسة وللأسرة دوراً فعالاً في اكتساب الفرد للثقافة البيئية التي تساعده

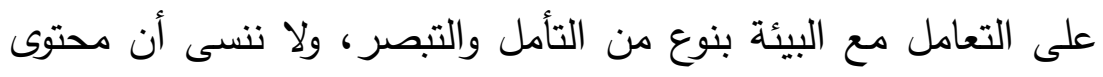
الثقافة عبارة عن مجموعة من القيم والمبادئ والمعايير السلوكية التي ترسم للفرد اتجاهاته في تعامله مع البيئة حتى يحافظ عليها.

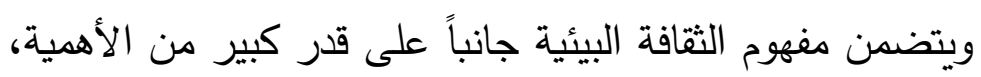

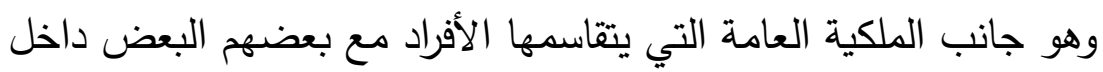

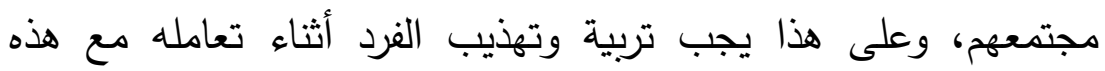
الأمور، ولا يمكن أن يتحقق ذلك إلا من خلال التربية التي يحصل عليها ولهاء ولهاه الطفل في الأسرة والمدرسة، ومن هنا يجب الاهن الانمام بمستوى الوعي والفهم الذي يتكون في عقله ووجدانه تجاه هذه الملكيات العامة. وقد احتوى البرنامج المعلوماتي المقترح في هذا البحث على تعريف الأطفال بموضوع الملكية العامة والتي تتمثل في الأسواق ووسائل

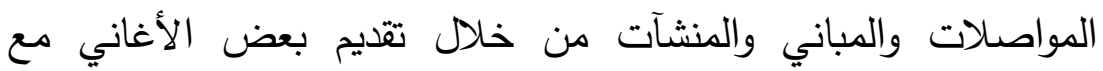
استخدام الموسيقى التي ترتبط بالبيئة.

\section{ه- التلوث البيئي Environmental Pollution}

إن التلوث البيئي هو أحد المخاطر التي تهدد العلاقة المتوازنة بين الكائنات الحية والماء والهواء، حيث إن التلوث البيئي هو أي تغير غير الهي مرغوب فيه في الخواص الطبيعية والكيميائية والبيولوجية للبيئة المحيطة بنا من هواء وماء وتربة، والذي يسبب أضرار في حياة الإنسان أو غيره

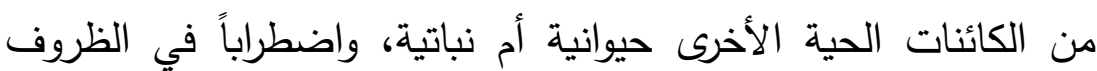

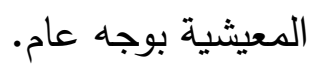

وليس للتلوث حدود، فالضوضاء التي تسببت فيها الصناعة، والموسيقى الصاخبة، ووسائل الإعلام والازدحام، واستخدام السيارات وغيرها من هن

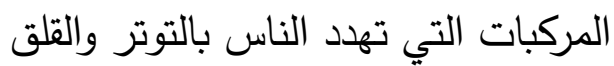

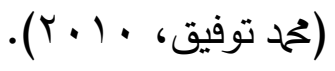


وتشير "سها رجب" (Y. . . P) إلى أن معظم أسباب تدهور البيئة

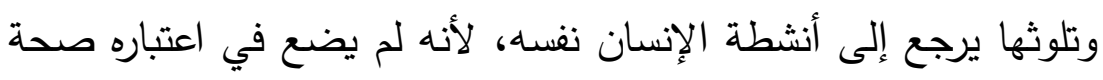
وسلامة البيئة والذي ينعكس بدوره على تغيير البيئة الطبيعية والمحيط البيط الذي يعيش فيه الإنسان والكائنات الحية الأخرى ويمارس فيه نشاطاته

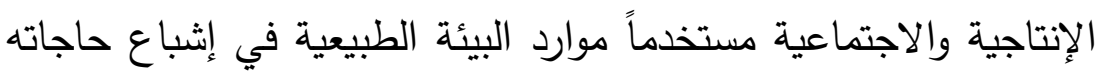

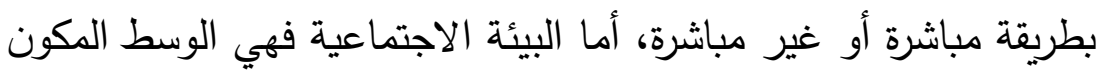
من البيئة الأساسية والنظم الاجتماعية.

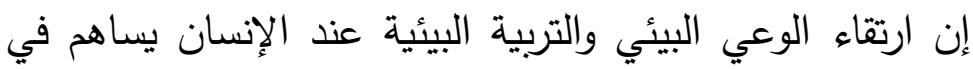
مساعدته على العيش بسلام على كوكب الأرض الذي يجب أن نحميه ونحافظ عليه من كل المشاكل التي يتعرض لها والتي قد تكون من صنع الإنسان نفسه عند استخدام الموارد الطبيعية استخداماً غير سليماً، وعليه يجب الاهتمام بتتمية الوعي البيئي لدى الإنسان وغرس القيم والمعرفة والشعور بالمسئولية تجاه البيئة، وهذا لن يحدث إلا من خلال إدرالك

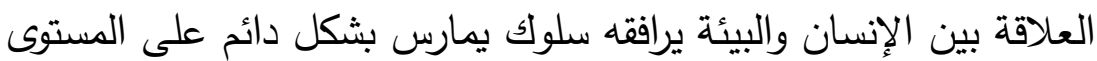
الفردي والجماعي لحماية البيئة وتحسينها وعدم الإخلال بها، وانطلاقاً من هذا فإنه يجب تنمية الوعي البيئي عند الفرد من خلال التربية البيئية من خلال نشر المعلومات الخاصة بها من منطلق التعريف بالمشاكل البيئية والدعوة إلى استخدام مواردها استخداماً سليماً يشكل أهمية بالغة لهنة

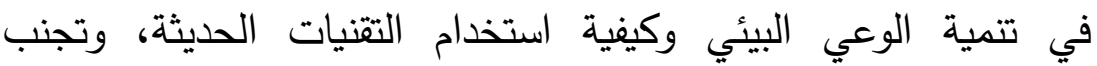
المخاطر البيئية واتخاذ القرارات البيئية العقلانية.

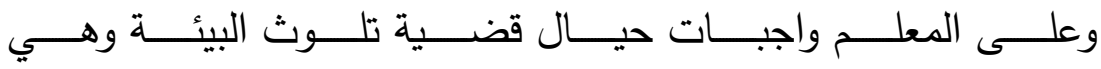
(Woodhouse, j,2011) وقضايا تحفزهم على دراستها والمشاركة في حلها. 
- تنظيم التلاميذ في مجموعات عمل وفقاً لظروف كل منهم، على أن تتكامل الأدوار في النهاية.

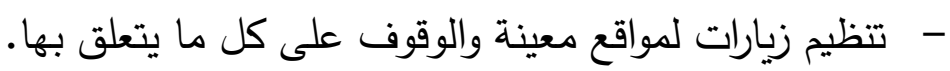

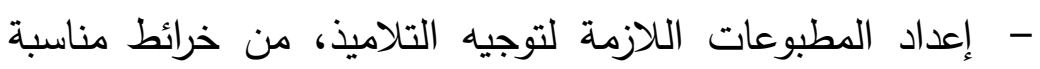

$$
\text { وجداول وإحصائيات. }
$$

- اتخاذ الترتيبات اللازمة لدعوة متحدثين من البيئة المحيطة.

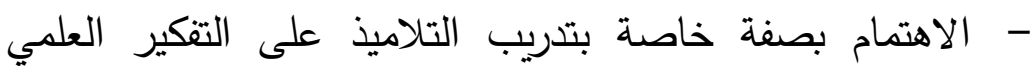
السليم في حل ما يواجهم من مشكلات بيئية وإكسابهم المهارات

$$
\text { وتتمية قدراتهم الابتكارية. }
$$

- التركيز على ترشيد السلوك البيئي للتلاميذ.

ثالثاً : الأنثطة الموسيقية

تعتبر الموسيقى أسمى اللغات التي يتخاطب بها الناس، وهي لغة سريعة

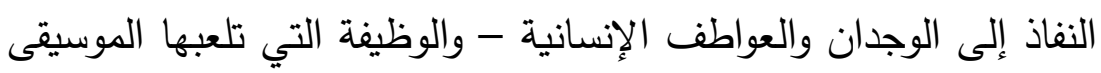
أنها وسيلة من وسائل التواصل، ولم يدخل إلى الآن في مدارسنا المناهج التربوية التي تتيح لكل طالب فرصة الحصول على قليل من التربية الجمالية أو غرس مبادئ للذوق الرفيع وحب الجمال في مظاهره المتعددة حتى يصبح الإحساس مشترك بين الجميع.

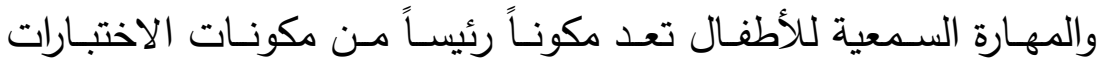
اللغوية التي تقيس مهارة الطفل في القدرة على التحدث، وتتطلب منـه القدرة على إدراك وحدات المقاطع التي تتشكل منها الكلمات، وفي هذا

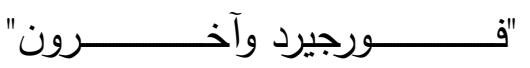
Forgeard, M. M. et al., 2008) (Huss, M. et al., 2011) الأطفال على الاختبارات الموسيقية وأدائهم على الاختبارات اللغوية. 
والعلاقة الارتباطية بين الموسيقى والوعي الصوتي قد تختلف عند الأطفال عندما تهيمن عمليات الوعي الصوتي على الذاكرة العاملة، وفي ولإيه هذا يشير "أنفيري وآخرون" (Anvari, S. et al., 2002) إلى وجود علاقة ارتباطية بين أداء الأطفال على اختبارات الموسيقى وعلى الاختبارات التي تقيس قدراتهم على القراءة. يمكن ملاحظة أنه ومن الضروري العمل على تعويد الأطفال لسماع الموسيقى وأن نهيئ لهم البيئة التي تتيح لهم تلمس مظاهر الجمال والبساطة من حيث الثكل واللون والتتسيق، كل هذه العوامل تساعد على تتمية ذوق الأطفال وتعاونهم على تفتح إدراكهم لجمال البيئة ومظاهرها. فالموسيقى في الحقيقية مستقاة من قيم ومعتقدات وأخلاق وأفكار البيئة،

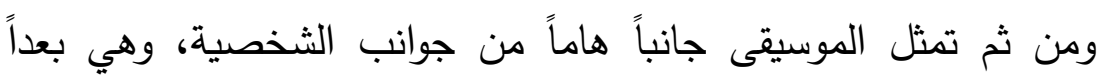
ثقافياً يمكن من خلالها تتمية الوعي البيئي لدى الأطفال، كما تعمل على جلى هلى

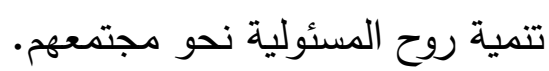
وفي ضوء ذللك يمكن الإشارة إلى أن عملية الغناء لبعض مله المقطوعات التي تخدم بعض الموضوعات البيئية، والعمل على استخدام

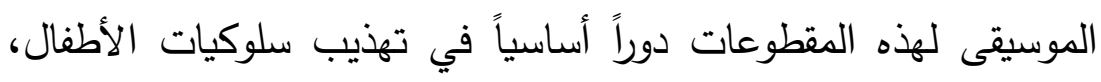
وتتمية إحساسهح بالجمال والتذوق والإدراك، وكذلك الارتقاء إلى درجات

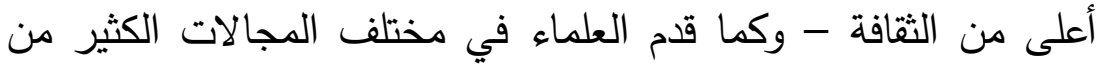
المعارف، فلقد قدمت الفنون مثل الغناء والموسيقى تراثاً ظل يثري وجدان

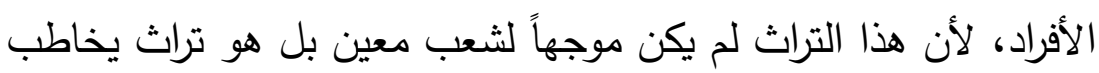

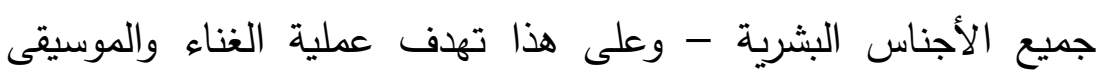
لبعض الموضوعات الدراسية إضافة المزيد من المتعة والبهجة على حياة الأطفال. الدراسات السابقة 
تمت مراجعة جميع الدراسات التي تتاولت متغير الوعي البيئي وتتميته

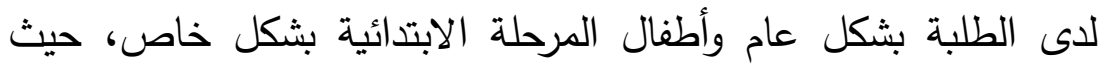

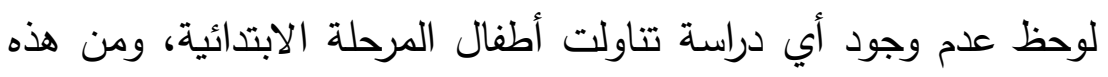

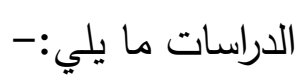
هدفت دراسة "عبدالله الزعبي" (10 ـ ب) إلى معرفة مستوى الوعي البيئي

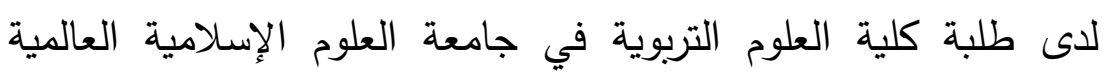
وعلاقته بمتغيري الجنس والتخصص، وتم تطبيق مقياس الوعي البيئي

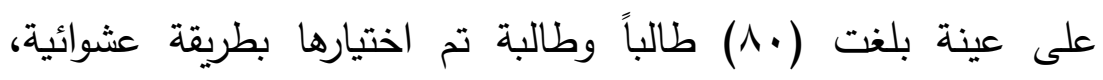

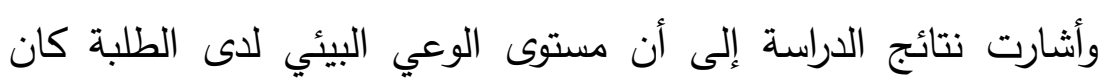
مرتفعاً، مع عدم وجود فروق دالة إحصائياً في مستوى الوعي البيئي

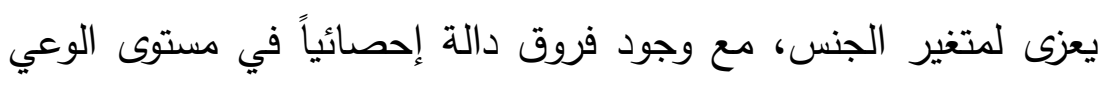

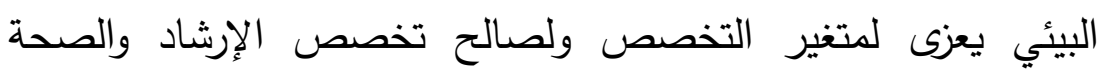
النفية.

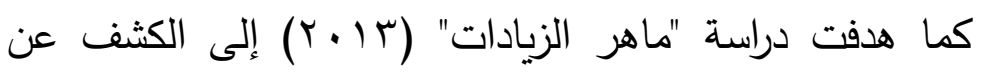
مستوى الوعي البيئي لدى معلمي الدراسات الاجتماعية في الأردن،

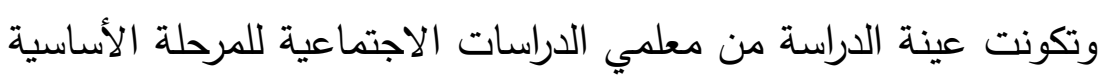

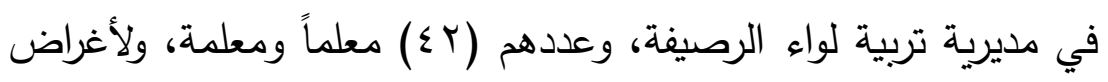
الدراسة أعد مقياس للوعي البيئي في أبعاد (المعرفة البيئية، الاتجاهات

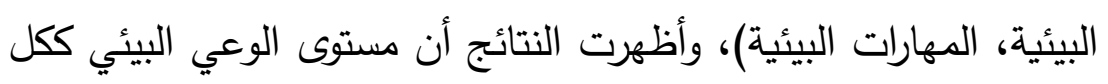

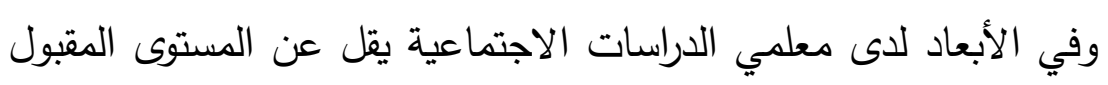

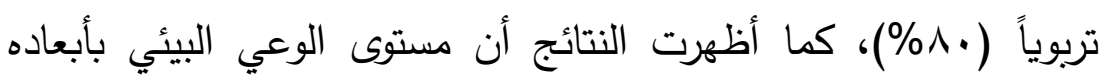
الثلاثة يختلف باختلاف التخصص ولصالح تخصص الجغرافيا، وأن مستوى الوعي البيئي بأبعاده الثلاثة لدى المعلمين لا يختلف باختلاف النوع الاجتماعي وعدد سنوات الخبرة. 
كما هدفت دراسة "إيكبو وإيكبو" (Ekpoh, U. and Ekpoh, I. 2011) إلى الكشف عن مستوى الوعي بتغير المناخ لدى معلمي المدارس الثانوية في

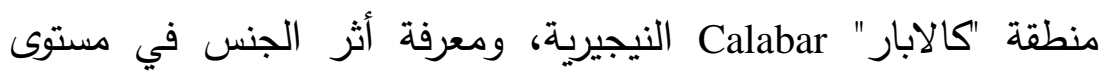

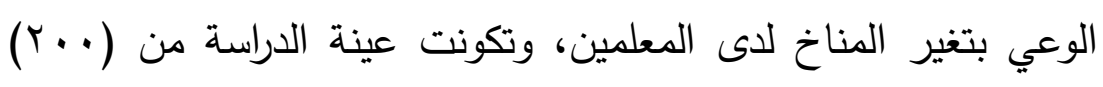

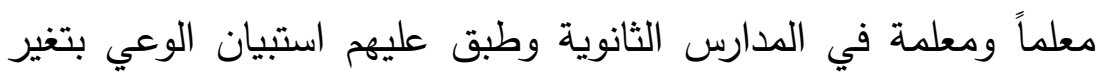
المناخ Climate Change Awareness Questionnaire، وأظهرت النتائج أن مستوى الوعي لدى المعمين كان منخفضاً، مع وجود فروق في مستوى الوعي بتغير المناخ بين المعلمين يعزى إلى الجنس ولصعالح الإناث.

وأجرى "إياد البنا" (11 · r) دراسة هدفت إلى قياس مستوى الوعي بالجوانب المعرفية لمخاطر التلوث البيئي ومستوى الاتجاه نحو مخاطر التلوث البيئي لدى معلمي المرحلة الأساسية في قطاع غزة، ومعرفة الفروق في مستوى الوعي بالجوانب المعرفية لمخاطر التلوث البيئي

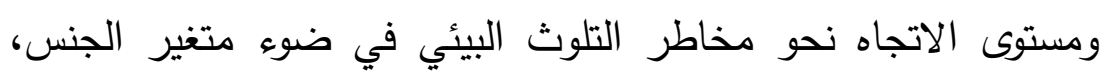

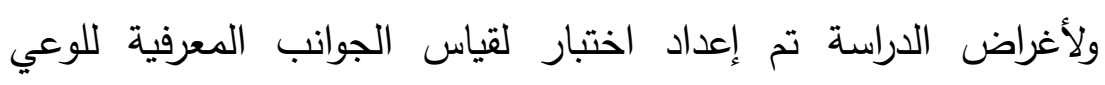

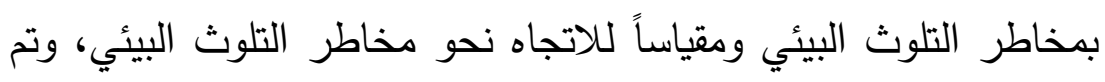
تطبيق الاختبار ومقياس الاتجاهات على عينة من معلمي المرحلة

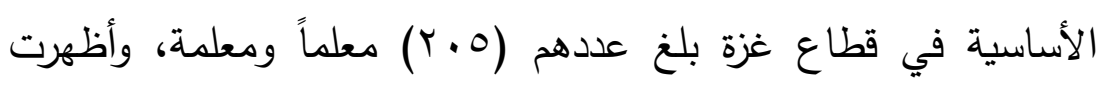
النتائج أن مستوى الوعي بالجوانب المعرفية لمخاطر التلوث البيئي

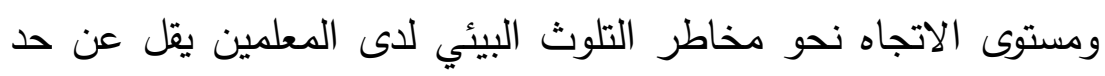

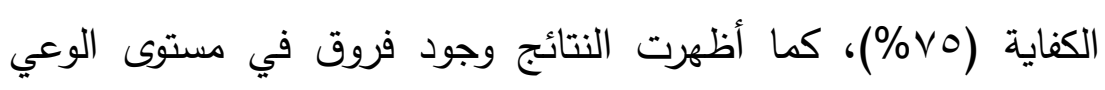
بالجوانب المعرفية لمخاطر التلوث البيئي تعزى إلى الجنس لصدان لصالح الإناث، وعدم وجود فروق في مستوى الاتجاه نحو مخاطر التلوث البيئي

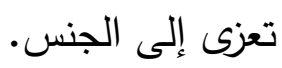




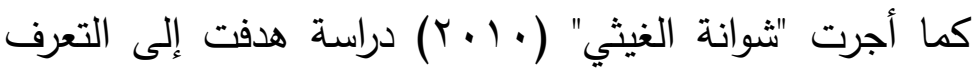

على مستوى الوعي البيئي لدى معلمي الدراسات الاجتماعية في سلطنة

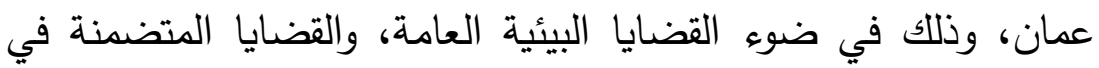
كتب الدراسات الاجتماعية بالمرحلة الثانوية، وفيما إذا كانت هناك فروق

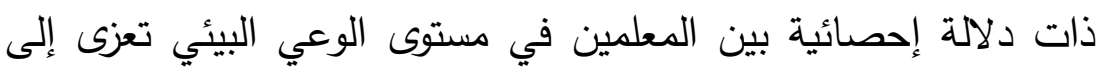

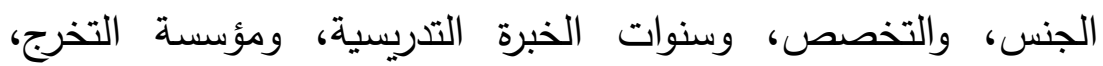
والمنطقة التعليمية. وتم استخدام مقياس للوعي البيئي مكون من جزأين ومنئن

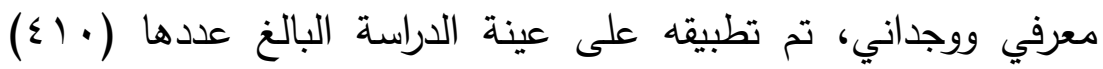
معلماً ومعلمة، يمثلون أربع مناطق تعليمية: الباطنة شمال، والباطنة جنوب، والداخلية، وظفار، وتوصلت الدراسة إلى تدني مستوى الوعي البيئي للى معلمي الدراسات الاجتماعية في سلطنة عمان، ووجود فروق بين المعلمين في مستوى الوعي البيئي تعزى إلى جنس لصالح

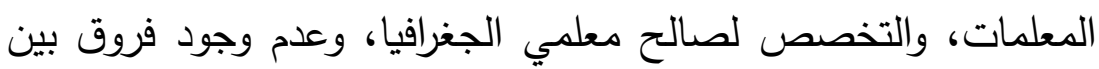
المعلمين في مستوى الوعي البيئي تعزى لسنوات الخبرة التدريسية، ومؤسسة التخرج، والمنطقة التعليمية. وهدفت دراسة "أهيوجا" (Ahuja, P. 2010) إلى التعرف على واسطه اله مستوى الوعي البيئي لاى عينة من المعلمين قبل الخدمة في الكليات

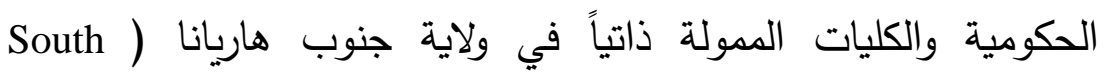
(Haryana الوعي البيئي لدى المعلمين قبل الخدمة في ضوه متغيرات الجنس والتخصص (مواد علمية، ومواد أدبية)، والمنطقة السكنية (ريف،

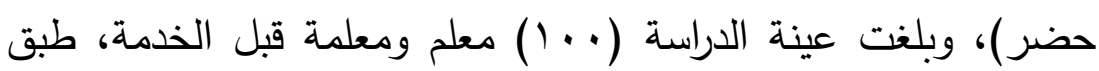
عليهم اختبار الوعي البيئي، وأظهرت النتائج أن مستوى الوعي البيئي لاى العينة كان متوسطاً، كما دلت النتائج على عدم وجود فروق في الت لني 
مستوى الوعي البيئي لدى المعلمين قبل الخدمة تعزى إلى متغيرات الجنس والتخصص والمنطقة السكنية.

وقد حاولت دراسة "لاريجاني" (Larijani, M. 2010) الكثف عن والن

مستوى الوعي البيئي لدى معلمي المدارس الابتدائية العليا في مدينة

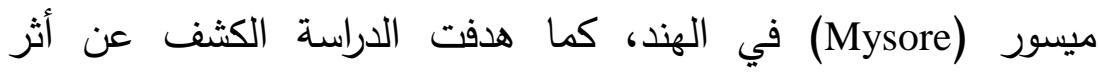
متغيرات الجنس والعمر ونوع المدرسة (حكومية، خاصة)، تكونت عينة

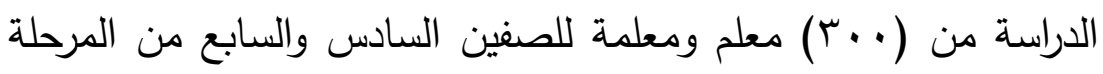
الابتدائية العليا، طبق عليهم اختبار لتقييم مستوى الوعي البيئي لديهم، وكثفت النتائج أن المعلمين لديهم مستويات متوسطة من الوعي البيئي، كما تبين أن مستوى الوعي البيئي لدى الإناث يفوق مستوى الوعي البيئي

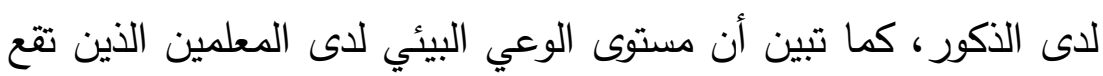

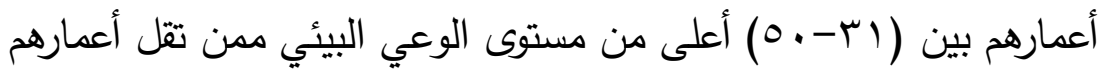

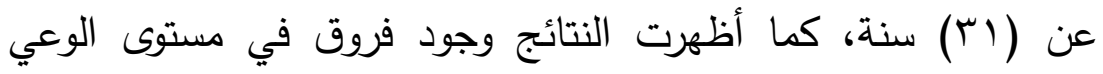
البيئي بين المعلمين تعزى إلى نوع المدرسة لصالح المدارس الخاصة.

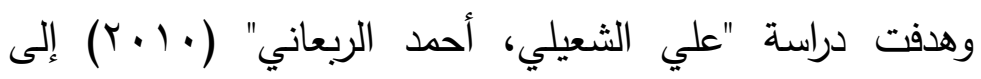
التعرف على مدى ارتباط مستوى الوعي بالتغيرات المناخية لدى الطلبة

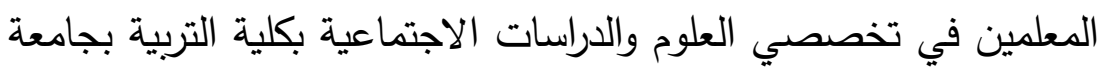
السلطان قابوس، ومدى اختلاف وعيهم تبعاً للتخصص والجنس. تكونت

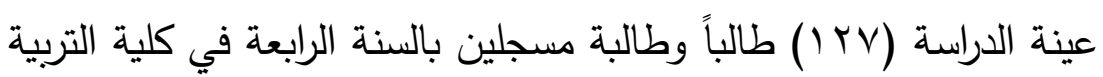
بتخصص العلوم والدراسات الاجتماعية، ولتحقيق أهداف الدراسة تم

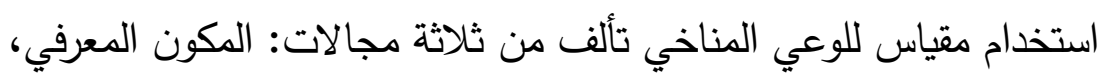

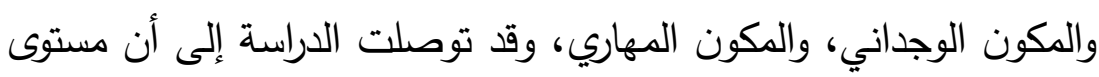

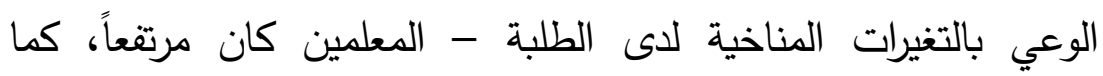
توصلت إلى وجود فروق دالة إحصائياً تعزى للجنس في المكون المعرفي لصالح الإناث، وفروق تعزى إلى التخصص في المكون الوجداني لصالح 
الدراسات الاجتماعية، بينما لا توجد فروق تعزى إلى متغير الجنس في

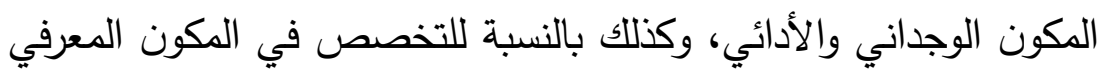
والأدائي.

كما هدفت دراسة "عبدالسلام العديلي" (· • • ( إلى الكثف عن مستوى الوعي البيئي لدى الطلبة المعلمين في جامعة الزرقاء الخاصة وعلاقته بمتغيرات النوع الاجتماعي والمستوى الدراسي ومكان الإقامة لوعين ودخل العائلة الشهري وعدد أفراد الأسرة ودراسة مساق يتعلق بالبيئة،

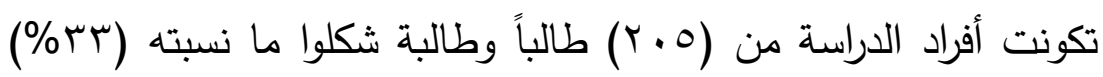
من الطلبة المسجلين في الكلية للفصل الدراسي الثاني للعام الجامعي

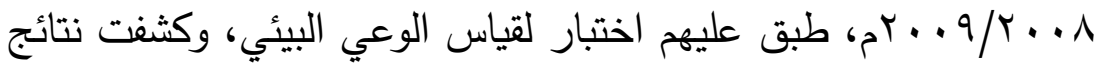

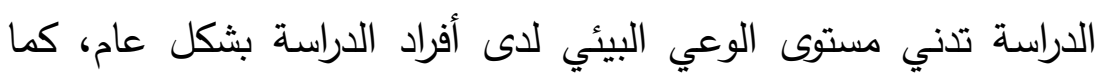

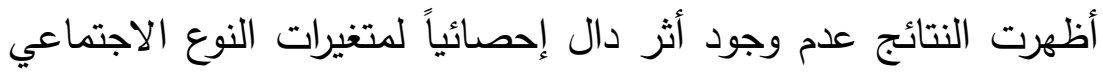
والمستوى الدراسي ودراسة مساق يتعلق بالبيئة في الوعي البيئي لأفراد

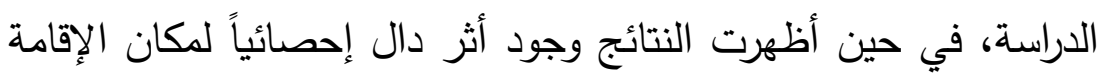
في الوعي البيئي لصالح من يقطنون غير المدينة من ريف أو بادية

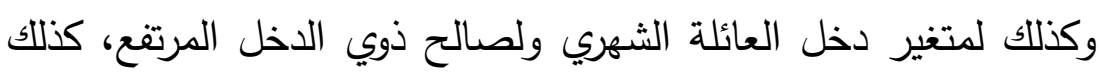
๑)

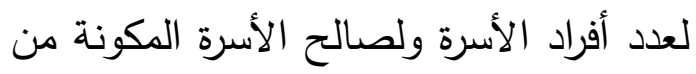
فأقل). الادا" ث" وحاول (Shobeiri, S. and Prahallada,N. 2008 إلى الكثف عن مستوى الوعي البيئي لاى عينة من معلمي المواد العلمية والمواد الأدبية للمرحلة

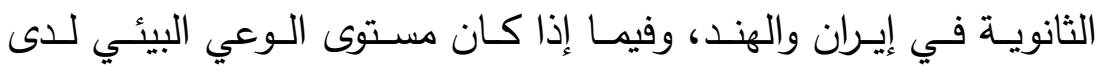

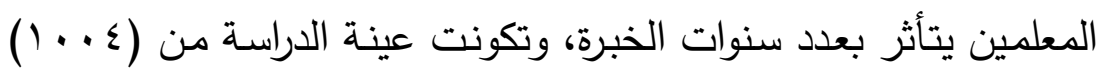

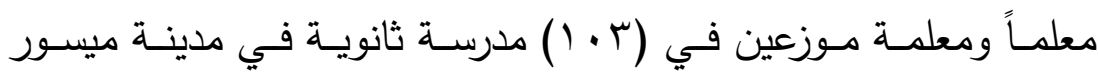

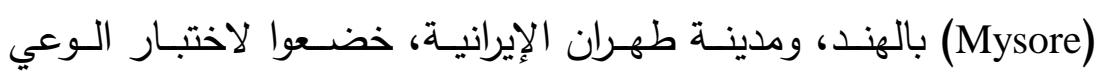


Jinaraja, ) البيئي "Environmental Awareness Test من إعداد 1999)، وكثـفت النتـائج أن مسـتوى الـوعي البيئـي بثـكل عـام كـان متوسطاً، وأن هنالك فروقاً في مستوى الوعي البيئي بين معلمي المواد

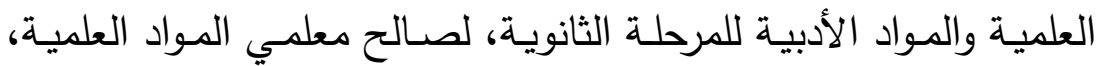
وأن مستوى الوعي البيئي لدى المعلمين لا يتأثر بعدد سنوات الخبرة.

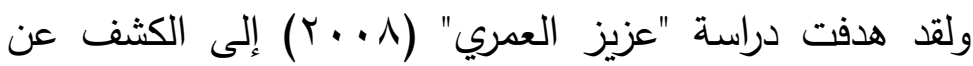
مستوى وعي معلمي العلوم في المرحلة الابتدائية بالوضع البيئي العالمي، والوعي بمشكلة التلوث البيئي، والوعي بأهمية صحة البيئة وسلامتها، ومعرفة دلالة الفروق في مستوى الوعي تبعاً لمتغيرات

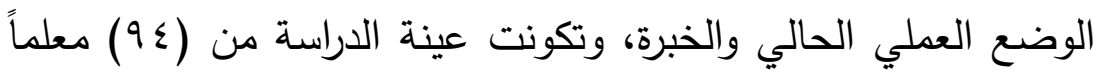
لمادة العلوم في مدينة تبوك، طبق عليهم استبيان لقياس مستوى الثقافة البيئية في ثلاثة مجالات (الوعي بالوضع البيئي العالمي، والوعي لئي

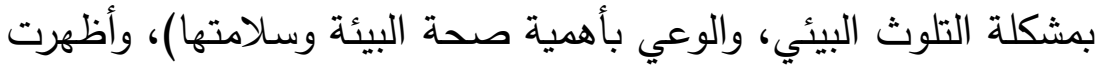
النتائج أن مستوى الوعي بالوضع البيئي العالمي، والوعي بأهمية صحة لهيه

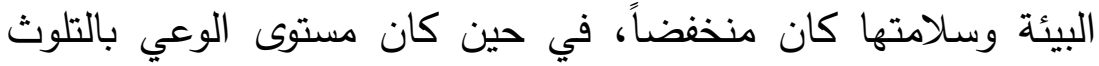
البيئي مرتفعاً، كما وجدت فروق ذات دلالة إحصائية في مستوى الوعي ليني على المجالات الثلاثة لدى استجابات العينة ترجع إلى الوضع العملي وعدد سنوات الخبرة.

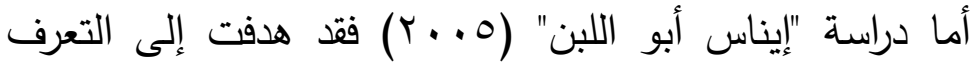
على مستوى الوعي البيئي وعلاقته ببعض المتغيرات لدى طلبة كلية التربية في الجامعات الفلسطينية بمحافظات غزة، وتكونت عينة الدراسة من (\&VY) طالب وطالبة من طلبة كلية التربية بالجامعات الفلسطينية: الإسلامية، والأزهر، والأقصى، والقدس المفتوحة في المستوى الأول والرابع. وأثارت نتائج الدراسة إلى أن مستوى الوعي البيئي لإى الطلبة

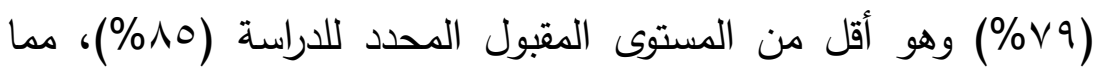


يشير إلى تدني الوعي البيئي لاى عينة الدراسة عن المستوى المقبول،

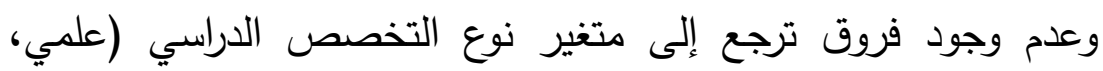

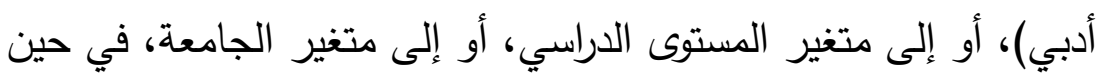

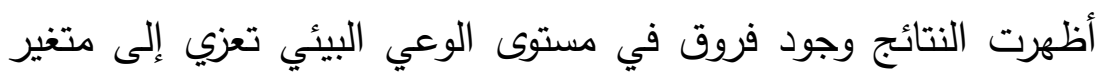
الجنس لصالح الإناث.

وهدفت دراسة "بدر" (Badr, H. 2003) إلى تقييم مستوى الوعي

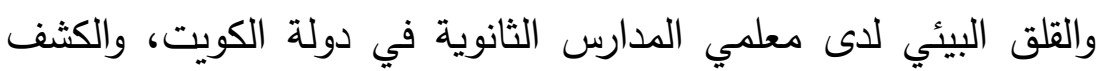
عن العلاقة بين الوعي البيئي والقلق البيئي، ومعرفة دلالة الفروق في

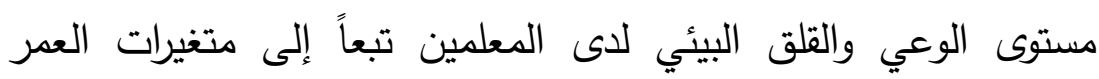

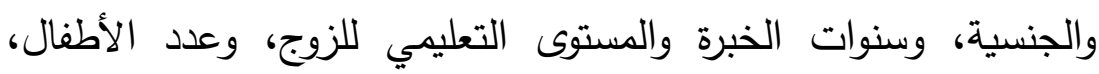
تكونت عينة الدراسة من (الج؛) معلماً ومعلمة في المدارس الثانوية التابعة لمنطقتي حولي والأحمدي طبق عليهم استبيان قياس الوعي والقلق البيئي، وكثفت النتائج أن (•r\%) من العينة لديهم مستوى مرتقع من الوعي البيئي، وأن حوالي (•0\%) من العينة لديهم مستوى مرتفع من القلق البيئي، يزداد بزيادة العمر، وسنوات الخبرة والمستوى التعليمي

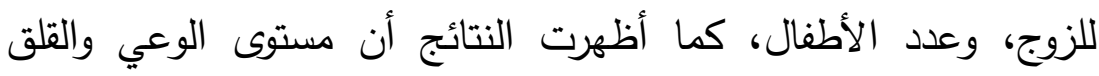
البيئي يتأثر بمتغير الجنسية ولصالح المعلمين غير الكويتيين، كما يتأثر بمتغير الجنس لصالح الإناث، كما كثفت النتائج وجود علاقة إيجابية ودالة إحصائياً بين القلق البيئي والوعي البيئي.

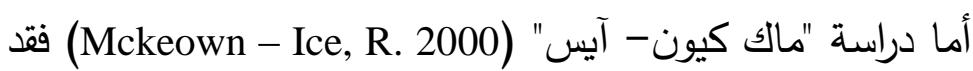
هدفت إلى تحديد مدى تضمين مفاهيم التربية البيئية في برنامج إعداد

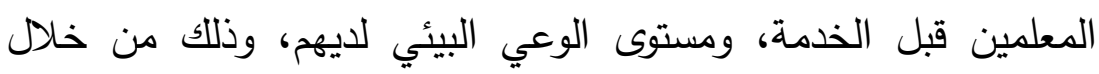

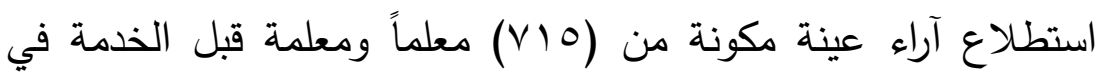
الولايات المتحدة الأمريكية، ولتحقق هدف الدراسة طبقت على على العينة استبيان يقيس مدى تضمين مفاهيم التربية البيئية في برنامج إعداد 
المعلمين قبل الخدمة، ومستوى الوعي البيئي لديهم، وقد أشارت النتائج إلى أن التربية البيئية غائبة في برنامج إعداد المعلمين، كما تبين أن الن النين مستوى الوعي البيئي لديهم كان منخفضاً.

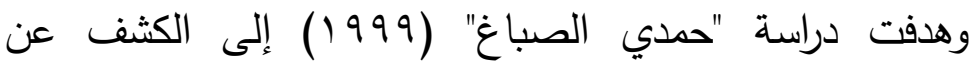
مستوى الوعي البيئي لدى طلاب كلية المعلمين بالمدينة المنورة وتأثير

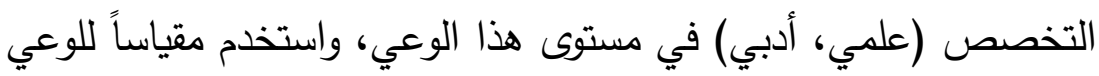
البيئي بتناول بعدي المعلومات البيئية والاتجاهات نحو البيئة، وأثارت النتائج إلى تدني الوعي البيئي لدى الطلاب سواء في بعد المعلومات

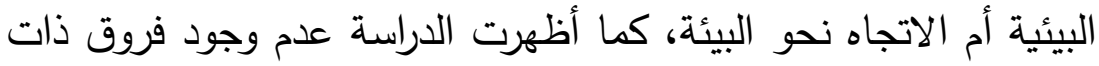

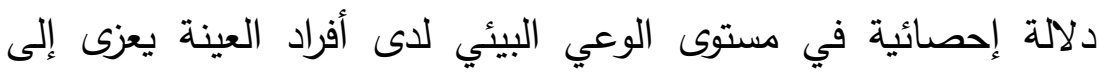
التخصص لصالح التخصص العلمي. تعقيب على الدراسات السابقة

\section{من خلال مراجعة نتائج الدراسات السابقة لوحظ ما يلي:-}

1- عدم وجود أي دراسة سابقة تتاولت أطفال المرحلة الابتدائية بالدراسة رغم أهمية هذه المرحلة فيما يرتبط بالتنشئة وبالوعي البيئي.

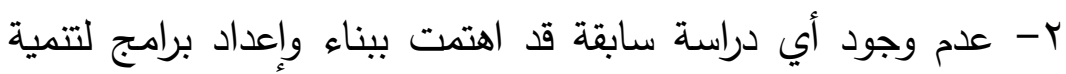
الوعي البيئي باستخدام الأنشطة الموسيقية أو باستخدام أي أنشطة

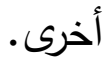

r- أظهرت نتائج دراسات كثيرة تدني مستوى الوعي البيئي لدى

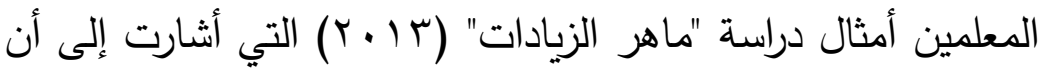

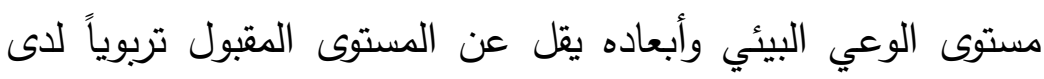

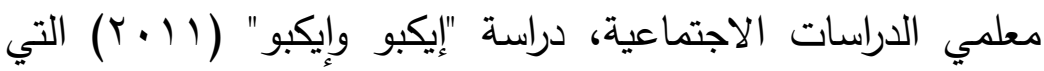
أشارت إلى أن مستوى الوعي لدى المعلمين كان منخفضاً، دراسة

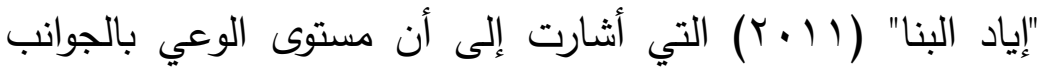

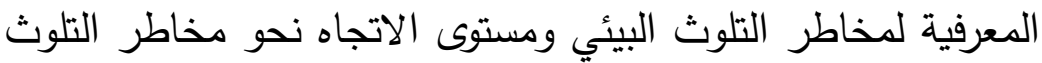




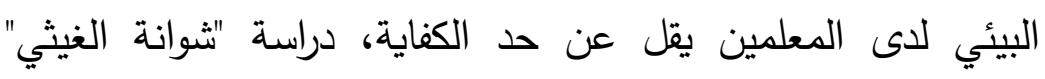

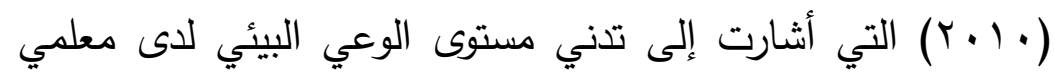

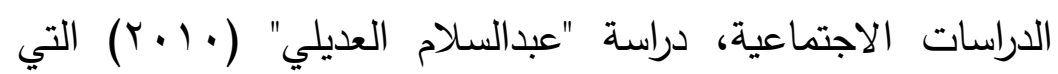

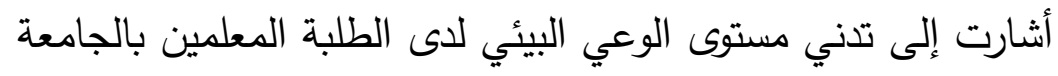

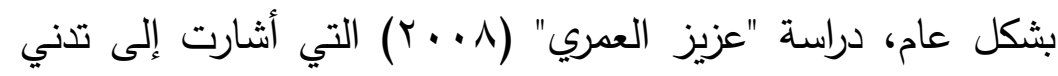

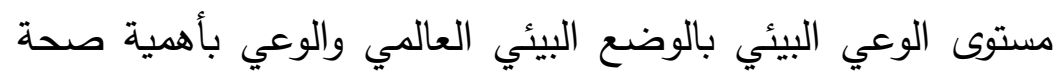

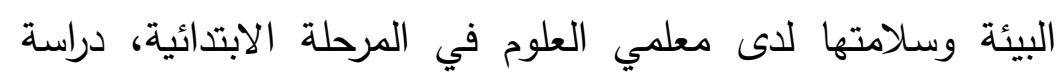

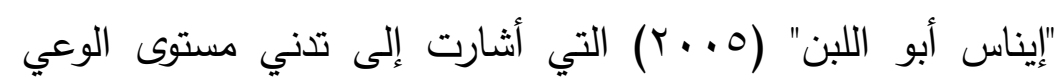

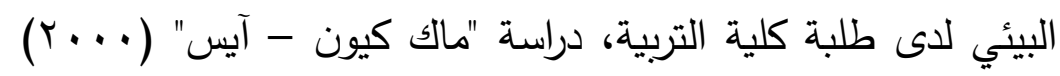
التي أشارت إلى تدني مستوى الوعي البيئي لدى طلبة كلية التربية،

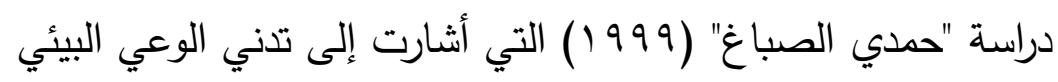

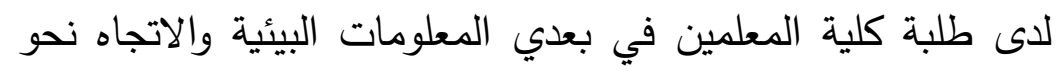

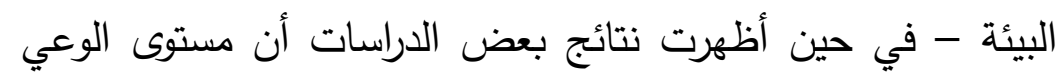

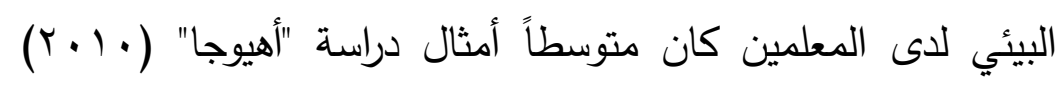

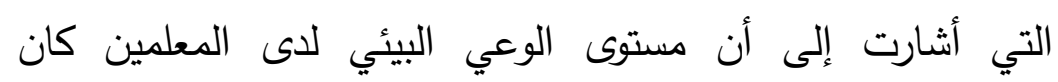

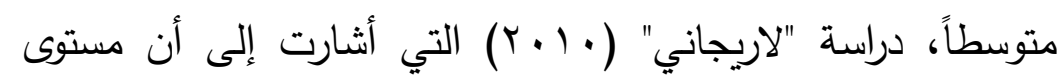

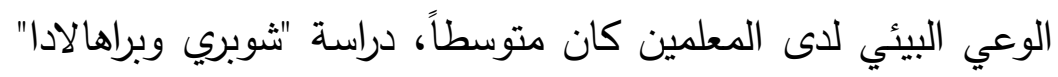

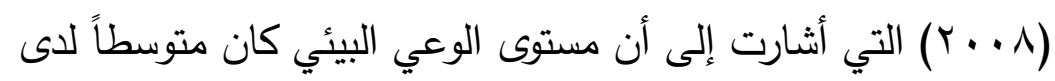

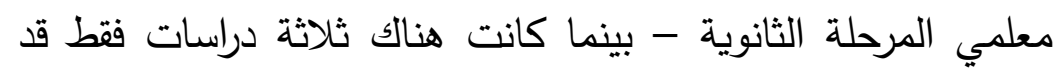
أظهرت نتائجهم ارتفاع مستوى الوعي البيئي لاى المعلمين أمثال

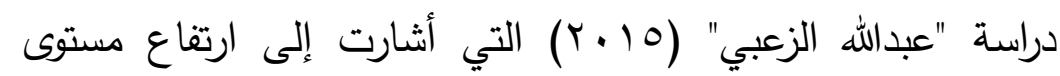

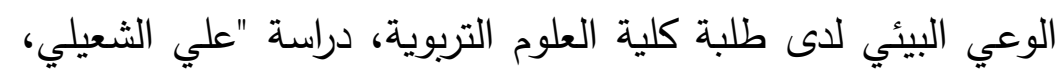

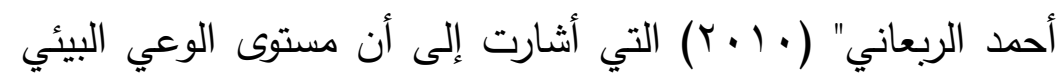

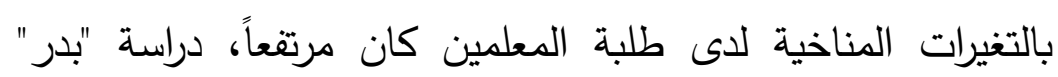




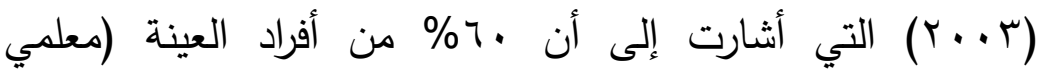
المدارس الثانوية) لديهم مستوى مرتفع من الوعي البيئي.

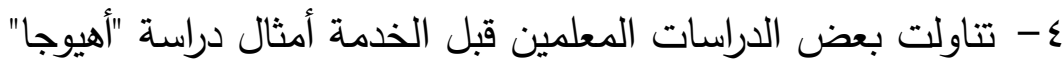

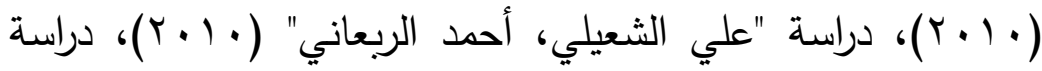

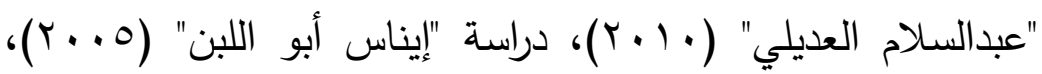

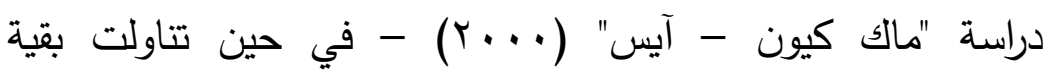

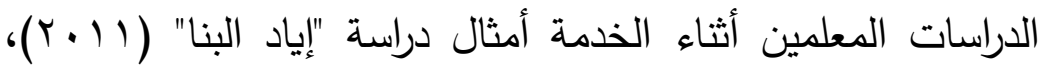

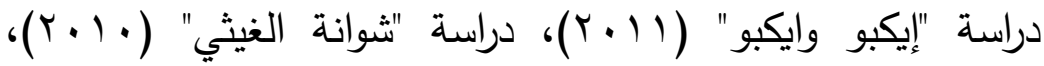

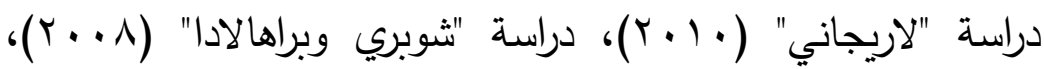

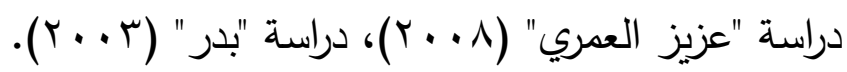
0- أظهرت نتائج بعض الدراسات إلى أن الإناث أكثر وعياً بالبيئة

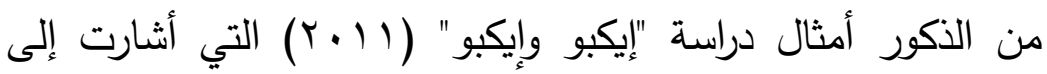
اختلاف مستوى الوعي البيئي لدى المعلمين باختلاف الجنس

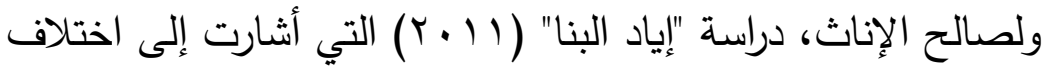
مستوى الوعي بالجوانب المعرفية لمخاطر التلوث لدى المعلمين باختلاف الجنس لصالح الإناث، دراسة "شوانة الغيثي" ( • • ب) التي أشارت إلى وجود فروق في مستوى الوعي البيئي بين المعلمين

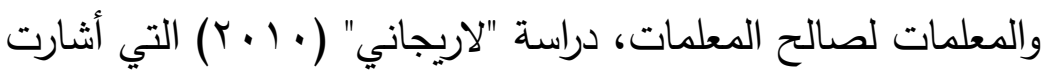
إلى أن مستوى الوعي البيئي عند المعلمات يفوق مستوى الوعي لإسي

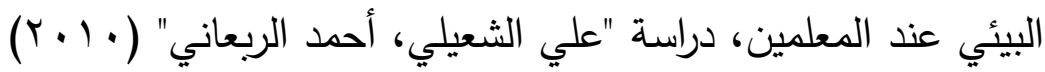
التي أثارت إلى وجود فروق في المكون المعرفي من مستوى الوعي

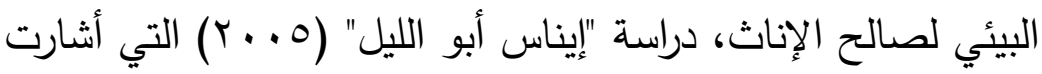

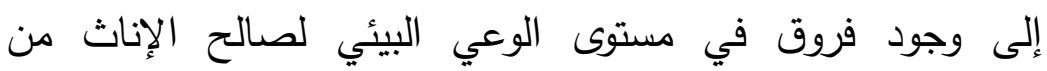

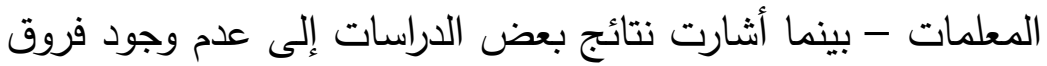

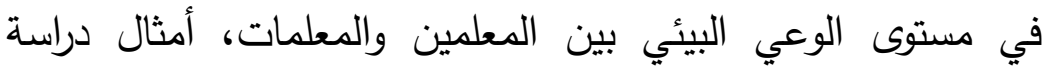


"عبدالله الزعبي" (10 • ب) التي أشارت إلى عدم وجود فروق دالة

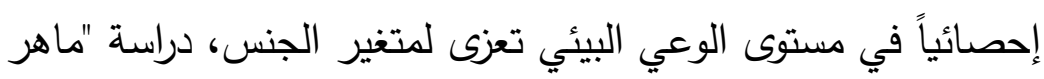

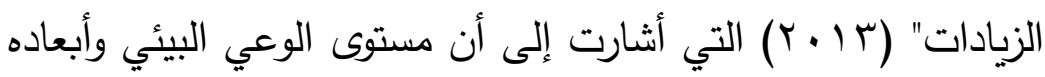

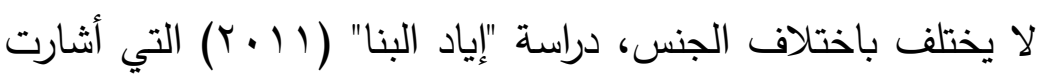
إلى أنه لا يختلف مستوى الاتجاه نحو مخاطر التلوث البيئي

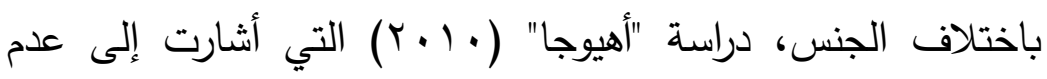

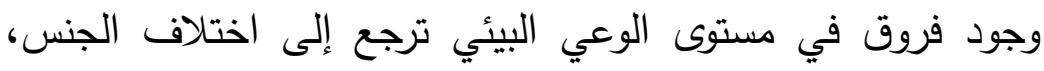

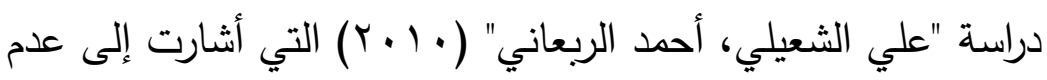
وجود فروق في المكون الوجداني والأدائي من مستوى الوعي البيئي

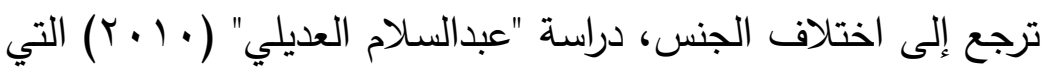
أشارت إلى عدم وجود فروق في مستوى الوعي البيئي لدى الطلبة المعلمين ترجع إلى اختلاف الجنس. צ- أظهرت نتائج بعض الدراسات إلى وجود فروق في مستوى الوعي

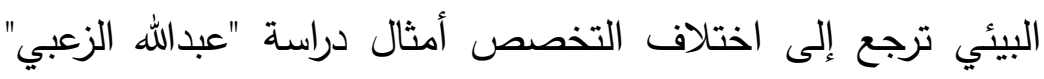

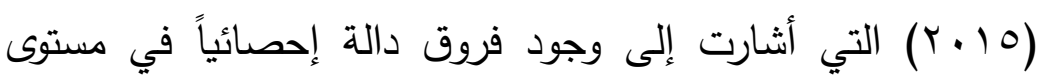
الوعي البيئي تعزى لمتغير التخصص وخاصة تخصص الإلىشاد

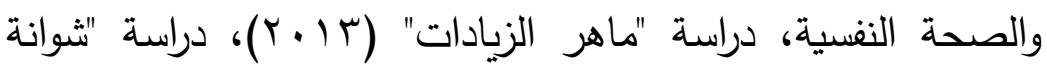

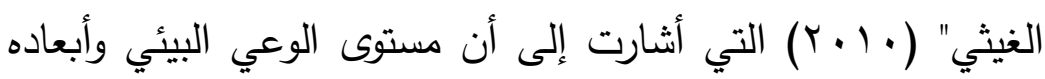
يختلف باختلاف تخصص المعلم لصالح تخصص الجغرافيا، دراسة

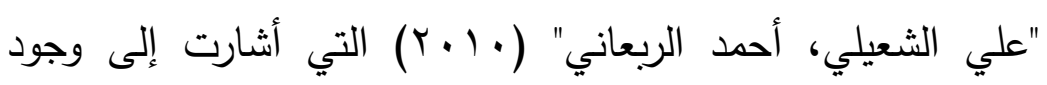
فروق في المكون الوجداني من مستوى الوعي البيئي لصالح الطلبة البعاني

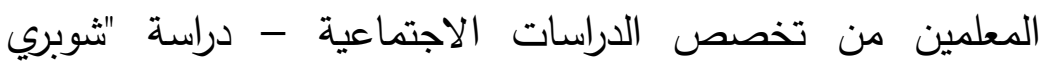

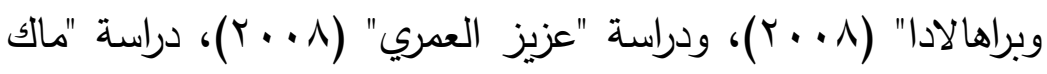

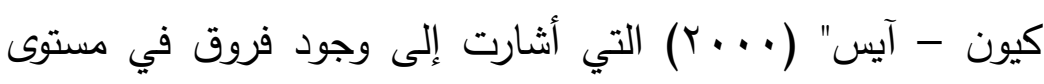
الوعي البيئي لدى معلمي المرحلة الثانوية من تخصص المواد الته وجود فروفية العلمية 
- بينما أشارت دراسة "أهيوجا" (· • (Y)، دراسة "إيناس أبو اللبن"

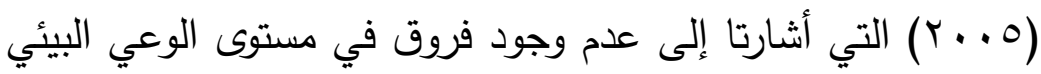

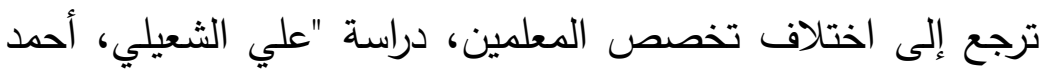

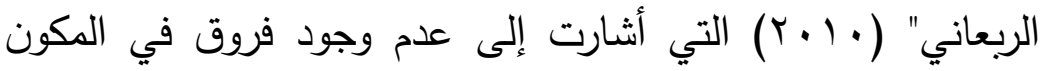
الوجداني والأدائي ترجع إلى اختلاف تخصص الطلبة المعلمين. - أظهرت نتائج بعض الدراسات إلى عدم وجود فروق في مستوى الفي الوعي البيئي ترجع إلى اختلاف عدد سنوات الخبرة أمثال دراسة

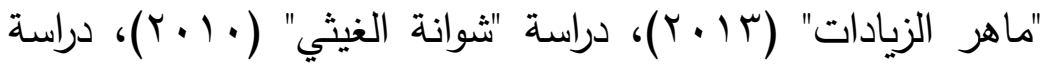

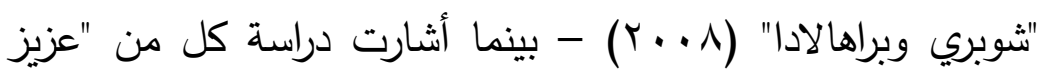

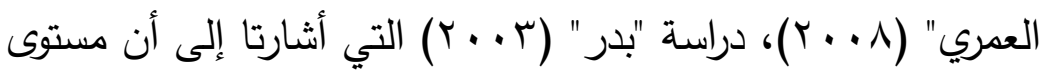

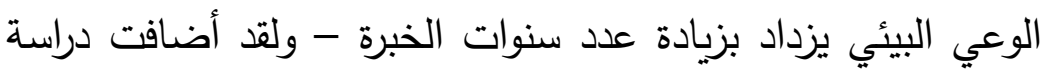

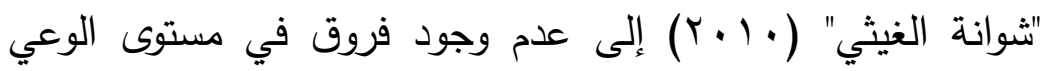

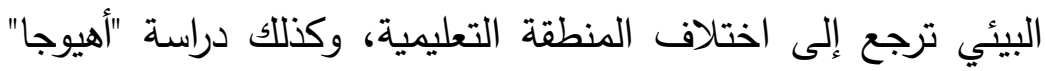

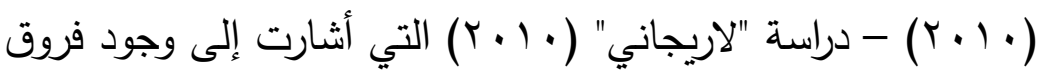
في مستوى الوعي البيئي بين المعلمين ترجع إلى نوع المدرسة

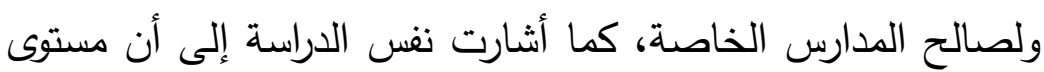
الوعي البيئي يرتفع أكثر لاى المعلمين من ذوي الأعمار المرتفعة -

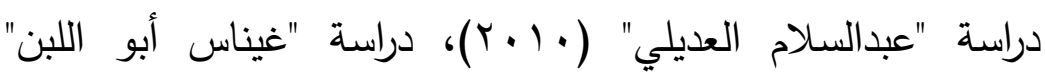

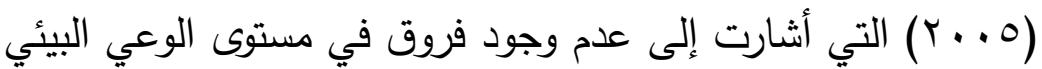
ترجع إلى اختلاف المستوى الدراسي. فروض الاراسة يفترض البحث الفروض التالية:1- لا توجد فروق دالة إحصائياً بين متوسطي درجات أطفال

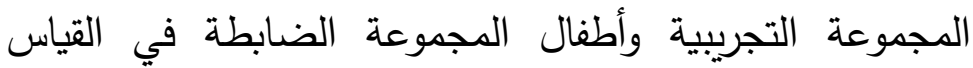


القبلي على مقياس الوعي البيئي بأبعاده لأطفال الصف الرابع

$$
\text { الابتدائي. }
$$

ץ- توجد فروق دالة إحصائياً بين متوسطي درجات أطفال المجموعة

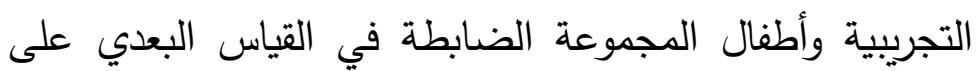
مقياس الوعي البيئي بأبعاده لصالح أطفال المجموعة التجريبية

$$
\text { من أطفال الصف الرابع الابتدائي. }
$$

ץ- هل توجد فروق دالة إحصائياً بين متوسطي درجات أطفال الطفال

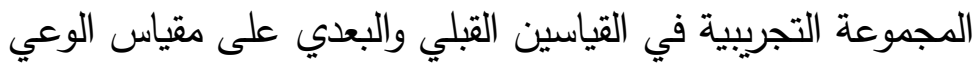

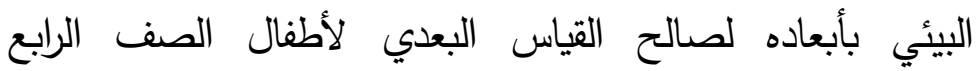

$$
\text { الابتذائي. }
$$

ع- لا توجد فروق دالة إحصائياً بين متوسطي درجات أطفال

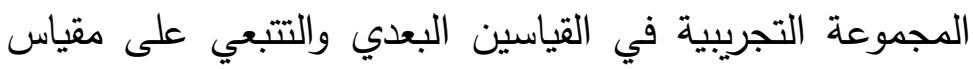

$$
\text { الوعي البيئي بأبعاده لأطفال الصف الرابع الابتدائي. }
$$

\section{إجراءات البحث \\ أولاً : منهج البحث أت البح}

تم الاستعانة بالمنهج شبه التجريبي ذو الهجموعتين من أطفال الصف

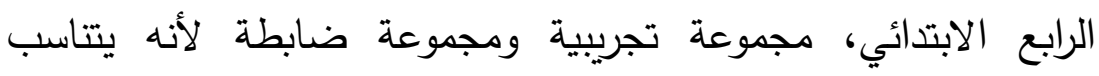

$$
\text { وطانياً : عينة البحث الحالي. }
$$

تكونت عينة البحث الحالي من (ب؟) طفلاً من أطفال الصف الرابع

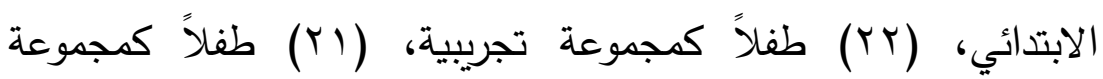


ضابطة، وجميع الأطفال من الذكور بمتوسط عمري قدره (ب.+.) سنوات، وتم اختيار عينة البحث من بين أطفال مدرسة علي بن أبي طالب الابتدائية للبنين التابعة لمنطقة حولي التعليمية بدولة الكويت. ثالثاً : أدوات البحث تم استخدام الأدوات التالية:- : الئت

1- مقياس الوعي البيئي (إعداد / تحما تحما عباس المغربي) ملحق (1) لتحقيق أهداف البحث الحالي والمتمثلة في فاعلية برنامج معلوماتي قائم على بعض الأنشطة الموسيقية في تنمية الوعي البيئي لاى عينة من أطفال المرحلة الابتدائية، استلزم الأمر بناء مقياس لقياس الوعي لتئه البيئي

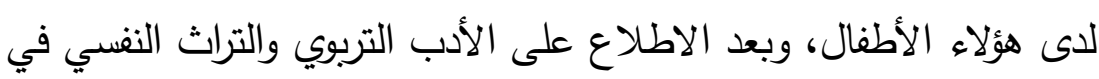
مجال قياس الوعي البيئي، ولقد تم الالتزام بالخطوات التالية في إعداد الاد لتعاد مقياس الوعي البيئي. أ - تحديد الهوف من المقياس الئي

هدف المقياس إلى قياس الوعي البيئي والذي تم تتاوله على أنه إدرالك الطفل لدوره في التعامل مـع البيئة ومواجهتها، وحسن استغلال الموارد

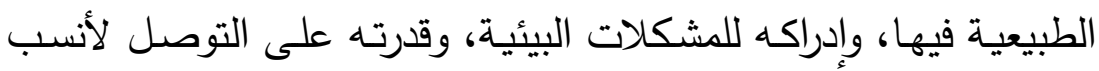

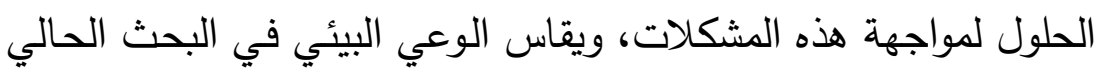

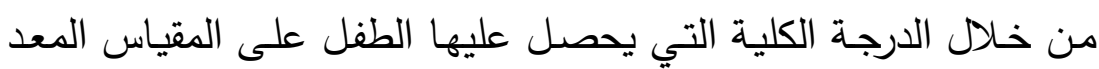

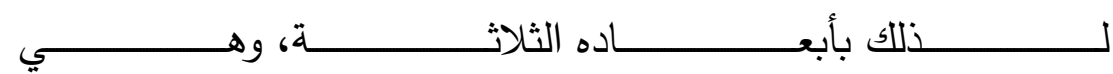
(المعرفة البيئية، الاتجاهات البيئية، المهارات البيئية).

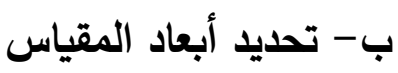
تمثلت أبعاد المقياس في مكونات الوعي البيئي، وهي:1- المعرفة البيئية: وتتمثل في تزويد الأطفال بالمعلومات البيئية التي تمكنهم من معرفة بيئتهم وعلاقتهم معها. 
ץ- الاتجاهات البيئية: وتتمثل في تكوين اتجاهات إيجابية لاى الأطفال نحو البيئة، وأهمية المحافظة عليها. r- المهارات البيئية: وتتمثل في إكساب الأطفال مهارات تمكنهم من المساهمة في حل المشكلات البيئية. ج- صياغة مفردات المقياس تم صياغة مفردات المقياس للأبعاد الثلاثة للمقياس، وبالنسبة للبعد الأول وهو بعد المعرفة البيئية، فلقد بلغت عدد المفردات التي تقيسه (ب0) مفردة، وكل مفردة عبارة عن موقف يليه ثلاث استجابات هي (أ، ب، ج)، وبالنسبة للبعد الثاني وهو بعد الاتجاهات البيئية، فلقد بلغت عدد عدان المفردات التي تقيسه (ب0) مفردة، وكل مغردة صيغت في صورة عبارة

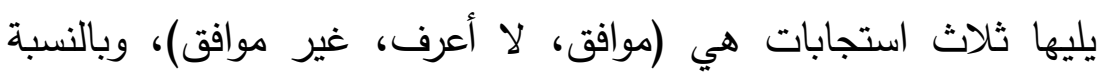

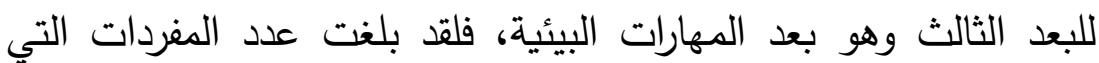
تقيسه (0) مفردة، وكل مفردة صيغت في صورة عبارة يليها ثلاث

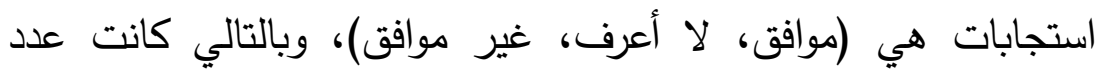
مغردات المقياس (0. 1) مغردة في صورته الأولية.

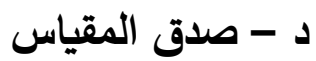
ا- تم التحقق من صدق المقياس بصورته الأولية بعرضه على مجموعة من المحكمين من ذوي الخبرة في مجال إعداد المقاييس بكلية التربية

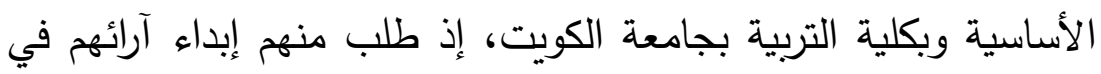

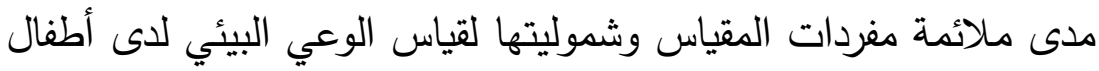
الصف الرابع الابتدائي، ومدى انتماء كل مفردة للبعد التي تتنمي إليه،

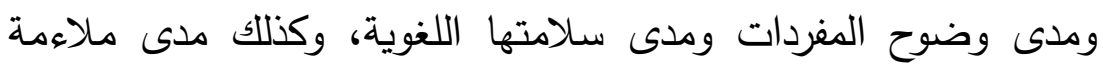

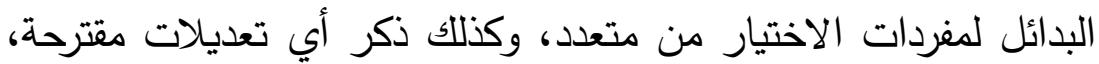


واقتراح مفردات يرونها ضرورية، وحذف المفردات غير الضرورية، وقد

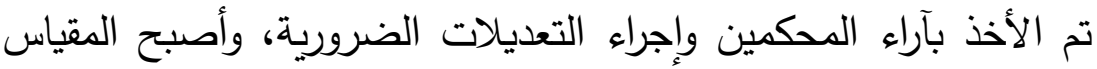
بعد الانتهاء من تحكيمه مكوناً من (0. (1) مفردة موزعة كالتالي:- بعد المعرفة البيئية : اشتمل على (ro) مفردة اختبارية من نوع الاهن الاختيار المتعدد تقيس البعد المعرفي للوعي البيئي، بحيث تأخذ الإجابة

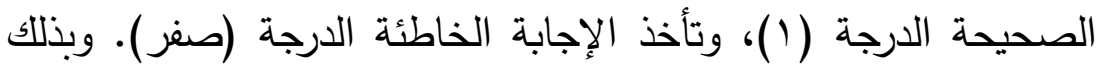

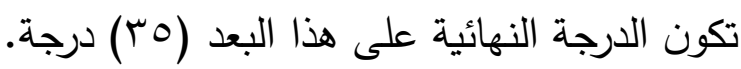
- بعد الاتجاهات البيئية: اشتمل على (ب0) مفردة اختبارية تكون الإجابة

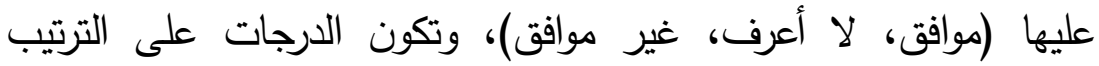

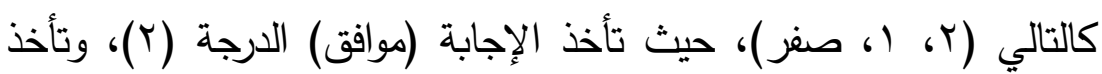
الإجابة (لا أعرف) الدرجة (1)، وتأخذ الإجابة (غير موافق) الدرجة الإجه (صفر)، وتقيس بعد الاتجاهات للوعي البيئي، وبذللك تكون الدرجة النهائية على هذا البعد (• V) درجة. - بعد المهارات البيئية: اشتمل على (مباهـ) مفردة اختبارية تكون الإجابة

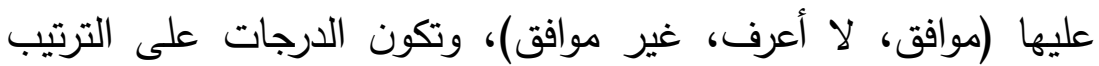

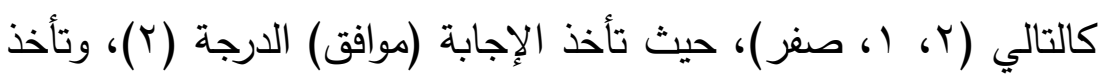

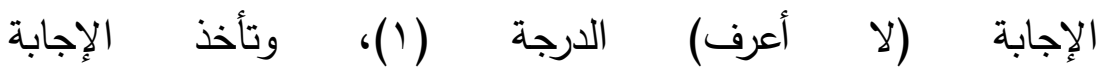

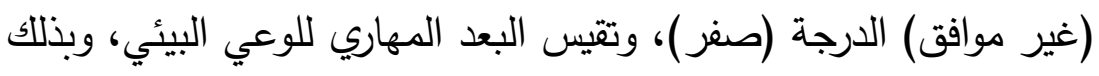

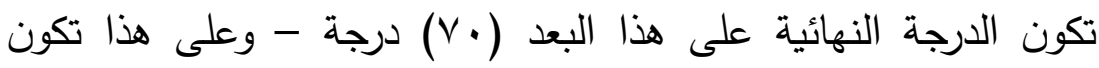

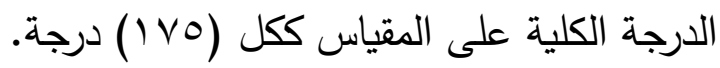
r- كما تم التحقق من صدق المقياس باستخدام صدق الاتساق الداخلي وفيه تم تطبيقه على عينة بلغ قوامها (Yo) طفلاً من أطفال الصف الصف الرابع الابتدائي، وتم حساب معاملات الارتباطات بين درجات الأطفال على كل بعد من أبعاد المقياس والدرجة الكلية عليه، كما تم حساب معاملات الارتباطات بين درجات الأطفال بين الأبعاد، كما تم حساب معاملات 
الارتباطات بين درجات الأطفال على كل مفردة والدرجة الكلية للمقياس، ورصدت نتائج ذلك في الجداول التالية:-

جدول (1)

معاملات الارتباطات ودلالتها بين درجات كل بعد واللارجة الكلية على المقياس

\begin{tabular}{|c|c|c|}
\hline مستوى الدلالة & معامل الارتباط & أبعاد مقياس الوعي البيئي \\
\hline$\ldots 1$ & 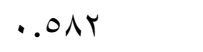 & الأول (المعرفة البيئية) \\
\hline$\ldots 1$ & .011 & الثاني (الاتجاهات البيئية) \\
\hline$\ldots 1$ & .079 & الثالث (المهارات البيئية) \\
\hline
\end{tabular}

يتضح من الجدول السابق أن أبعاد مقياس الوعي البيئي ترتبط بالدرجة

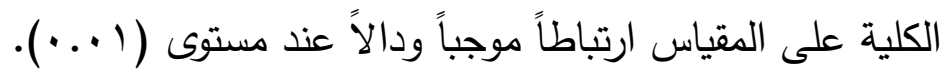

جدول (ז)

معاملات الارتباطات ودلالتها بين درجات أبعاد مقياس الوعي البيئي

\begin{tabular}{|c|c|c|c|}
\hline البعد الثالث & البعد الثاني & البعد الأول & أبعاد مقياس الوعي البيئي \\
\hline & & - & الأول (المعرفة البيئية) \\
\hline & - & $.0 \mathrm{VV}$ & الثاني (الاتجاهات البيئية) \\
\hline- & .711 & . OPr & الثالث (المهارات البيئية) \\
\hline
\end{tabular}

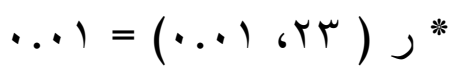

يتضح من الجدول السابق ارتباط أبعاد مقياس الوعي البيئي ببعضها

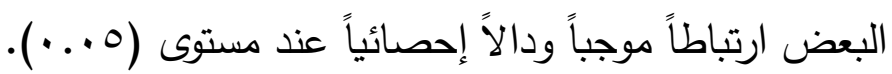


جدول (ץ) - (ب)

معاملات الارتباط بين درجات كل مفردة والارجة الكلية على المقياس

\begin{tabular}{|c|c|c|c|c|c|}
\hline الكلية & مفردات البعد الثالث & الكلية & مفردات البعد الثاني & الكلية & مفردات البعد الأول \\
\hline$\cdot, 0 \wedge r$ & 1 & ., Or & 1 & $\cdot, \bullet \vee \diamond$ & 1 \\
\hline$\cdot, \leqslant 99$ & $r$ & V & $r$ &., 411 & $r$ \\
\hline,,$\leqslant \vee 0$ & $r$ &., 011 & $r$ & $\cdot, 0 \times \wedge$ & $r$ \\
\hline 9צו, & $\varepsilon$ & $\cdot, \leqslant$ ४ & $\varepsilon$ & A & $\varepsilon$ \\
\hline.,$O Y V$ & 0 &.,$\leqslant 11$ & 0 & •, & 0 \\
\hline$\cdot, \leqslant 9 \wedge$ & 7 & $\cdot, 0 \wedge r$ & 7 & $\cdot, 0 \vee 1$ & 7 \\
\hline ., & $\mathrm{v}$ & סזס, & v &., $01 r$ & v \\
\hline., 040 & $\Lambda$ &.,$\leqslant 70$ & $\wedge$ & , O & $\wedge$ \\
\hline$\cdot, \leqslant \vee r$ & 9 &., ४ १ & 9 & $\cdot$, Trv & 9 \\
\hline$\cdot, \varepsilon \wedge r$ & 1. &.,$\leqslant 1 \wedge$ & 1. & , oro & 1. \\
\hline., $0 \wedge 1$ & 11 & $\cdot, 0 \wedge r$ & 11 &., 011 & 11 \\
\hline 1.,0 & ir & V Tr, & ir &., 01. & ir \\
\hline ., & ir &., 711 & ir &., $01 r$ & 14 \\
\hline., 010 & $1 \leq$ &., 017 & $1 \leqslant$ & $\cdot, 4 \vee 1$ & $1 \leq$ \\
\hline $0, \leq 91$ & 10 &., 0 , & 10 & ו ו & 10 \\
\hline$\cdot, \varepsilon \wedge r$ & 17 & $\cdot,\{\wedge 1$ & 18 & r & 18 \\
\hline$\cdot, \leqslant \mid V$ & iv &.,$\leqslant \vee 0$ & iv & $\cdot, \leqslant 11$ & iv \\
\hline$\cdot, 11 \wedge$ & 11 &., 091 & 11 &., 011 & 11 \\
\hline ., IV & 19 &., $01 r$ & 19 & $\cdot, \leqslant \wedge r$ & 19 \\
\hline., 011 & $r$. &.,$\circ \vee V$ & $r$. & $\cdot, \leqslant 7 V$ & r. \\
\hline., $0 \vee 4$ & YI & $\cdot, \leqslant \wedge \leqslant$ & YI &., 091 & $r$ \\
\hline., $0 \wedge 1$ & $r r$ &.,$\leqslant \vee 4$ & $r r$ &., 011 & $r r$ \\
\hline$\cdot, \leqslant 94$ & $r r$ & $\cdot,\{\wedge 1$ & $r$ & $\cdot, \leqslant r r$ & $r r$ \\
\hline$\cdot, \leqslant \vee 1$ & $r \leq$ & $\cdot, 0 \wedge \wedge$ & $r \varepsilon$ & $\cdot, 0 \wedge 1$ & $r \leq$ \\
\hline$\cdot, \leqslant \wedge \wedge$ & ro &., $01 \mathrm{~V}$ & ro & • & ro \\
\hline., $01 \mathrm{~V}$ & YY &.,$\leqslant 1 r$ & Y &., 071 & ry \\
\hline . & $r v$ &.,$\leqslant 1 r$ & $r v$ & $\cdot, \leqslant \vee 1$ & $r v$ \\
\hline$\cdot, \leqslant \vee 1$ & $r \wedge$ & $\cdot, \leqslant \wedge \Gamma$ & $r \wedge$ & $\cdot, \leqslant 94$ & $r \wedge$ \\
\hline$\cdot, \leqslant \wedge \wedge$ & rq & $\cdot, \leqslant 4 \wedge$ & ra & $\cdot, \leqslant 9 \wedge$ & ra \\
\hline., $0 \vee 4$ & $r$. &.,$\circ \vee V$ & $r$. & $\cdot, 711$ & $r$. \\
\hline., 011 & r &., 011 & r &., $09 \leq$ & r \\
\hline$\cdot,\{91$ & rr &., 0 ४ & rr &., 011 & rr \\
\hline., 011 & $r r$ & $\cdot, \leqslant \vee 1$ & $r$ & $\cdot, \leqslant 94$ & $r r$ \\
\hline$\cdot, \varepsilon \mid r$ & $r \varepsilon$ &., 711 & $r \varepsilon$ & $\cdot, 011$ & $r \leq$ \\
\hline r & ro & $\cdot,\{\wedge r$ & ro & $\cdot, \leqslant 9 \vee$ & ro \\
\hline
\end{tabular}


يتضح من الجدول السابق ارتباط مفردات المقياس ارتباطاً موجباً ودالاً

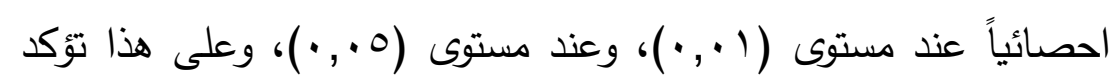

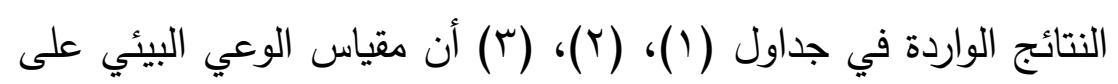

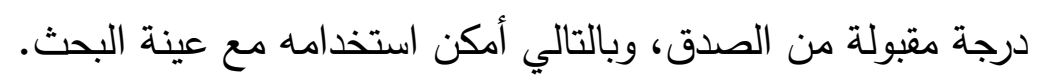

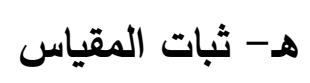

\section{1- تم التحقق من ثبات المقياس عن طريق:}

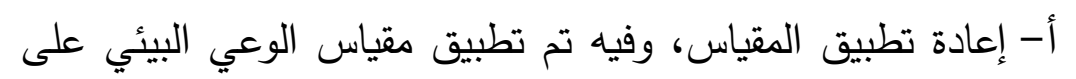

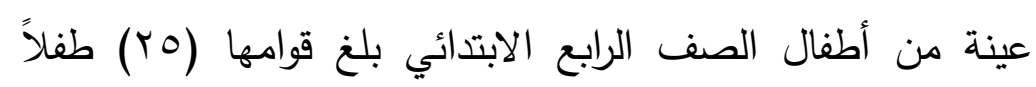
مرتين متتاليتين بفاصل زمني ثلاثة أسابيع، ثم تم حساب معامل

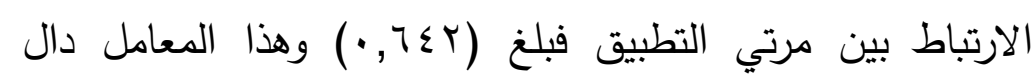

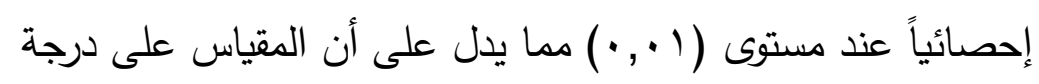
مقبولة من الثبات.

ب- القسمة النصفية، وفيه تم حساب معامل الارتباط بين الدرجات على المفردات ذات الأرقام الفردية وبين الدرجات على المفردات ذات الت الهات

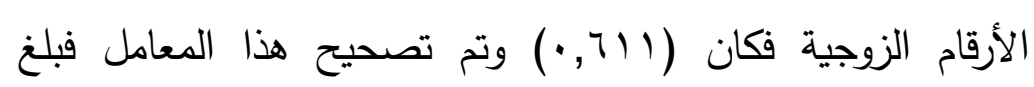

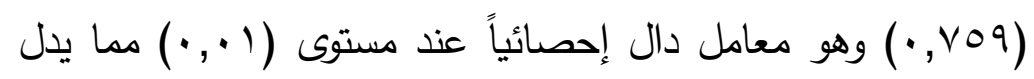
على أن المقياس على درجة مقبولة من الثبات، وبالتالي أمكن استخدامه مع عينة البحث.

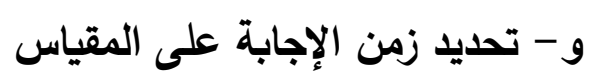

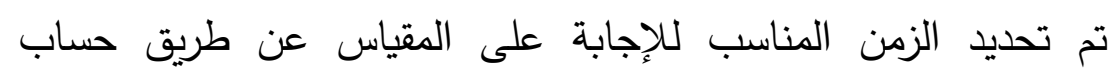

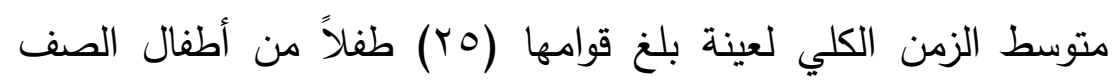

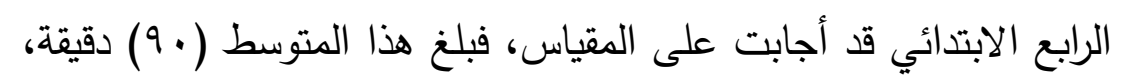
الذي أصبح هو الزمن المناسب للإجابة على المقياس. 


\section{ز - وضع المقياس في صورته الصالحة للتطبيق}

تم وضع المقياس في صورته النهائية في كراسة مستقلة، كما تم وضع تعليمات المقياس في صفحة مستقلة عنه احتوت على ضرورة مله البيانات الواردة من كتابة الاسم واسم المدرسة، وتاريخ الميلاد، والجنس،

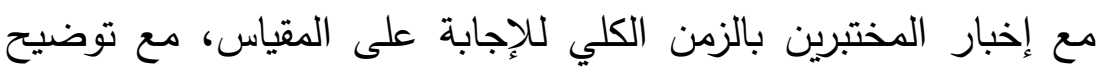
طريقة الإجابة على مفردات المقياس.

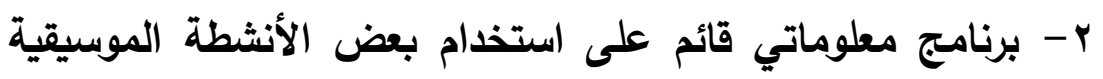

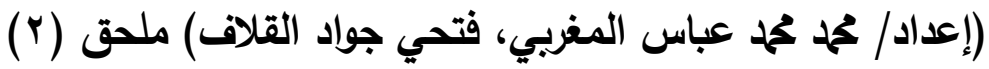

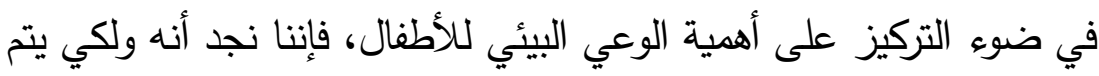

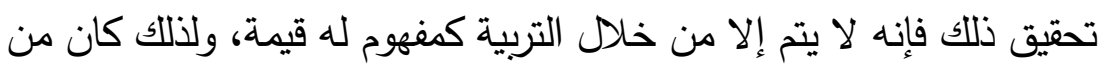

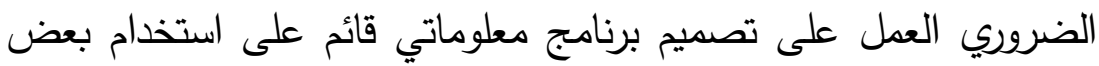

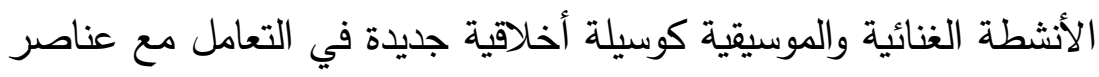

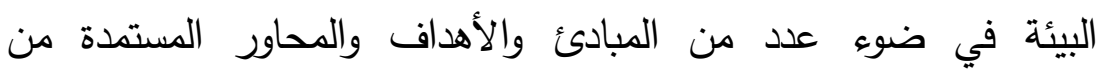

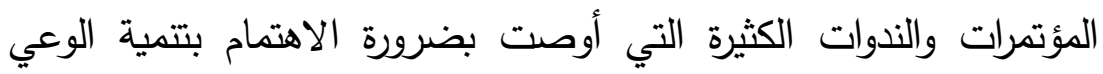
البيئي لدى جميع الأفراد، وهذا ما يحاول أن يقوم به البحث الحالي فيما يتم

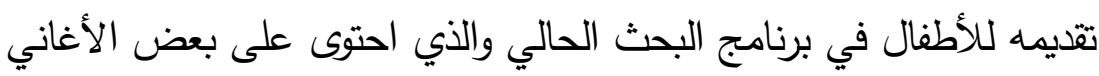

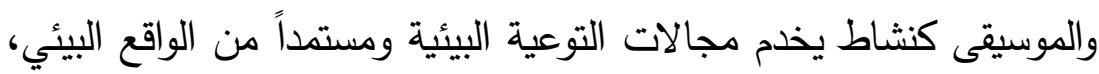

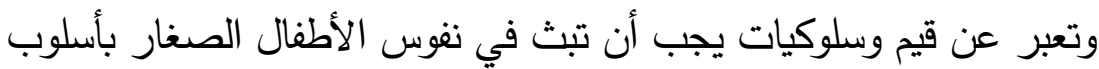

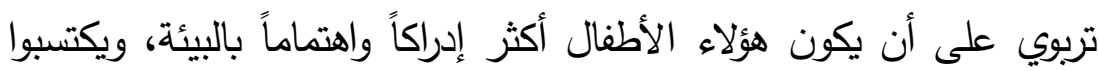
المعرفة في حل الشككلات البيئية وهي تربية مبنية على التجارب العملية. وعلى هذا تقوم فكرة برنامج البحث الحالي على مجموعة من الأنشطة التي يقوم بها الأطفال بكل حيوية وحماس وفي شكل تعاوني يحقق بكان

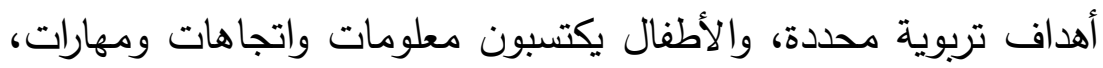
ويتعلمون كيف يقومون بحل المشكلات التي تواجهم من خلال الاندماج في أنشطة كل خطوة من خطوات البرنامج. 
ولقد تم إعداد برنامج معلوماتي قائم على استخدام بعض الأنشطة الغنائية

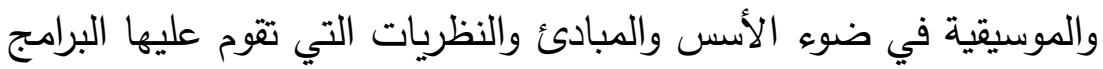
المعلوماتية، كما تم الاطلاع على بعض الدراسات التجرببية المتعلقة

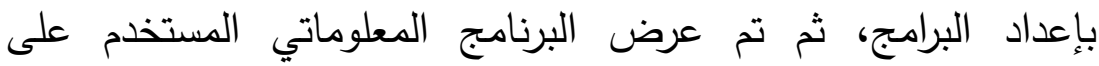
مجموعة من أساتذة علم النفس بجامعة الكويت، وتم الأخذ بتوصياتهم وملاحظاتهم للخروج بالبرنامج بصورته النهائية، وبعد إجراء التعديلات المناسبة التي أوصى بها المحكمون، وكانت الصورة النهائية للبرنامج كالتالي:أولاً : تحديد الهـف العام للبرنامج المعلوماتي يهدف البرنامج المعلوماتي القائم على استخدام بعض الأنشطة الغنائية

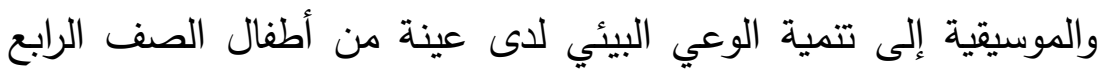

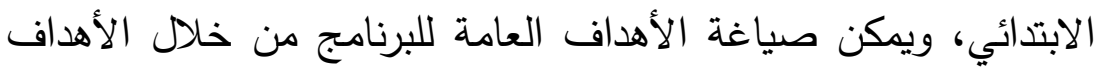
السلوكية التالية:-

1 أن يتمكن الأطفال من اكتساب معلومات متنوعة ومعارف خاصة بالتلوث البيئي في دولة الكويت، وبالكائنات الحية البرية والبحرية، تطورها، والمشكلات التي يمكن أن تتعرض لها لوات والمعرفة البيئية). r- أن يكون الأطفال قادرين على اكتساب الوعي بأهمية الكائنات

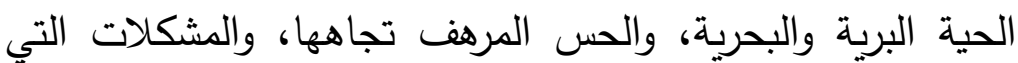
يمكن أن تقترن بها (الوعي البيئي).

r- أن يتكون لدى الأطفال اتجاهات وقيم بيئية إيجابية تجاه الكائنات

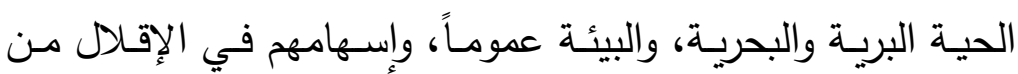
a لمة بالكائن

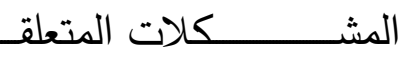
(الاتجاهات والقيم البيئية). 
ع - أن يتمكن الأطفال من اكتساب المهارات البيئية اللازمة للمحافظة على البيئة وعلى الكائنات الحية البرية والبحرية، والاستفادة منها في (المهــارات إطــار عـدم الأضــــار بالبيئـة البيئية).

0- أن تتاح الفرصة للأطفال ليكونوا مشاركين إيجابيين في العمل على حل المشكلات البيئية المتعلقة بالكائنات البرية والبحرية (المشاركة البيئية). ثانياً : محتوى البرنامج المعلوماتي احتوى البرنامج على معلومات عن الطبيعة البيئية لدولة الكويت، كما

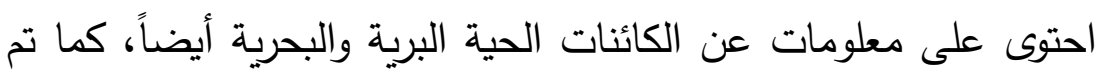
تجهيز بعض الأدوات اللازمة لتنفيذ البرنامج من توافر بعض النباتات

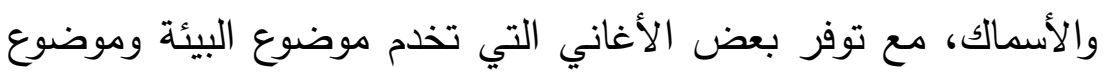

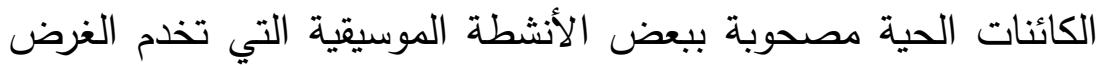

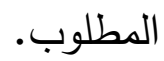

ثالثاً : مصادر البرنامج المعلوماتي تم إعداد البرنامج المعلوماتي في ضوء الاستعانة بكتاب العلوم المقرر على

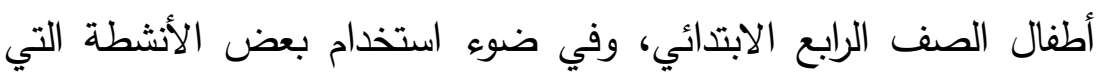

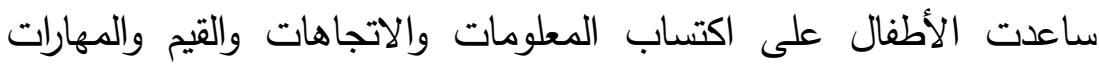
اللازمة، وفي ضوء نتائج بعض الدراسات المرتبطة بتمية الوعي البيئي.

رابعاً : الفئة المستفيدة من البرنامج المعلوماتي الفئة المستفيدة من البرنامج المعلوماتي هم فئة الأطفال الذكور بمدرسة

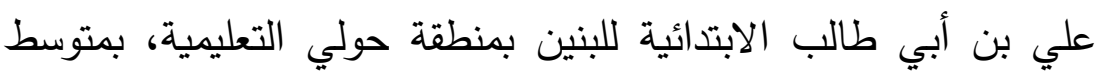

$$
\text { عمري قدره (r, • ( ) سنوات. }
$$

خامساً : مراحل البرنامج المعلوماتي لوني 
تمثلت مراحل البرنامج المعلوماتي القائم على استخدام بعض الأنشطة الغنائية والموسيقية لتنمية الوعي البيئي في التالي:ا - مرحلة البداء تم في هذه المرحلة التعارف بين الأطفال (العينة التجريبية) للبحث وبين أحد الباحثين * الذي قام بشرح أهداف البرنامج المعلوماتي للأطفال، وقام لإلئ بتطبيق مقياس الوعي البيئي قبلياً على أطفال مجموعتي البحث التجريبية والضابطة.

\section{r - مرحلة تنفيذ البرنامج المعلوماتي}

قام الباحث بتتفيذ عدد من الخطوات في هذه المرحلة كالتالي:أ - قام بإعداد مكان في حديقة المدرسة بالتعاون مع إدارة المدرسة لشرح

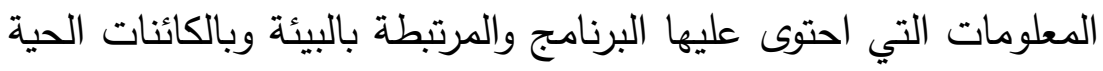
البرية والبحرية.

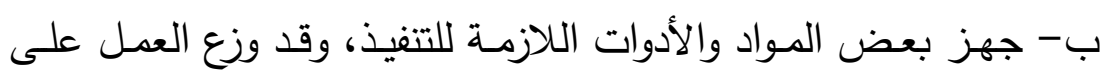

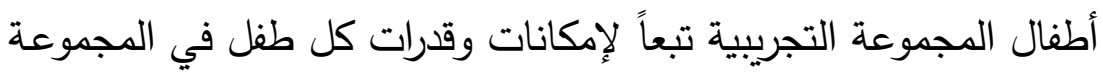

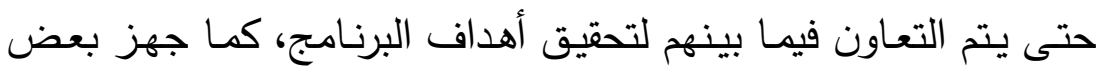

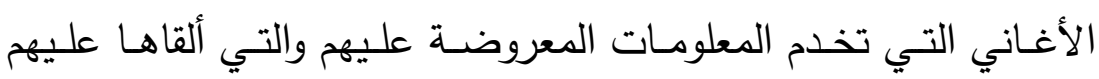
حسب ترتيبها في سياق المعلومات مصحوبة ببعض النغمات الموسيقية

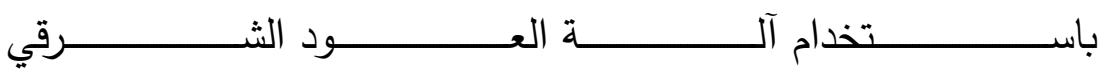
(وهي آلة وترية رئيسية في التخت الموسيقي الثرقي) كالتالي:- 


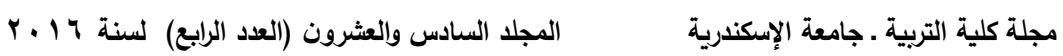

نشيد: مناخنا صحراوي حار صيفاً وبارد شتاءاً / يؤثر في بيئتا ويؤثر

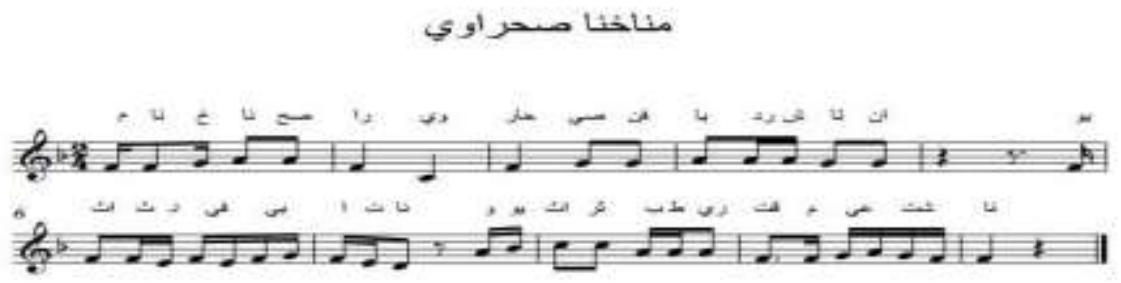

بطريقة معيثتنا نشيد: طق يا مطر طق بيتنا يديد مرزامنا حديد

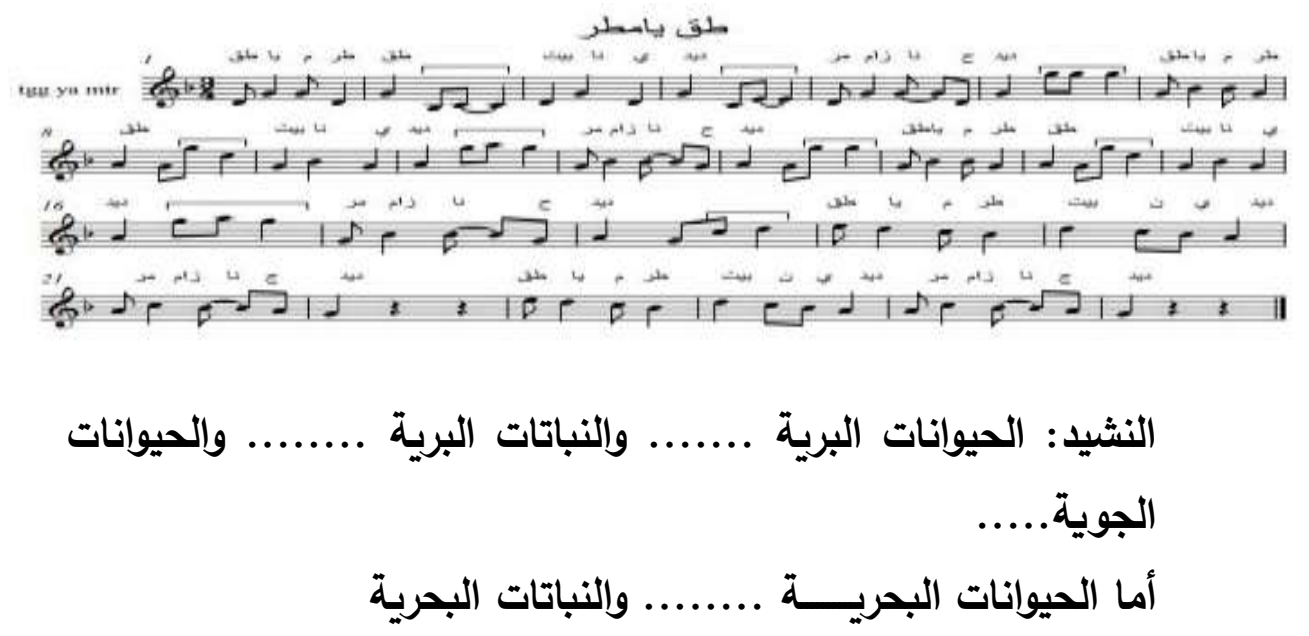

كائنات البيئه الكويتيه

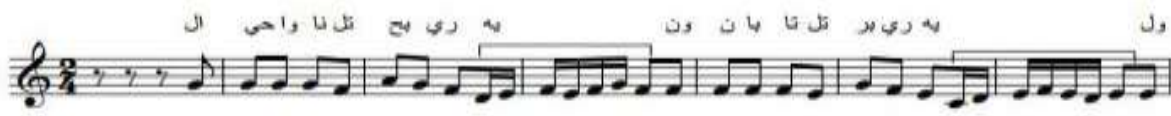

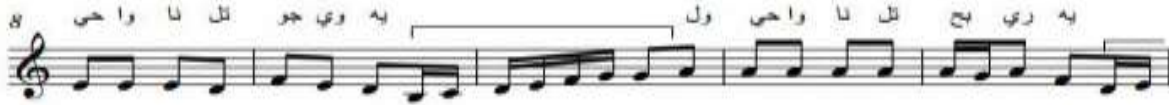

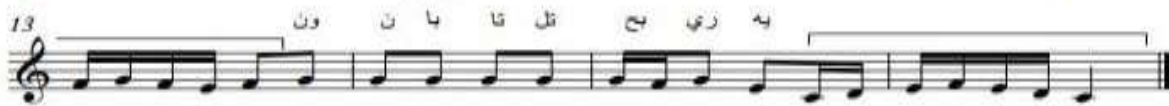


النشيد: شوط شوط يالبطه ولعن ابو من حطه ...... مـا حطتهـه الا

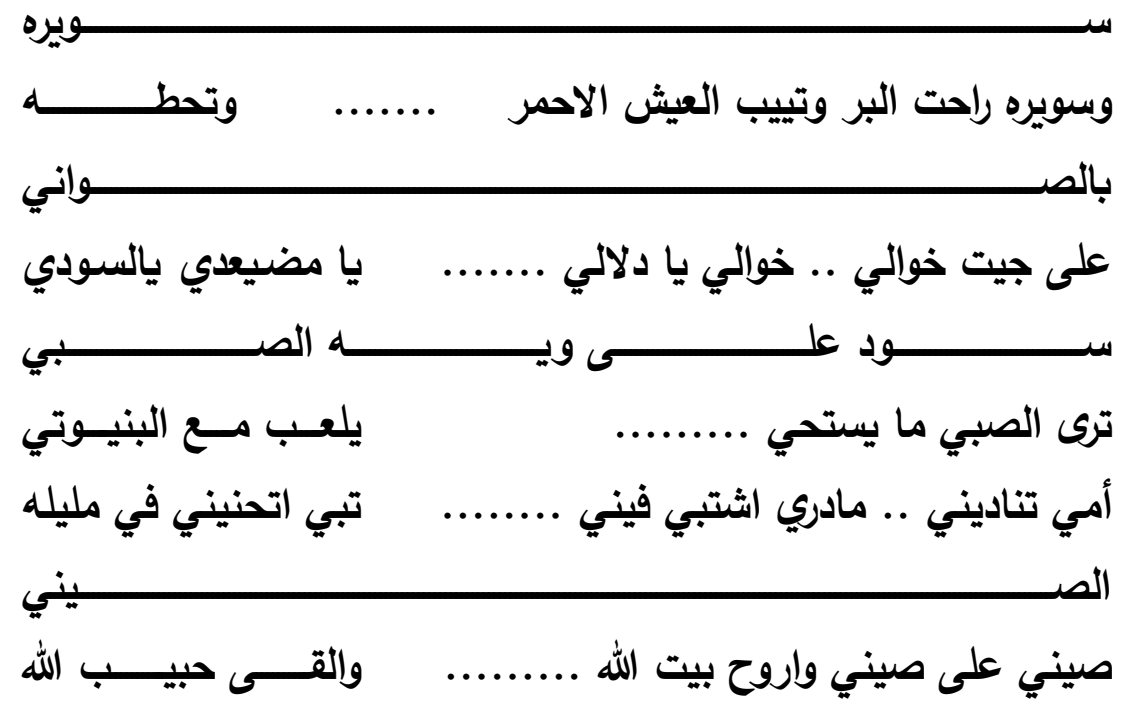

\section{شورط شوط بالبطل

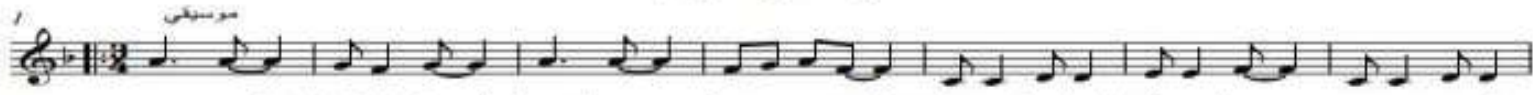

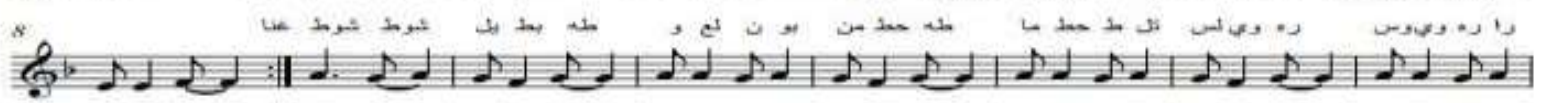

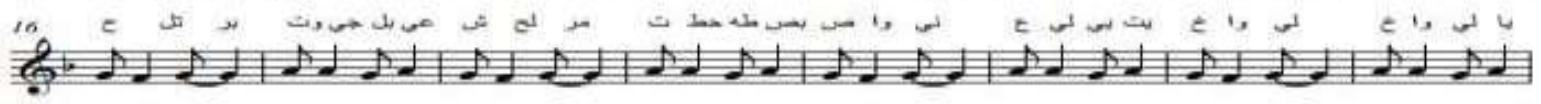 है (5)}

قاعد على سجادته ياته الغزاله ونادته 


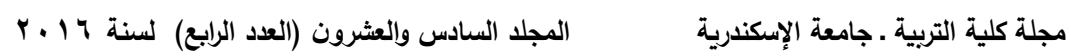

$$
\begin{aligned}
& \text { النشيد:يا يما قومي طلي .. يا يمه قومي طلي } \\
& \text { شوفي البحر محتاس .. شوفي البحر محتاس } \\
& \text { شوفي شراع أبيي .. شوفي شراع أبيي } \\
& \text { أبيض جنه القرطاس .. (بيض جنه القرطاس } \\
& \text { شوفي شراع بوغبور .. شوفي شراع بوغبور } \\
& \text { اسود جنه الاخان .. اسود جنه الاخان }
\end{aligned}
$$

$$
\text { يايمه قومي طلي }
$$


فاعلية برنامج معلوماتي قائم د.سميرة علي د. محم حمد د. ناصر عبد العزيز + د. فتحى جواد أ.د. محم محما

النشيد:يا كوس عود .. ما نبيك الليلة الليلة

نبي لغربيى .. والهبوب الزينه الزينة

سبعة مراكب .. شبهوها ابثيله ابثيله

ياكوس

موسيقى
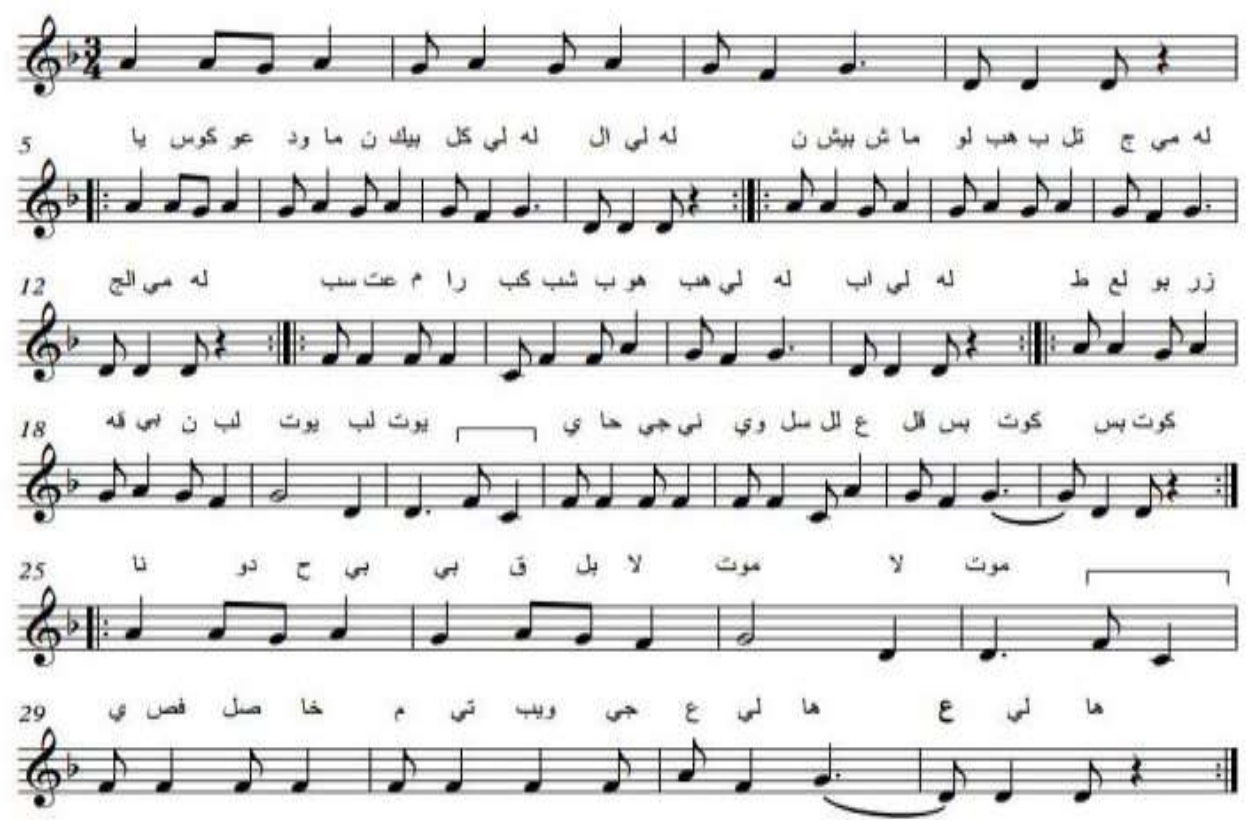

طلع بو زرقه .. يم البيوت البيوت

rar 
ج- استخدم الأساليب التالية مع المجموعة التجريبية للبحث وهي

(أسلوب العرض المصحوب بالأغاني والموسيقى - المناقثات -

$$
\text { الحوارات). }
$$

د- قام بعرض المعلومات على أطفال المجموعة التجريبية في عدد من

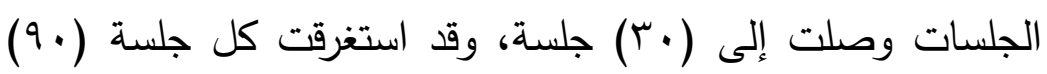

$$
\text { دقيقة في عدد من الأيام وصلت إلى (0ء ) يوماً. }
$$

هـ استخدم في كل جلسة أسلوب العرض للمعلومات مصحوباً ببعض الإض

$$
\text { الأغاني مع استخدام الموسيقى في عرضها. }
$$

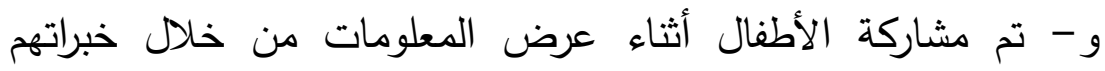
السابقة حول المعلومات الحالية للبرنامج والتي دارت حول البيئة وحول

$$
\text { الكائنات الحية البرية والبحرية. }
$$

ز - تم مناقشة الأطفال أثناء عرض المعلومات، كما تم الاستعانة ببعض النماذج الطبيعية والمصورة عن موضوع البرنامج، وهذا كان بمثابة

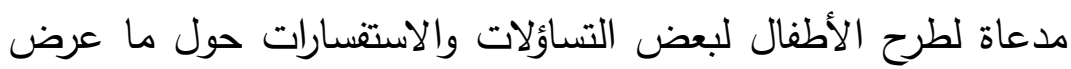

\section{عليهم.}

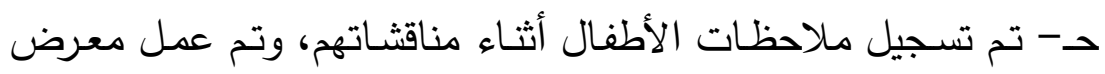

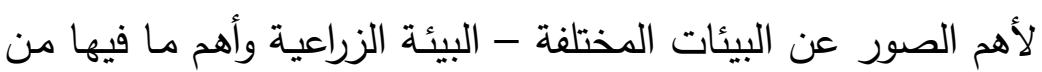

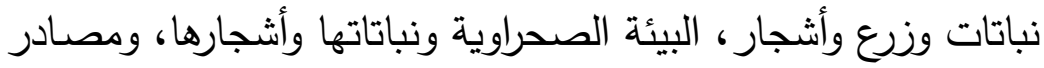
a

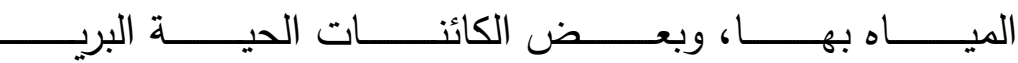
(الحيوانيـة مثل الثدييات (الحصـني، الجربـوع، الضـب، الظربـان، الورل) والطيور (بو الخصيف، القيسة، بوحقب، الرهيز، الثرياص)،

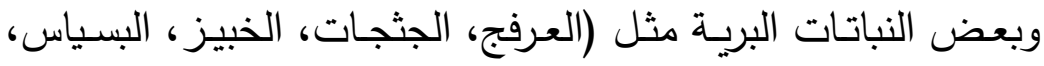
a البحري ات الحي

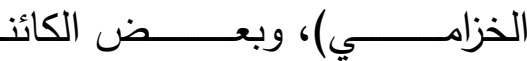
(الحيوانية مثل الزبيدي، الميد، اللخمة، اليريور، الهامور)، (النباتات مثل القصيع، الزريع، الخيدوش، الصويفة، المهفة). 
ط- تم مناقثة الأطفال بعد إعداد بعض الصور في كل الفوائد الرائعة

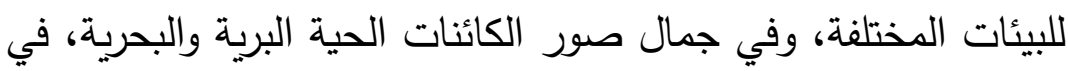

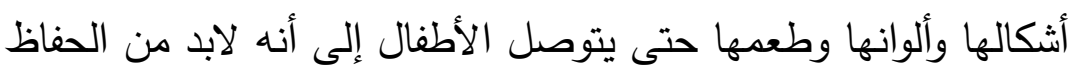

$$
\text { عليها لأهميتها في الحياة. }
$$

ي- أمكن عمل رحلة ميدانية للأطفال إلى المركز العلمي بعد تطبيق لألميته

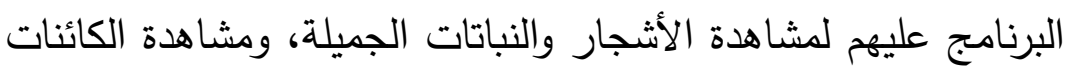

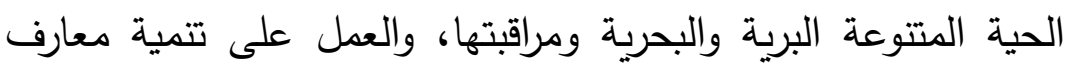
الأطفال عنها وكيفية الحفاظ عليها، وكيفية التمييز بينها. ك- إكساب الأطفال معارف عن كيفية الحفاظ على موارد البيئة

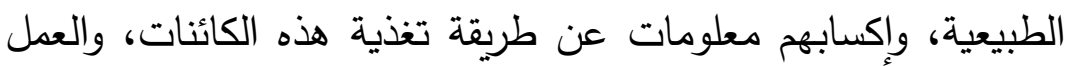
على إكساب الأطفال السلوك السوي المتمثل في كيفية انتهاج صفة صنة النظافة.

ل- إكساب الأطفال الاتجاهات الإيجابية نحو تقدير الكائنات الحية البرية والبحرية ونحو المحافظة على البيئة، والعمل على تجنب التلوث البيئي. م- إكساب الأطفال بعض من المهارات البيئية مثل رمي القمامة في سلة

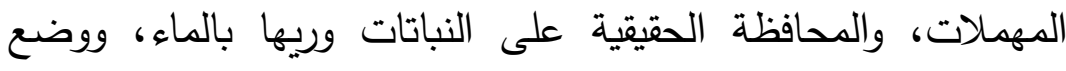

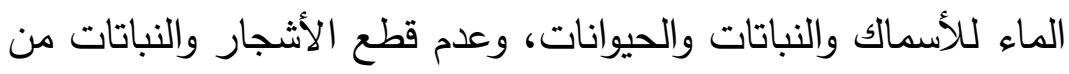
البيئة، وزراعة بعض النباتات والأشجار في حديقة المدرسة، وكيفية الاعتناء بالنباتات والأسماك. r- مرحلة النهاية تم في هذه المرحلة التالي:أ- اشترك الأطفال مع بعضهم البعض في وصف وتمثيل الخبرات

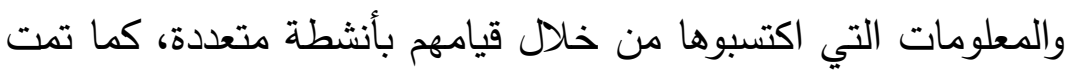


مجلة كلية التربية ـ جامعة الإسكندرية المجلد السادس والعشرون (العدد الرابع) لسنة 17 ب ب

مناقشة ما شاهدوه من صور مختلفة للأشجار والنباتات والكائنات الحية

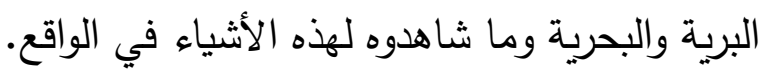

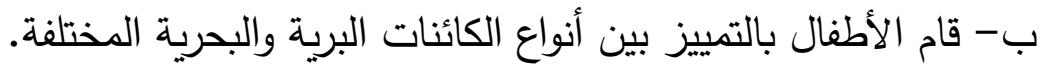

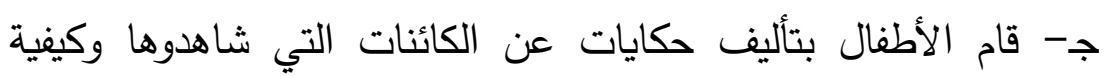
المحافظة عليها. د- قام الأطفال بتأليف قصص غنائية من عندهم حول الكائنات البرية والبحرية.

هـ قام الأطفال بصناعة بعض الكائنات البرية والبحرية مستخدمين

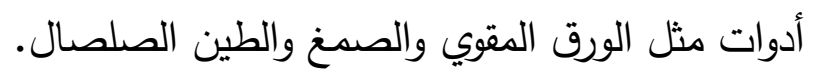

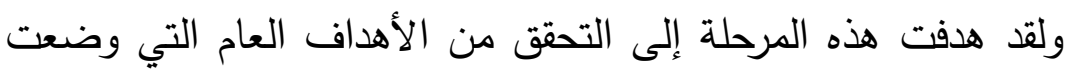
للبرنامج المعلوماتي - كما تم تطبيق مقياس الوعي البيئي تطبيقاً بعدياً

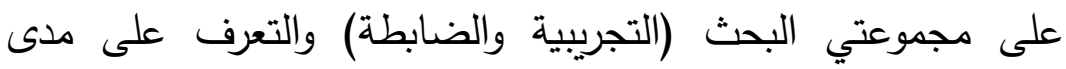
فاعلية البرنامج المعلوماتي في تتمية الوعي البيئي لأطفال المجموعة ولئي التجريبية.

\section{ع - مرحلة المتابعة}

تمثلت هذه المرحلة في متابعة أطفال المجموعة التجريبية مع المعلمين وذلك بعد انتهاء مدة تطبيق البرنامج لمدة لا تقل عن شهرين لمعرفة مدى فاعلية البرنامج المعلوماتي في تتمية الوعي البيئي، ولمعرفة التغيرات التي أحدثها البرنامج بالفعل، وفيها تم تطبيق مقياس الوعي البيئي على أطفال المجموعة التجريبية تطبيقاً تتبعياً. الأساليب المستخدمة في البرنامج المعلوماتي تم استخدام الأساليب التالية مع أطفال المجموعة التجريبية للبحث وهي لإئي

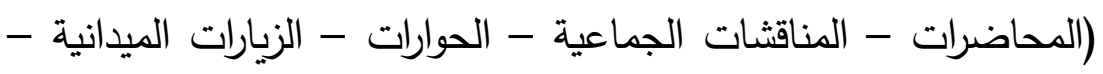
المعارض الفنية - الصور - الأنشطة الغنائية والموسيقية) في كل جلسة المناتيه من جلسات البرنامج، كما تم تقويم كل جلسة من جلسات البرنامج، وتم 
استخدام تقويم شامل للبرنامج المعلوماتي في الجلسة الأخيرة من جلسات البرنامج.

\section{رابعاً : الأساليب الإحصائية}

تم استخدام الأساليب الإحصائية التالية:- الإساتها 1 - المتوسطات والانحرافات المعيارية.

$$
\text { r- r- بليل التباين أحادي الاتجاه. }
$$

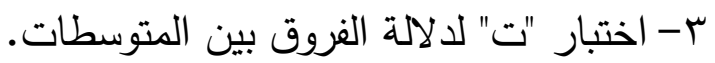
ع - اختبار "w2" لقياس حجم أثر البرنامج المعلوماتي.

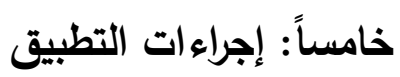

تم إتباع الإجراءات التالية أثناء تجربة البحث الحالي:1- تم اختيار عينة البحث الحالي، وهي عبارة عن مجموعتين من الإه

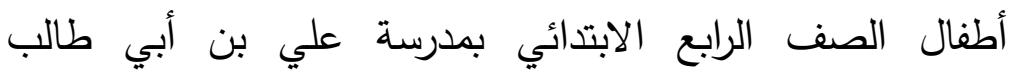

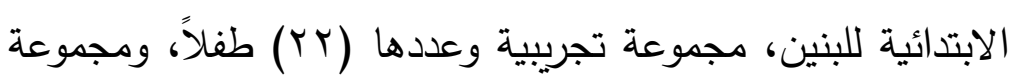

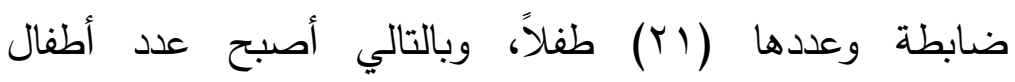

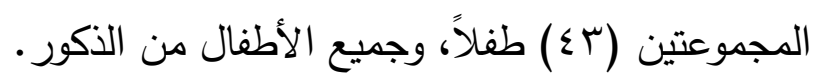

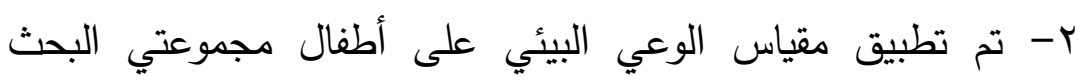
(التجريبية - الضابطة) تطبيقاً قبلياً بالتعاون مع الأخصائية النفسية

$$
\text { بالمدرسة. }
$$

r- تم تطبيق البرنامج المعلوماتي على أطفال المجموعة التجريبية من

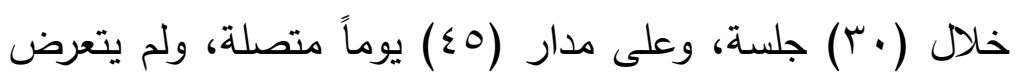
أطفال المجموعة الضابطة للبرنامج المعلوماتي.

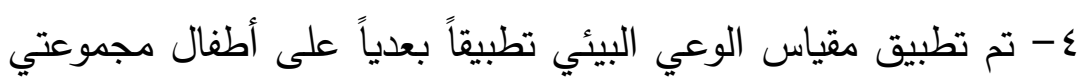

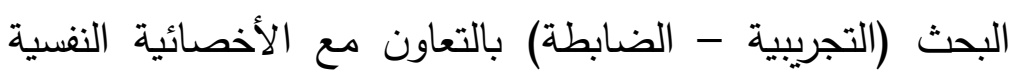
بالمدرسة. 
0- تم تطبيق مقياس الوعي البيئي تطبيقاً تتبعياً على أطفال المجموعة التجريبية وذلك بعد مرور شهرين من التطبيق البعدي لنفس لتسي المقياس.

؟- تـــ تصـــيح مقيــاس الــوعي البيئـي فــي مــرات التطبيــق (قبلياً - بعدياً - تتبعياً) لأطفال مجموعتي البحث.

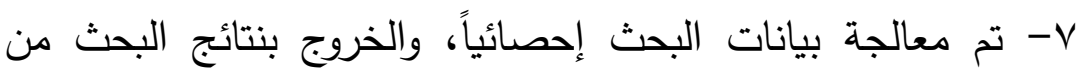
خلال الإجابة والتحقق من صحة فروضه. 1 - تفسير نتائج البحث ومناقشتها.

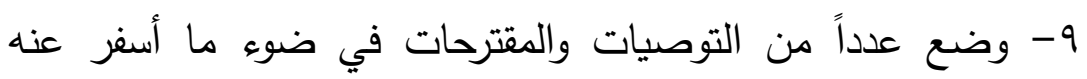
البحث من نتائج. نتائج البحث - مناقثتها وتففيرها

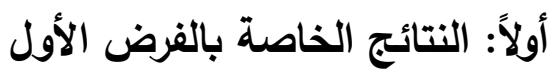

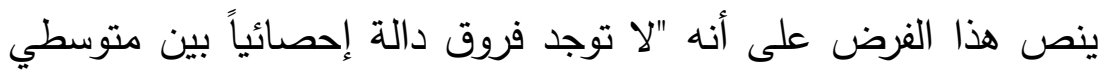

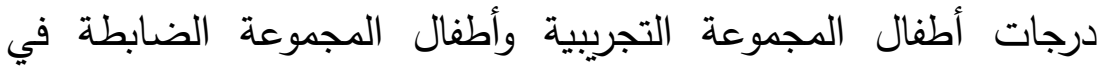
القياس القبلي على مقياس الوعي البيئي بأبعاده لأطفال الصف الرابع

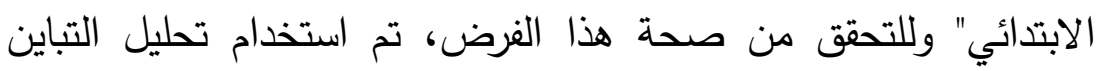

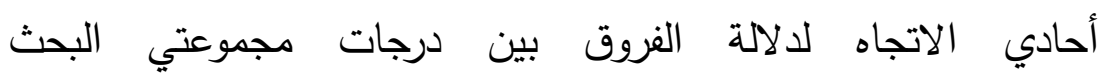
(التجريبية - الضابطة) في القياس القبلي لمقياس الوعي البيئي بأبعاده لأطفال الصف الرابع الابتدائي، ورصدت نتائج ذلك في الجدول التالي:- 
نتائج استخدام تحليل التباين أحادي الاتجاه لدلالة الفروق بين درجات أطفال مجموعتي البحث (التجريبية - الضابطة) في القياس القبلي لمقياس الوعي البيئي بأبعاده لأطفال الصف الرابع الابتدائي

\begin{tabular}{|c|c|c|c|c|c|c|}
\hline مستوى & ف & المربعات & الحرية & المربعات & مصدر التباين & أبعاد مقياس الوعي البيئي \\
\hline \multirow{3}{*}{ غير } & \multirow[t]{2}{*}{$r, 79$} & $11 \Lambda, T V$ & 1 & $11 \wedge, 7 V$ & بين المجموعات & \multirow{3}{*}{ المعرفة البيئية } \\
\hline & & $r r, 1 T$ & « & $|M| 1,04$ & $\begin{array}{c}\text { داخل المجموعات) } \\
\text { (الخطأ) }\end{array}$ & \\
\hline & & & $\varepsilon r$ & $1 \leq r V, r r$ & الكلي & \\
\hline \multirow{3}{*}{ دالة غير } & \multirow[t]{2}{*}{$r, \cdot 1$} & $M r, 1 r$ & 1 & $M r, 1 r$ & بين المجموعات & \multirow[t]{3}{*}{ الاتجاهات البيئية } \\
\hline & & rv, ro & \& & lorv, ro & $\begin{array}{c}\text { داخل المجموعات } \\
\text { (الخطأ) }\end{array}$ & \\
\hline & & & $\varepsilon r$ & I $17 \mathrm{rq}, \mathrm{VV}$ & الكلي & \\
\hline \multirow{3}{*}{ غالة } & \multirow[t]{2}{*}{$r, 90$} & $10 \Lambda, \wedge \mathrm{V}$ & 1 & $10 \wedge, \wedge \mathrm{V}$ & بين المجموعات & \multirow[t]{3}{*}{ المهارات البيئية } \\
\hline & & $\varepsilon \cdot, r$ & «1 & $17 \leq 9, \cdot r$ & $\begin{array}{c}\text { داخل المجموعات } \\
\text { (الخطأ) }\end{array}$ & \\
\hline & & & $\varepsilon r$ & $1 \wedge \cdot v, \wedge q$ & الكلي & \\
\hline \multirow{3}{*}{ غالة غير } & $r, O V$ & $I r \cdot, V \varepsilon$ & 1 & $M r \cdot, V \leq$ & بين المجموعات & \multirow{3}{*}{ المقياس ككل } \\
\hline & & rT,Ar & «1 & Ir人T,TY & 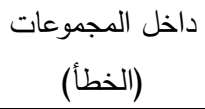 & \\
\hline & & & $\varepsilon r$ & $10 \cdot V, r 4$ & الكلي & \\
\hline
\end{tabular}

يتضح من الجدول السابق عدم وجود فروق دالة إحصائياً بين درجات أطفال مجموعتي البحث (التجريبية - الضابطة)، في القياس القبلي للدرجات الكلية على مقياس الوعي البيئي، وعلى درجات أبعاده الثلاثة وهي (المعرفة البيئية - الاتجاهات البيئية - المهارات البيئية)، مما يدل على أن مجموعتي البحث (التجربية - الضابطة) متكافئتين في الوعي البيئي قبل إجراء تجربة البحث، وعلى هذا قد تحقق صحة الفرض الأول. ثانياً: النتائج الخاصة بالفرض الثاني 
مجلة كلية التربية ـ جامعة الإسكندرية المجلد السادس والعشرون (العدد الرابع) لسنة 14

ينص هذا الفرض على أنه "توجد فروق دالة إحصائياً بين متوسطي

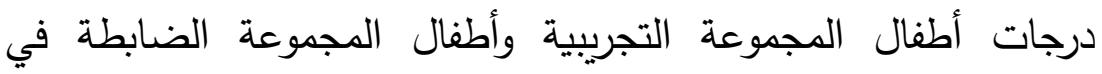

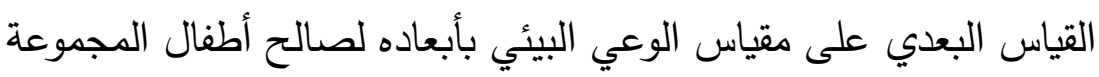

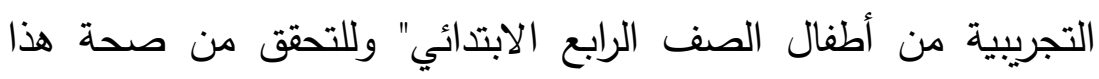

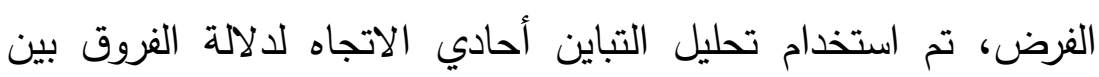
درجات مجموعتي البحث (التجريبية - الضابطة) في القياس البعدي

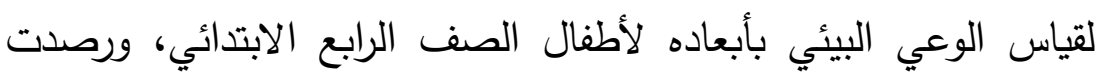
نتائج ذلك في الجدول التالي:-

جدول (0)

نتائج استخدام تحليل التباين أحادي الاتجاه لالالة الفروق بين درجات أطفال مجموعتي البحث (التجريبية - الضابطة) في القياس البعدي لمقياس الوعي البيئي بأبعاده لأطفال الصف الرابع الابتدائي 


\begin{tabular}{|c|c|c|c|c|c|c|}
\hline مستوى & ف & متوبط المربعات & لدرجات & المربعات & مصدر التباين & أبعاد مقياس \\
\hline \multirow[t]{3}{*}{$*, \cdot 1$} & \multirow[t]{2}{*}{$9, \mu_{4}$} & ONT, 9 & 1 & ONY, Q & بين المجموعات & \multirow{3}{*}{ المعرفية } \\
\hline & & $T Y, Y A$ & \&1 & roor, \&A & 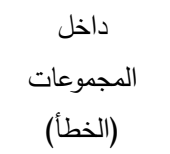 & \\
\hline & & & $\leq r$ & M & الكلي & \\
\hline \multirow[t]{3}{*}{$* \cdot, \cdot 1$} & \multirow[t]{2}{*}{$11,1 \mathrm{~V}$} & $\vee ৭ 7, \wedge \vee$ & 1 & $\vee ৭ ५, \wedge \vee$ & بين المجموعات & \multirow{3}{*}{ الاتجاهات } \\
\hline & & $v 1, r \leq$ & \&1 & rqY $\leq, 9 \leq$ & المجموعات & \\
\hline & & & $\varepsilon r$ & TVYI,NI & الكلي & \\
\hline \multirow[t]{3}{*}{$* \cdot, \cdot 1$} & \multirow[t]{2}{*}{$1 \cdot, 01$} & VTV, QY & 1 & VYV, qY & بين المجموعات & \multirow{3}{*}{ المهارات البيئية } \\
\hline & & $79, Y 7$ & $\varepsilon 1$ & r人ז৭,т & المجموعات & \\
\hline & & & $\leqslant r$ & rotv,01 & الكلي & \\
\hline \multirow[t]{3}{*}{$*, \cdot 1$} & \multirow[t]{2}{*}{$1 \cdot, \times 9$} & VTY,T & 1 & VIT,TE & بين المجموعات & \multirow{3}{*}{ المقياس ككل } \\
\hline & & $v \cdot, T \Lambda$ & «1 & 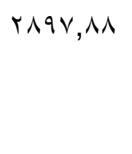 & المجموعات & \\
\hline & & & $\varepsilon r$ & ry & الكلي & \\
\hline
\end{tabular}

يتضح من الجدول السابق وجود فروق دالة إحصائياً عند مستوى (1 (, • (بين درجات أطفال مجموعتي البحث (التجرببية - الضابطة) في القياس البعدي على أبعاد الوعي البيئي (المعرفة البيئية، الاتجاهات البيئية، المهارات البيئية) وعلى المقياس ككل. وتؤكد النتائج الواردة في جدول (0) على وجود فاعلية للبرنامج المعلوماتي القائم على استخدام بعض الأنشطة الموسيقية في تنمية الوعي البيئي في القياس البعدي لأطفال المجموعة التجريبية، ولقياس حجم أثر هذا البرنامج، فإنه تم استخدام مربع أو ميجا (W2) مع البيانات الواردة في جدول (0)، ورصدت نتائج ذلك في الجدول التالي:- 


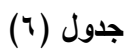

نتائج استخدام مريع أو ميجا (w2) لقياس حجم أثر البرنامج المعلوماتي المستخدم في تنمية الوعي البيئي في القياس البعدي لأطفال المجموعة التجريبية

\begin{tabular}{|c|c|c|c|}
\hline مستوى حجم التأثير & $w^{2}$ & ف & أبعاد مقياس الوعي \\
\hline قوي & $\cdot, 17$ & $9, \varphi^{9}$ & المعرفة البيئية \\
\hline قوي & $\cdot, 19$ & $11,1 \mathrm{~V}$ & الاتجاهات البيئية \\
\hline قوي & $\cdot, 11$ & $1 \cdot, 01$ & المهارات البيئية \\
\hline قوي & $\cdot, 19$ & $1 \cdot, \vee 9$ & المقياس ككل \\
\hline
\end{tabular}

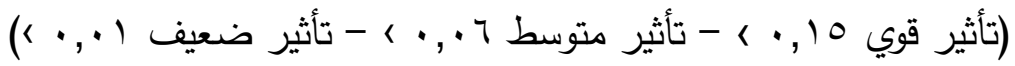
يتضح من الجدول السابق أن للبرنامج المعلوماتي القائم على استخدام بعض الأنشطة الموسيقية تأثيراً قوياً في تتمية الوعي البيئي، وفي تتمية

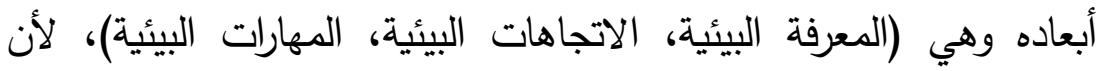

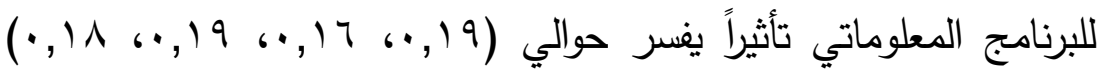
على الترتيب من التباين الكلي في القياس البعدي على الدرجة الكلية على

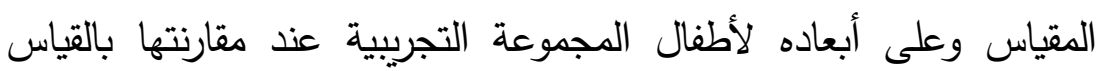
البعدي لنفس المقياس لأطفال المجموعة الضابطة.

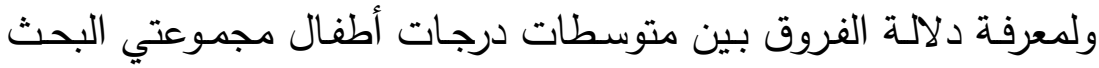
(التجريبية - الضابطة) في القياس البعدي لمقياس الوعي البيئي بأبعاده

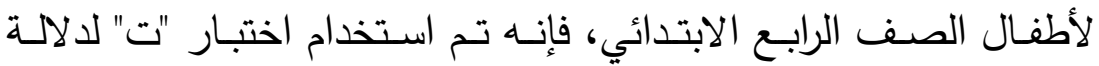

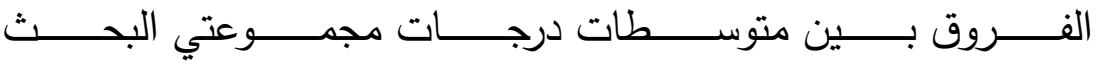
(التجريبية - الضابطة) في القياس البعدي لمقياس الوعي البيئي بأبعاده

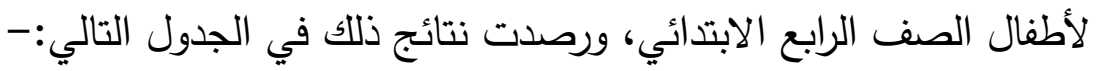
جدول (v)

نتائج استخام اختبار "ت" ودلالته للفروق بين متوسطي أطفال مجموعتي البحث (التجريبية الضابطة) في القياس البعي لمقياس الوعي البيئي بأبعاده لأطفال الصف الثرابع الابتدائي 


\begin{tabular}{|c|c|c|c|c|c|c|}
\hline \multirow{2}{*}{ مستوى الالالة } & \multirow[t]{2}{*}{$ت$} & \multicolumn{2}{|c|}{ الضابطة ( l Y) } & \multicolumn{2}{|c|}{ التجريبية (Yr) } & \multirow{2}{*}{ 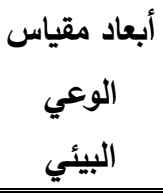 } \\
\hline & & $\varepsilon$ & b & $\varepsilon$ & r & \\
\hline$* \cdot, \cdot 1$ & $r, .0$ & $0, Y \Lambda$ & $|v, v|$ & $\varepsilon, 17$ & 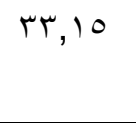 & البيئية \\
\hline$* \cdot, \cdot 1$ & $r, \varepsilon$. & 0,91 & $0 \cdot, 1 \leq$ & $\varepsilon, r V$ & $\Upsilon \Lambda, Y V$ & $\begin{array}{r}\text { الاتجاتهات } \\
\text { البيئية }\end{array}$ \\
\hline$* \cdot, \cdot 1$ & $r, \cdot \Lambda$ & 0,11 & $01, V \leq$ & $\varepsilon, \cdot 1$ & 77, r & $\begin{array}{r}\text { البيئية } \\
\end{array}$ \\
\hline$* \cdot, \cdot 1$ & $r, q 1$ & $1 Y, 74$ & 119,09 & 11,11 & ITV,A. & ككل \\
\hline
\end{tabular}

يتضح من الجدول السابق وجود فروق دالة إحصائياً عند مستوى (1 (., ) بين درجات أطفال مجموعتي البحث (التجريبية - الضابطة) في القياس البعدي على مقياس الوعي البيئي وعلى أبعاده وهي (المعرفة

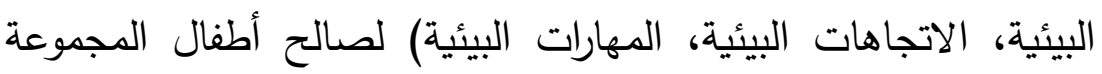

التجريبية.

وتؤكد النتائج الواردة في جدول (V) أيضاً على وجود فاعلية للبرنامج المعلوماتي القائم على استخدام بعض الأنشطة الموسيقية في تتمية الوعي البيئي في القياس البعدي لأطفال المجموعة التجريبية، ولقياس

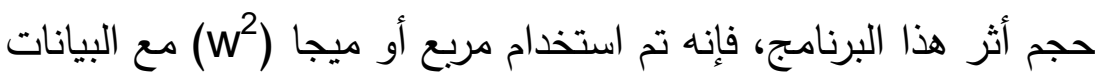
الواردة في جدول (V)، ورصدت نتائج ذلك في الجدول التالي:-

جدول (^)

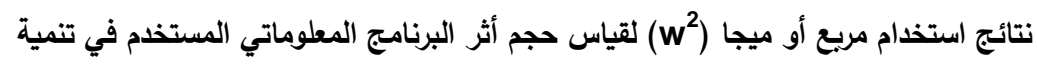

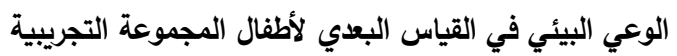

\begin{tabular}{|c|c|c|c|}
\hline مستوى حجم التأثير & $\mathbf{w}^{2}$ & $ت$ & أبعاد مقياس الوعي البيئي \\
\hline قوي & $\cdot, 17$ & $r, .0$ & المعرفة البيئية \\
\hline قوي & $\cdot, 19$ & $r, \varepsilon$. & الاتجاهات البيئية \\
\hline
\end{tabular}




\begin{tabular}{|l|l|l|r|}
\hline المهارات البيئية \\
\hline المياس ككل
\end{tabular}

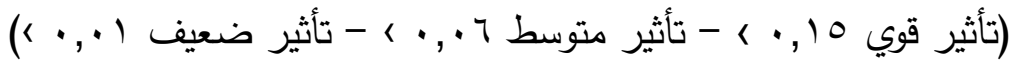

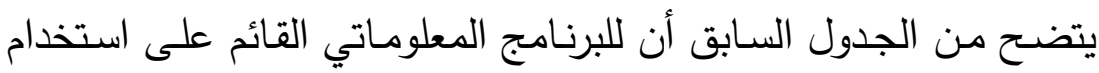
بعض الأنشطة الموسيقية تأثيراً قوياً في تتمية الوعي البيئي، وفي تتمية لإنية

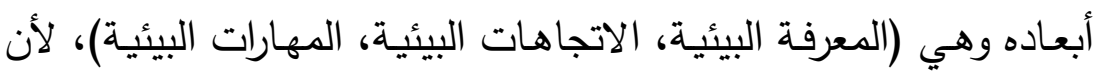

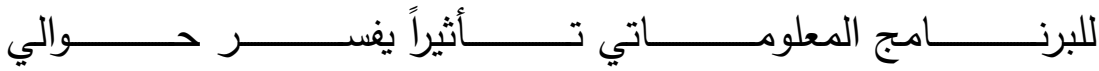

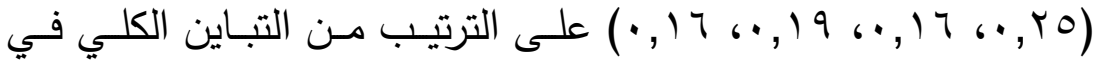
القياس البعدي على الدرجـة الكلية على المقياس وعلى أبعاده لأطفال المجموعة التجريبية عند مقارنتها بالقياس البعدي لنفس المقياس لأطفال المجموعة الضابطة، وعلى هذا قد تحقق صحة الفرض الثاني.

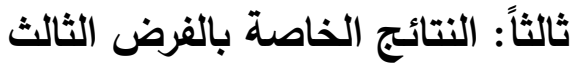
ينص هذا الفرض على أنه "توجد فروق دالة إحصائياً بين متوسطي درجات أطفال المجموعة التجريبية في القياسين القبلي والبعدي على لهي مقياس الوعي البيئي بأبعاده لصالح القياس البعدي لأطفال الصف التفئ الرابع الابتدائي" وللتحقق من صحة هذا الفرض، تم استخدام تحليل التباين أحادي الاتجاه لدلالة الفروق بين درجات أطفال المجموعة التجريبية في

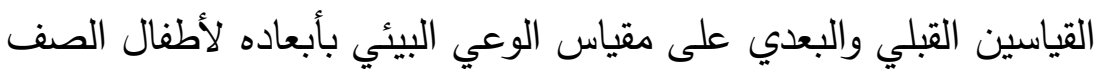

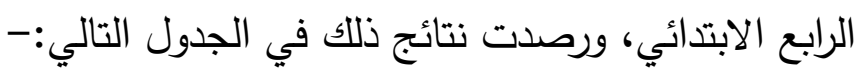

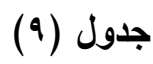

نتائج استخام تحليل التباين أحادي الاتجاه لدلالة الفروق بين درجات أطفال المجموعة التجريبية في القياسين القبلي والبعدي على مقياس الوعي البيئي بأبعاده لأطفال

\begin{tabular}{|c|c|c|c|c|c|c|}
\hline \multicolumn{7}{|c|}{ الصف الرابع الابتدائي } \\
\hline 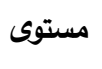 & ف & متوسط & درجات & مجموع & مصدر التباين & أبعاد مقياس \\
\hline الدلالة & & المربعات & الحرية & المربعات & & الوعي البيئي \\
\hline
\end{tabular}




\begin{tabular}{|c|c|c|c|c|c|c|}
\hline \multirow[t]{2}{*}{$* \cdot, \cdot 1$} & \multirow[t]{2}{*}{$1 \cdot, 79$} & 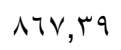 & 1 & 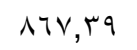 & بين المجموعات & \multirow{3}{*}{ المعرفة البيئية } \\
\hline & & $\wedge 1,1 \leq$ & $\leqslant r$ & $\Gamma \varepsilon \cdot v, \wedge \Lambda$ & $\begin{array}{c}\text { داخل المجموعات } \\
\text { (الخطأ) }\end{array}$ & \\
\hline & & & $\varepsilon r$ & $\sum Y V O, Y V$ & الكلي & \\
\hline \multirow[t]{3}{*}{$* \cdot, \cdot 1$} & \multirow[t]{2}{*}{11,11} & $\lambda \leqslant 1,0 \leqslant$ & 1 & $\wedge \leq 1,0 \leq$ & بين المجموعات & \multirow{3}{*}{ الاتجاهات } \\
\hline & & $v 0,7)$ & $\varepsilon r$ & r & $\begin{array}{c}\text { داخل المجموعات } \\
\text { (الخطأ) }\end{array}$ & \\
\hline & & & $\varepsilon$ & $\varepsilon .17,17$ & الكلي & \\
\hline \multirow[t]{3}{*}{$* \cdot, \cdot 1$} & \multirow[t]{2}{*}{11,14} & $9 \leqslant 1,91$ & 1 & $9 \leq 1,9 \wedge$ & بين المجموعات & \multirow[t]{3}{*}{ المهارات البيئية } \\
\hline & & $\wedge \varepsilon, V)$ & $\varepsilon r$ & roov,Ar & $\begin{array}{c}\text { داخل المجموعات } \\
\text { (الخطأ) }\end{array}$ & \\
\hline & & & $\varepsilon r$ & $\varepsilon \leqslant ৭ १, \wedge$. & الكلي & \\
\hline \multirow[t]{3}{*}{$* \cdot, \cdot 1$} & $11,0 \leq$ & $q \cdot r, v$. & 1 & $q \cdot r, v$. & بين المجموعات & \multirow{3}{*}{ المقياس ككل } \\
\hline & & $\vee \wedge, \Gamma_{l}$ & $\varepsilon r$ & r $\wedge q, \cdot r$ & $\begin{array}{c}\text { داخل المجموعات } \\
\text { (الخطأ) }\end{array}$ & \\
\hline & & & $\varepsilon$ & $\varepsilon 19 r, V r$ & الكلي & \\
\hline
\end{tabular}

يتضح من الجدول السابق وجود فروق دالة إحصائياً عند مستوى (1 (, · ) بين درجات أطفال المجموعة التجريبية في القياسين القبلي والبعدي على أبعاد الوعي البيئي (المعرفة البيئية، الاتجاهات البيئية، المهارات البيئية) وعلى المقياس ككل. وتؤكد النتائج الواردة في جدول (9) على وجود فاعلية للبرنامج المعلوماتي القائم على استخدام بعض الأنشطة الموسيقية في تنمية الوعي البيئي في القياسين القبلي والبعدي لأطفال المجموعة التجربية، ولقياس حجم أثر هذا البرنامج، فإنه تم استخدام مربع أو ميجا (W2) مع لع البيانات الواردة في جدول (9)، ورصدت نتائج ذلك في الجدول التالي:-

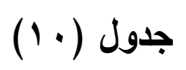

نتائج استخدام مربع أو ميجا (w20 لقياس حجم أثر البرنامج المعلوماتي المستخدم في تنمية الوعي البيئي في القياسين القبلي والبعدي لأطفال المجموعة التجريبية 


\begin{tabular}{|c|c|c|c|}
\hline مستوى حجم التأثير & $w^{2}$ & ف & أبعاد مقياس الوعي البيئي \\
\hline قوي & $\cdot, 1 \wedge$ & $1 \cdot, 79$ & المعرفة البيئية \\
\hline قوي &., 19 & 11,14 & الاتجاهات البيئية \\
\hline قوي &., 19 & $11,1 r$ & المهارات البيئية \\
\hline قوي &., 19 & $11,0 \leqslant$ & المقياس ككل \\
\hline
\end{tabular}

يتضح من الجدول السـابق أن للبرنامج المعلوماتي القائم على استخدام بعض الأنشطة الموسيقية تأثيراً قوياً في تتمية الوعي البيئي، وفي تتمية

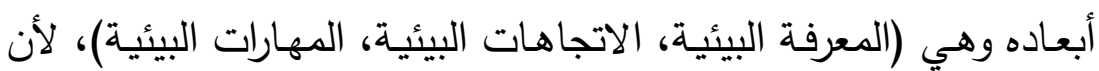

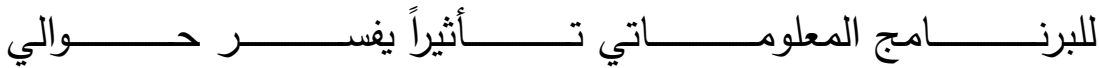

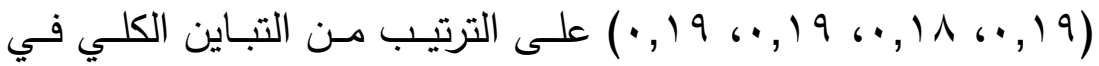

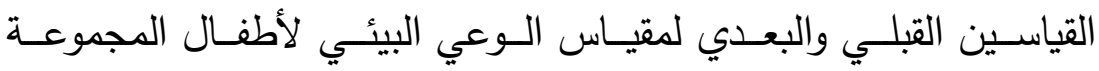
التجريبية.

ولمعرفة دلالة الفروق بين متوسطات درجات أطفال المجموعة التجريبية

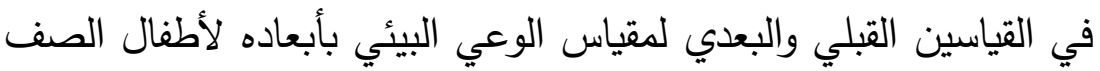

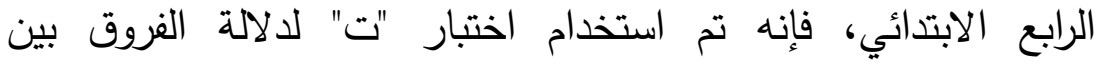

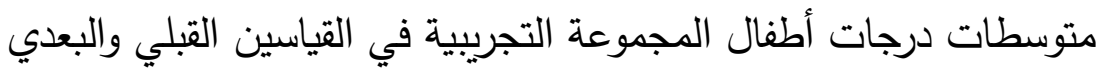
لمقياس الوعي البيئي بأبعاده لأطفال الصف الرابع الابتدائي (المجموعات المرتبطة)، ورصدت نتائج ذللك في الجدول التالي:-

جدول (II)

نتائج استذام اختبار "ت" ودلالته للفروق بين متوسطي درجات أطفال المجموعة

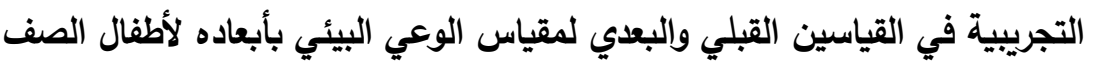

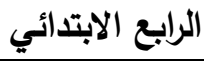

\begin{tabular}{|c|c|c|c|c|c|}
\hline مستوى الدلالة & ت & الحمرافوت فربعات & الفروق الدرجات المرتبطة (م ق) & القياس & أبعاد مقياس \\
\hline
\end{tabular}




\begin{tabular}{|c|c|c|c|c|c|}
\hline & & الفروق مج ح־ّ) & & & \\
\hline \multirow[t]{2}{*}{$* \cdot, \cdot 1$} & \multirow[t]{2}{*}{ IV,rq } & \multirow[t]{2}{*}{$r) \cdot, V r$} & \multirow[t]{2}{*}{$r}$. & قبلي & \multirow[t]{2}{*}{ المعرفة البيئية } \\
\hline & & & & بعدي & \\
\hline \multirow[t]{2}{*}{$* \cdot, \cdot 1$} & \multirow[t]{2}{*}{$r \cdot, \varepsilon}$. & \multirow[t]{2}{*}{ אות,I } & \multirow[t]{2}{*}{$\varepsilon$} & قبلي & الاتجاهات \\
\hline & & & & بعدي & البيئية \\
\hline \multirow[t]{2}{*}{$* \cdot, \cdot 1$} & \multirow[t]{2}{*}{ Y),, . } & \multirow[t]{2}{*}{ Y10.,11 } & \multirow[t]{2}{*}{$\leqslant 7$} & قبلي & المهارات \\
\hline & & & & بعدي & البيئية \\
\hline \multirow[t]{2}{*}{$* \cdot, \cdot 1$} & \multirow[t]{2}{*}{ Tr,人T } & \multirow[t]{2}{*}{$\sum \pi r \cdot, \vee \wedge$} & \multirow[t]{2}{*}{$1 \cdot V$} & قبلي & \multirow[t]{2}{*}{ المقياس ككل } \\
\hline & & & & بعدي & \\
\hline
\end{tabular}

يتضـح مـن الجدول السـابق وجـود فـروق دالـة إحصـائياً عند مسـتىى (1 ( • · ) بين درجـات أطفـال المجموعـة التجريبيـة في القياسـين القبلي

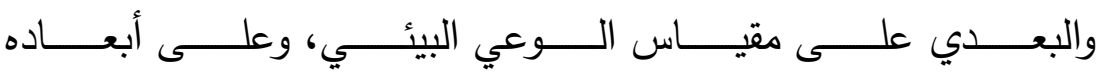
(المعرفـة البيئيـة، الاتجاهـات البيئيـة، المهارات البيئيـة) لصـالح القيـاس البعدي، وعلى هذا قد تحقق صحة الفرض الثالث. وتؤكد النتائج الواردة في جدول (1) أيضاً على وجود فاعلية للبرنامج المعلوماتي القائم على استخدام بعض الأنشطة الموسيقية في تنمية الوعي البيئي في القياسين القبلي والبعدي لأطفال المجموعة التجرببية لصالح التطبيق البعدي، ولقياس حجم أثر هذا البرنامج، فإنه تم استخدام مربع أو ميجا (Ww2) مع البيانات الواردة في جدول (1 (1)، ورصدت نتائج ذلك في الجدول التالي:-

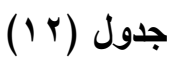

نتائج استخدام مربع أو ميجا (w2) لقياس حجم أثر البرنامج المعلوماتي المستخدم في تنمية الوعي البيئي في القياسين القبلي والبعدي لأطفال المجموعة التجريبية

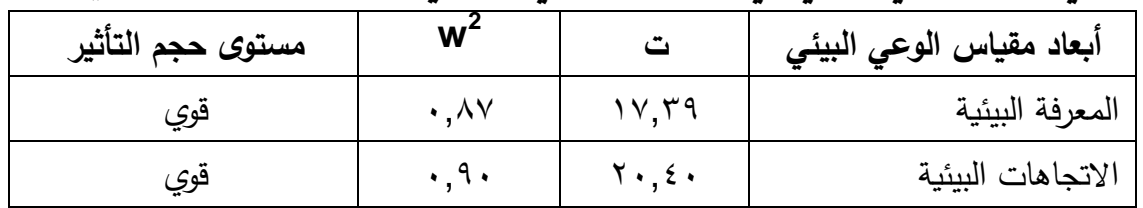




\begin{tabular}{|c|c|c|c|}
\hline قوي & $\cdot, 91$ & $r, v$. & المهارات البيئية \\
\hline قوي & $\cdot, 97$ & Tr,AT & المقياس ككل \\
\hline
\end{tabular}

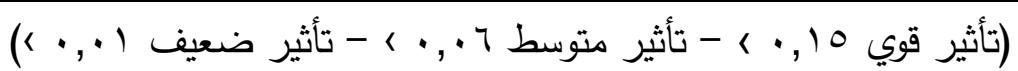

يتضح من الجدول السابق أن للبرنامج المعلوماتي المستخدم تأثيراً قوياً في $\quad$ تنمية $\quad$ الوعي $\quad$ البيئي، (المعرفة البيئية، الاتجاهات البيئية، المهارات البيئية)، لأن للبرنامج

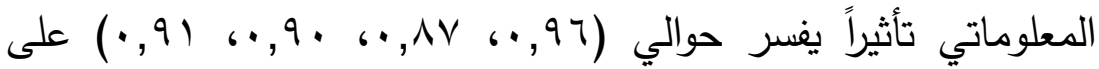
الترتيب.

رابعاً: النتائج الخاصة بالفرض الرابع

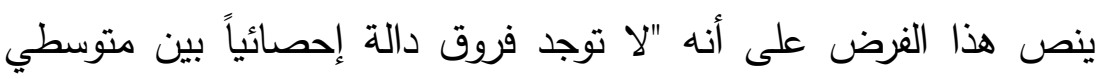

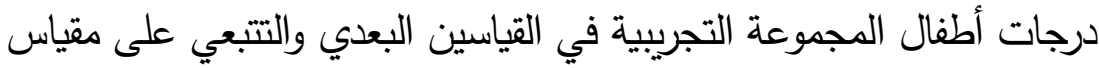
الوعي البيئي بأبعاده لأطفال الصف الرابع الابتدائي" وللتحقق من صحة هذئ ولئه

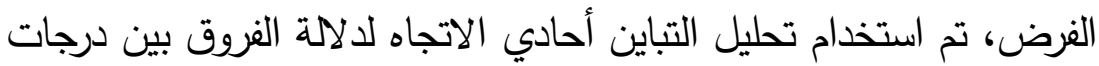
أطفال المجموعة التجريبية في القياسين البعدي والتتبعي على مقياس الوعي البيئي بأبعاده لأطفال الصف الرابع الابتدائي، ورصدت نتائج ذلك في في فئي

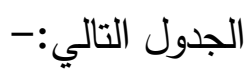

\section{جدول (r)}

نتائج استخام تحليل التباين أحادي الاتجاه لدلالة الفروق بين درجات أطفال المجموعة التجريبية في القياسين البعدي والتتبعي على مقياس الوادي التلائي البيئي بأبعاده لأطفال الصف الرابع الابتدائي

\begin{tabular}{|c|c|c|c|c|c|c|}
\hline الدلالة & ف & المربعات & الرجية & المربعات & مصدر التباين & أبعاد مقياس \\
\hline \multirow{3}{*}{ ع غالة" } & $r, 1$ ร & $17 \pi, V Y$ & 1 & $17 r, V Y$ & بين المجموعات & \multirow{3}{*}{ البيئة } \\
\hline & & or, & $\varepsilon r$ & 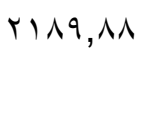 & داخل المجموعات & \\
\hline & & & $\varepsilon r$ & rrot,r. & الكلي & \\
\hline
\end{tabular}




\begin{tabular}{|c|c|c|c|c|c|c|}
\hline \multirow{3}{*}{ غير } & \multirow[t]{2}{*}{$r, \wedge)$} & $1 \wedge 9, \leqslant \vee$ & 1 & $1 \wedge 9, \leqslant V$ & بين المجموعات & \multirow{3}{*}{ الاتجاهات البيئية } \\
\hline & & $\sum q, V \Gamma$ & $\varepsilon r$ & $r \cdot \wedge \Lambda, 7 \tau$ & $\begin{array}{c}\text { داخل المجموعات) } \\
\text { (الخطأ) }\end{array}$ & \\
\hline & & & $\varepsilon r$ & rrVA,IT & الكلي & \\
\hline \multirow{3}{*}{ غالة } & \multirow{2}{*}{$r, 90$} & $1 V V, 17$ & 1 & $1 V V, 17$ & بين المجموعات & \multirow{3}{*}{ البهارات } \\
\hline & & $\varepsilon \varepsilon, \wedge 0$ & $\varepsilon r$ & lıᄉr,v. & $\begin{array}{c}\text { (الخطل المجموعات) } \\
\text { (الخطات }\end{array}$ & \\
\hline & & & $\varepsilon r$ & $r \cdot T \cdot, \wedge T$ & الكلي & \\
\hline \multirow{3}{*}{ غير } & \multirow[t]{2}{*}{$r, v\urcorner$} & Y) $7,0$. & 1 & Y17,0. & بين المجموعات & \multirow{3}{*}{ المقياس ككل } \\
\hline & & $O V, 01$ & $\varepsilon r$ & $r \leqslant 1 \wedge, r q$ & $\begin{array}{c}\text { داخل المجموعات } \\
\text { (الخطأ) }\end{array}$ & \\
\hline & & & $\varepsilon r$ & TTY,NT & الكلي & \\
\hline
\end{tabular}

يتضـح من الجدول السـابق عدم وجود فروق دالة إحصائياً بين درجات أطفال المجموعـة التجريبية في القياسـين البعدي والتتبعي على مقيـاس

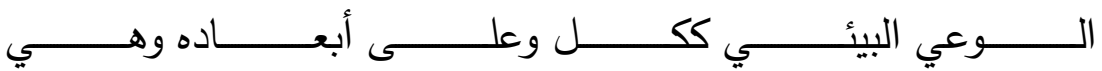
(المعرفـة البيئيـة، الاتجاهـات البيئية، المهارات البيئية)، وعلى هذا قد تحقق صحة الفرض الرابع. - تبين النتائج التي تم التوصل إليها في البحث الحالي عن حدوث تنمية في الوعي البيئي لدى أطفال الصف الرابع الابتدائي، ويتضح هذا من النتيجة الخاصة بالفرض الثالث والتي أشارت إلى وجود اختلاف في القياسين القبلي والبعدي على مقياس الوعي البيئي وعلى أبعاده (المعرفة البيئية، الاتجاهات البيئية، المهارات البيئية) لصالح القياس البعدي لأطفال المجموعة التجريبية التي تعرضت للبرنامج المعلوماتي القائم على استخدام بعض الأنشطة الغنائية والموسيقية، كما تتضح أيضاً حدوث التنمية في الوعي البيئي من النتيجة الخاصة بالفرض الثاني والتي أشارت إلى وجود اختلاف في القياس البعدي على مقياس الوعي البيئي 
(التجريبية وعلى أبعاده بين أطفال مجموعتي البحث

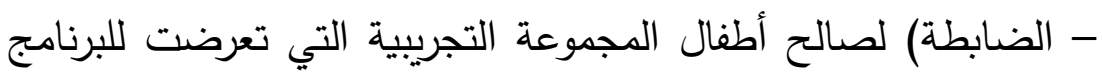
المعلوماتي، وما يؤكد على حدوث التتمية في الوعي البيئي واستمراره

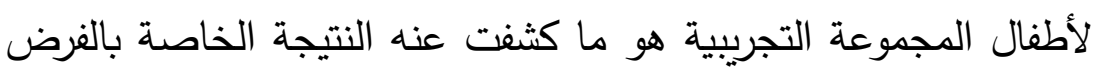
الرابع والتي أشارت إلى عدم وجود اختلاف في القياسين البعدي والتتبعي على مقياس الوعي البيئي وعلى أبعاده لأطفال المجموعة التجريبية، وما

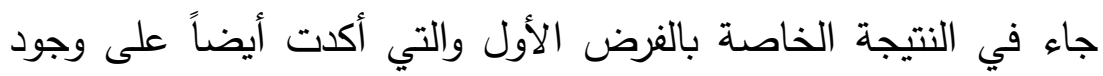
تنمية في الوعي البيئي لأطفال المجموعة التجريبية والتي أشارت إلى الى ولى ولى

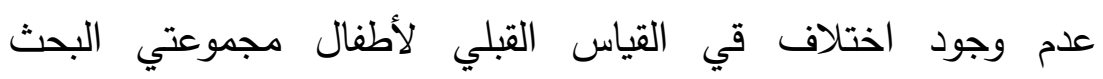
(التجريبية - الضابطة) - يمكن لنا أن نستنتج من خلال هذه النتائج

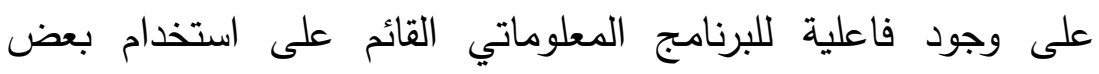
الأنشطة الموسيقية في تتمية الوعي البيئي بأبعاده الثلاثة وهي (المعرفة

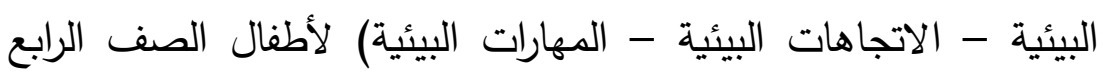
الابتدائي. - ويمكن قراءة نتائج هذا البحث التي أشارت إلى حدوث تتمية في الوعي البيئي وفي أبعاده لأطفال المجموعة التجريبية وتفسيرها في ضوه

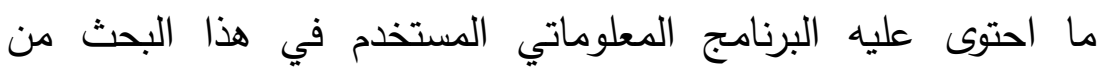

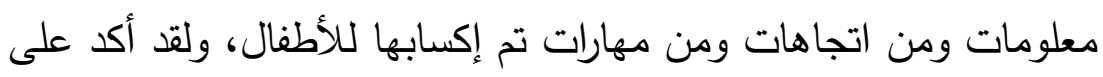
ذلك ما قام به أطفال المجموعة التجريبية من مشاركة بخبراتهم السابقة

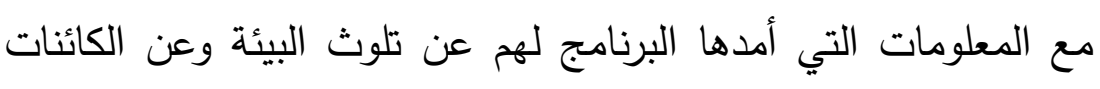

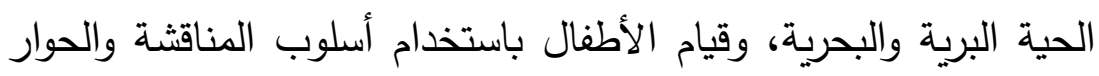
حول توخي الحذر أثناء حدوث ما يلوث البيئة من ملوثات، وأثناء التعامل مع الكائنات التي تعيش في البيئة برياً وبحرياً لأنه قد تصيب لتئه

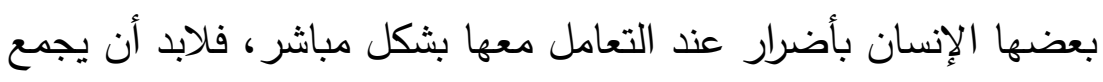
كل طفل معلومات كثيرة عنها قبل التعامل معها. 
- كما يمكن تفسير نتائج هذا البحث من خلال إضافة عنصر إقامة معرض بالمدرسة يحتوي على أشكال ونماذج لبعض الكائنات البرية

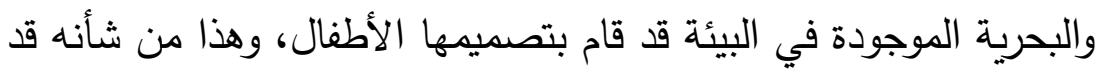

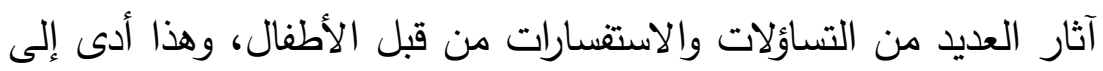
سعي الأطفال بشغف إلى اكتشاف العديد من المعارف البيئية الحقيقية

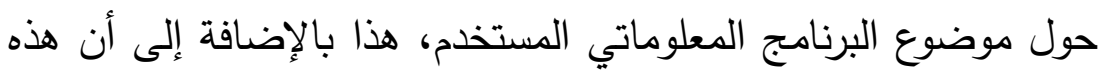
المعارض قد آثارت لدى الأطفال ميل وحب نحون هور هذه الكائنات البيئية

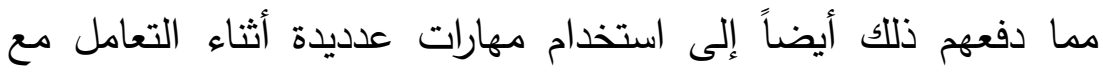
الكائنات البيئية - والذي يمكن ملاحظته أثناء التعامل مع أطفال المجموعة التجريبية وأثناء إعدادهم للخامات والنماذج والصور والأشكال الخاصة بالكائنات الحية الموجودة في البيئة أنهم كانوا يقومون بمهارات عقلية عديدة تمثلت في مهارات مثل الاختيار والترتيب والتصنيف والفهر والإدرالك والمقارنة والاستدلال والتركيب والتفكير، وكان الأطفال يقومون بتسجيل بعض الملاحظات حول ما يقومون به عمليات مختلفة، وكانوا يستخدمون هذه الملاحظات أثناء إجراء المناقشة معهم، ولقد قام الأطفال بتكوين معرضاً للصور ضم صور للبيئات المختلفة (الزراعية، الصناعية،

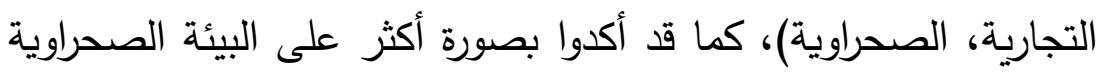

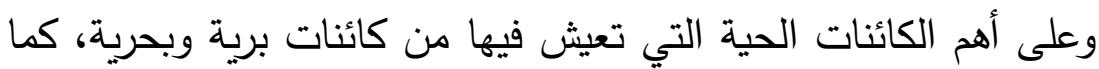
كانت تدور المناقثات مع الأطفال حول أهمية الاعتناء بما تحتويه البيئة من كائنات مفيدة للإنشان، وكيفية المحافظة عليها، وكيفية تقديرها والالهتمام بها. - ويمكن تفسير نتائج هذا البحث أيضاً من خلال قيام أطفال المجموعة التجريبية برحلة مدرسية إلى النادي العلمي، وقد اكتسبوا معلومات كثيرة عن الكائنات الحية من خلال مشاهدة بعضها بصورة حقيقية في النادي

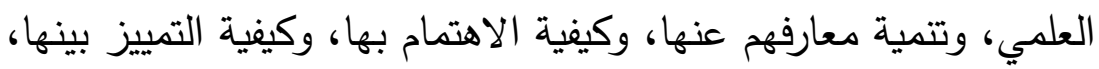


هذا بالإضافة إلى أنه قد تم تعريف الأطفال بكل ما يحتاجونه من كائنات برية وبحرية وما تحتاجه هذه الكائنات من ماء وهواء وشمس وضوه وحرارة، وكيفية الحفاظ على هذه الموارد الطبيعية، كما قد اكتسب الأطفال الكثير من الاتجاهات البيئية الايجابية مثل الاهتمام والمحافظة

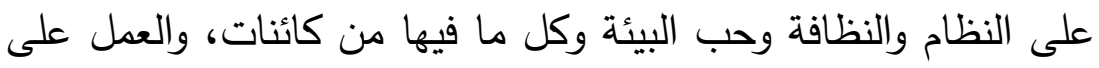
تجنب الملوثات، كما اكتسب الأطفال العديد من المهارات البيئية التي وحني مكنتهم من كيفية التعاون والتعامل مع البيئة، وكيفية الوصول إلى حلول

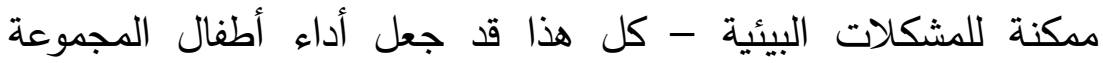

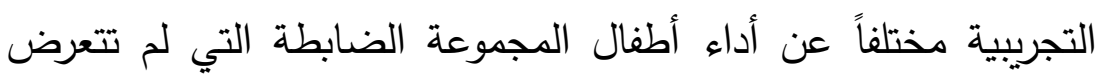
لأنشطة البرنامج المعلوماتي المستخدم. - ويمكن تفسير نتائج هذا البحث في ضوه ماني ما تضمنه البرنامج المعلوماتي المستخدم من خلال مشاركة أطفال المجموعة التجريبية بوصف وتمثيل المعلومات التي اكتسبوها من البرنامج ومناقثة وتفسير الصور والنماذج المختلفة عن الكائنات الحية وفي ضوء ما تم مشاهدته في الواقع وما عرفوه عنها، كما شارك الأطفال بحركات تمثيلية لتقليد حركات بعض الكائنات الحية التي تم مشاهدتها في الواقع من خلال قيامهر بتأليف تمثيليات عن الأشجار والكائنات الحية، وكانوا يألفون

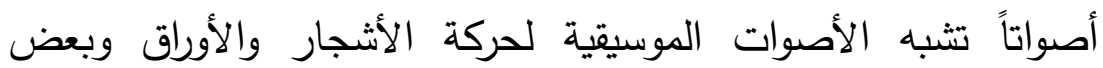

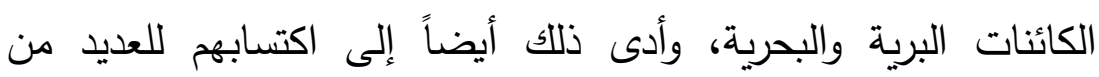

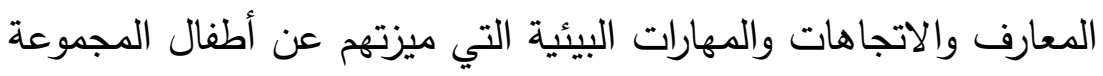
الضابطة. - وقد صاحب اكتساب أطفال المجموعة التجريبية للمعارف والاتجاهات والمهارات البيئية سماعهم وترويدهم لبعض الأغاني من خلال عزفها باستخدام آلة العود، وكانت تلك الأغاني بسيطة جداً وقصيرة وسهلة لبهن

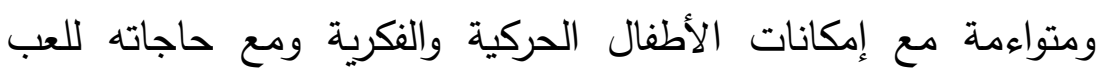


والنشاط، وكان سماع الطفل للموسيقى من أبرز وأهم الأنشطة التي اعتمد

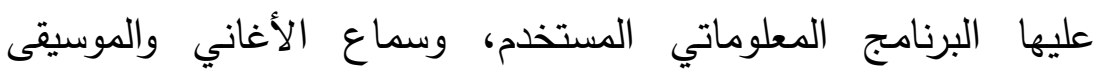
وترديدها من أهم الأنشطة في مرحلة الطفولة التي يستغرق فيها الطفل

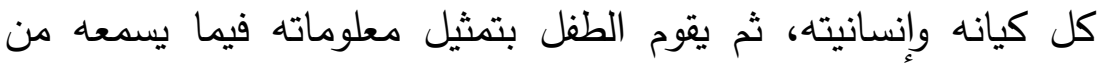

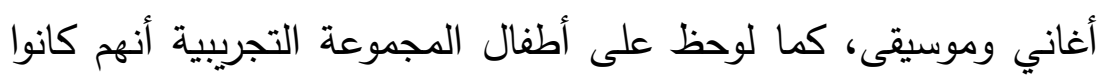

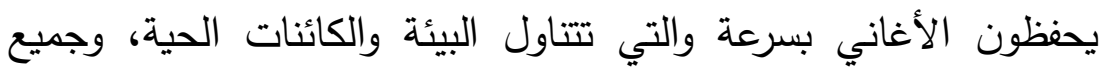

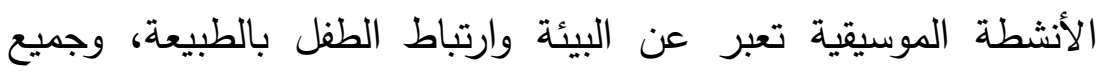
الموسيقى التي احتوى عليها البرنامج المعلوماتي المستخدم في هذا لهان البحث ترتبط بالبيئة المحيطة بالطفل لتعريفه بالبيئة بكائناتها الحية البرية

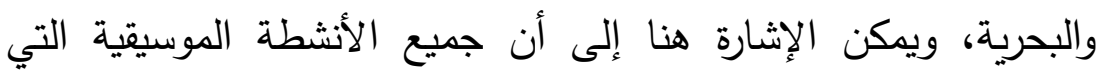

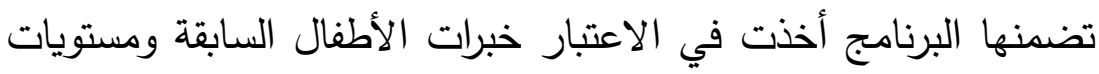

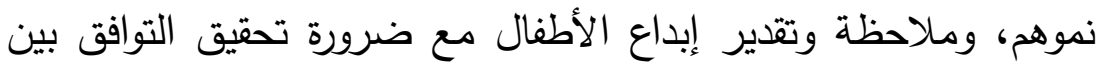
محتويات البرنامج وحاجات الأطفال. - وعند تفسير نتائج هذا البحث يمكن الإشارة إلى أن البرنامج المعلوماتي المستخدم قد احتوى على مجموعة من الأنشطة قد قام بها أطفال المجموعة التجريبية بكل نشاط وحيوية في شكل تعاوني، وفي أثناء خطوات البرنامج فإن الأطفال كانوا يكتسبون معلومات واتجاهات لتُبهات

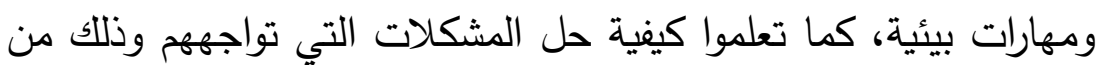
خلال انخراطهم في أنشطة كل خطوة من خطوات البرنامج، ومن خلال

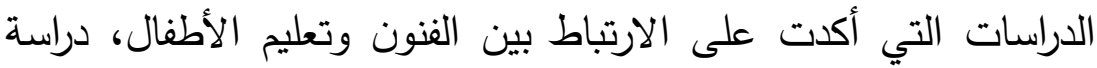
"سبنسر" (Spencer, C. et al. 1999) التي قدمت للأطفال خمسة أمثلة لمشروعات مختلفة لتنمية الوعي البيئي، والمهارات البيئية للأطفال

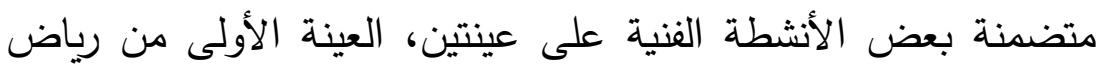
الأطفال، العينة الثانية من أطفال المرحلة الابتدائية، وأثارت نتائج هذه الانه

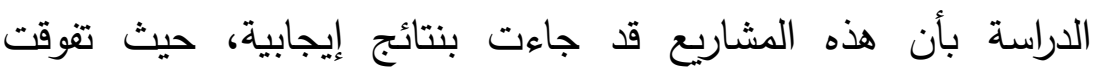


المجموعة التجريبية عن المجموعة الضابطة من حيث اكتسابهم الإدراك والوعي البيئي والمهارات البيئية. - والنتائج التي تم التوصل إليها في البحث الحالي أكدت فاعلية البرنامج المعلوماتي القائم على استخدام بعض الأنشطة الموسيقية في تتمية

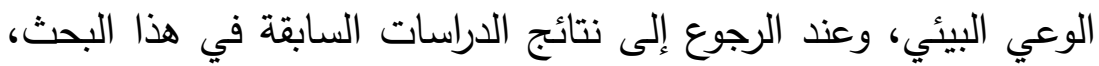
اتضح أنه لا توجد أي دراسة تتاولت تتمية الوعي البيئي من خلال

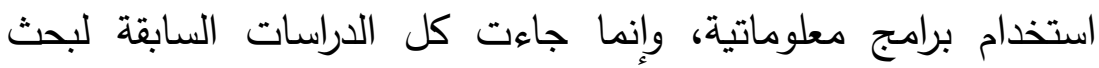
العلاقة بين الوعي البيئي وبين متغيرات أخرى - ومن هنا كانت أهمية

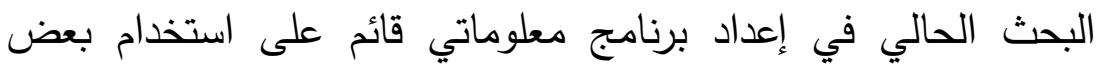
الأنشطة الموسيقية في تتمية الوعي البيئي لدى عينة من أطفال الصف الصفاتي

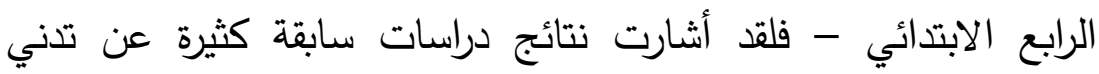

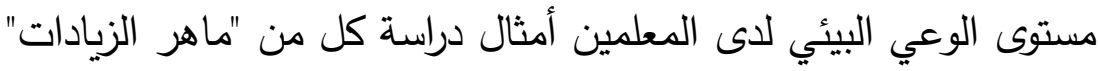

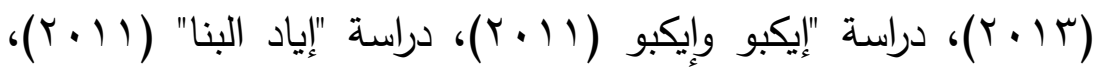

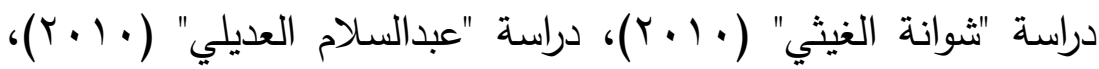

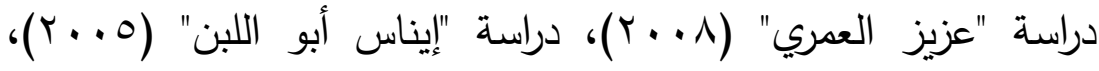
دراسة "ماك كيون - آيس" ( . . . ب)، دراسة "حمدي الصباغ" (999 (199)

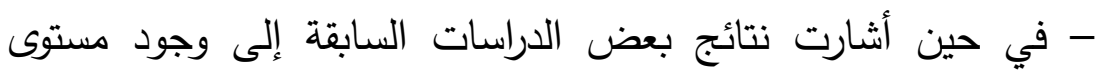

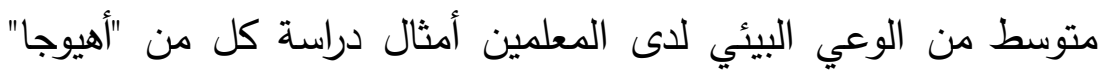

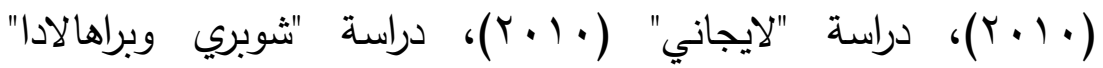

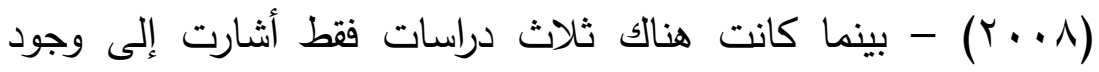

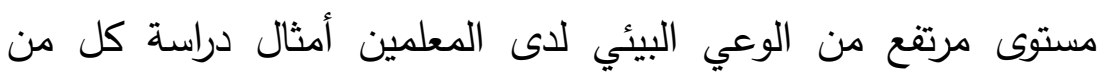

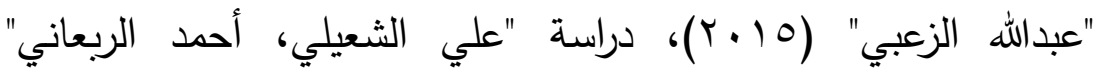

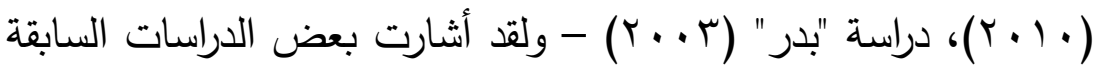
إلى أن الإناث الأكثر وعياً بالبيئة من الذكور، وأثارت البعض باته الآخر إلى عدم اختلاف مستوى الوعي البيئي بين الذكور والإناث - كما 
أشارت نتائج بعض الدراسات إلى اختلاف مستوى الوعي البيئي باختلاف تخصص المعلم أو المعلمة. التوصيات والمقترحات في ضوء ما توصل إليه البحث الحالي من نتائج، فإنه يوصي بالتالي:ا - إجراء دراسات مماثلة على عينات مختلفة من المراحل التعليمية المختلفة.

r - عقد دورات تدريبية للمعلمين والمعلمات في مختلف التعليم للتدريب على استخدام برامج معلوماتية قائمة على بعض الأنشطة الموسيقية لتنمية الوعي البيئي للطلبة.

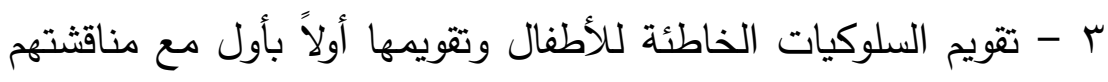
فيما يجب أن يفعلوه تجاه بيئاتهم. ع - الاهتمام بحديقة المدرسة نظيفة أمام الأطفال.

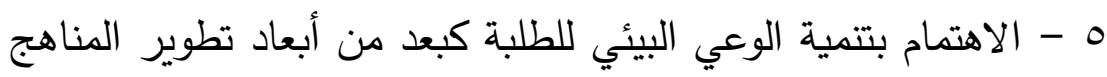
والمقررات الدراسية في مختلف مراحل التعليم. 7 - تطوير مهارات وقدرات الطلبة على التفكير كأبعاد من الوعي البيئي. V تدرس في كليات التربية. ᄉ - تشجيع الطلبة على الحفاظ على البيئة من خلال تتمية الحس الفني والروحي لديهم.

9 - الاهتمام بتضمين عناصر مثل القيم والعادات والتقاليد المجتمعية أثناء تصميم البرامج التي تساعد في تتمية الوعي البيئي للى لهي الطلبة.

• 1- الاهتمام بتنمية حب الطلبة للطبيعة من خلال القيان بالزيارات المستمرة للحدائق والمتنزهات لمشاهدة المناظر الطبيعية. 
المجلد السادس والعشرون (العدد الرابع) لسنة 7 r r

مجلة كلية التربية ـ جامعة الإسكندرية

11- استخدام بعض الأنشطة لتتمية معارف واتجاهات ومهارات الطلبة

نحو البيئة. 


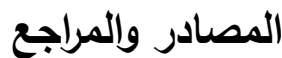

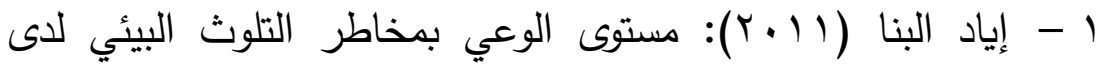

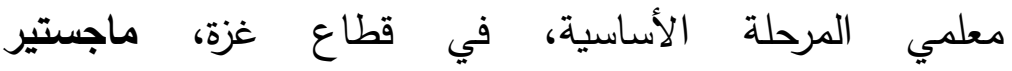
(غير منشورة)، الجامعة الإسلامية، غزة، فلسطين.

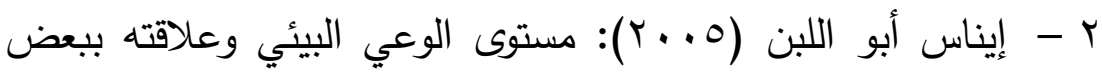
المتغيرات لدى طلبة كليات التربية في الجامعات الفلسطينية بمحافظة غزة، ماجستير (غير منشورة)، الجامعة الإسلامية، غزة، فلسطين.

r - جورجيت دميان جورج (ץ+ץ): متطلبات تفعيل الدور التربوي لرياض الأطفال والحلقة الابتدائية في تتمية الوعي البيئي في مرحلة الطفولة، المؤتمر السنوي الأول لمركز رعاية وتنمية

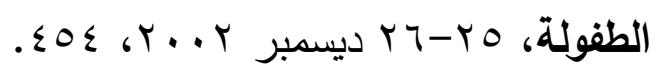

ـ - حدي الصباغ (999 (1): الوعي البيئي لدى طلاب كلية المعلمين بالمدينة المنورة، ورقة عمل مقدمة للمؤتمر التربوي الثالث لإعداد المعلم، المنعقد بكلية التربية، جامعة أم القرى، السعودية، مكة

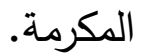

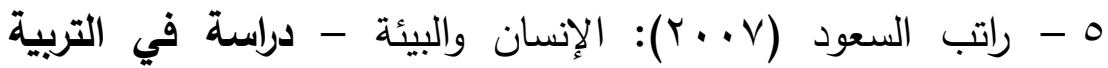

البيئية، طץ، عمان، الأردن، دار ومكتبة الحامد للنشر والتوزيع.

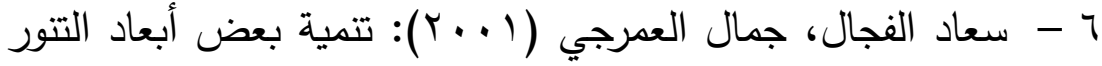
البيئي لدى تلاميذ الصف الرابع الابتدائي من خلال منهج الدراسات الاجتماعية في ضوء متطلبيات الثورة المعرفية والتكنولوجيا المعاصرة، ورقة عمل مقدمة للمؤتمر العلمي الثالث عشر: مناهج التعليم والثورة المعرفية والتكنولوجيا المعاصرة، ولمبه القاهرة، كلية التربية، جامعة عين شمس. 
- V

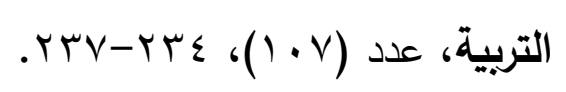

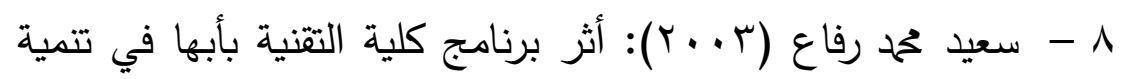

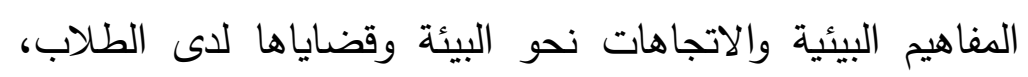

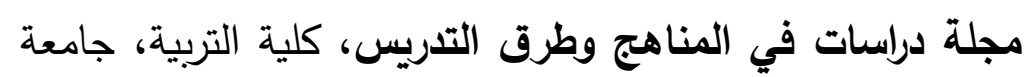

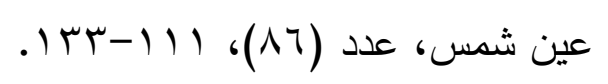

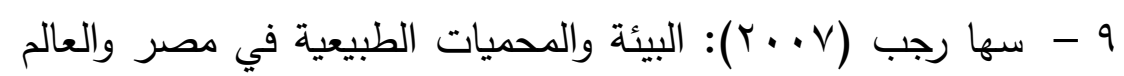

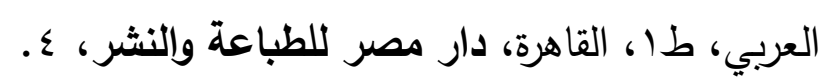

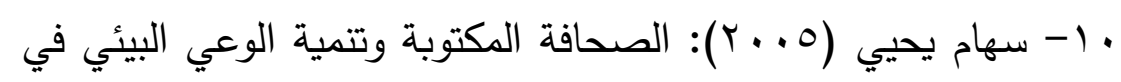

الجزائر ، ماجستير (غير منشورة)، الجزائر ، جامعة منتوري. (باه

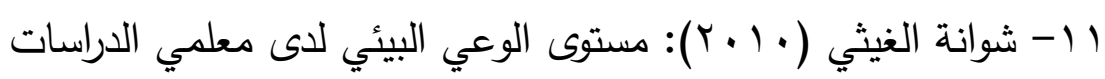

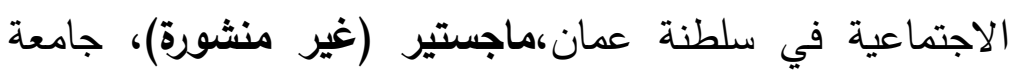

السلطان قابوس، سلطنة عمان، مسقط.

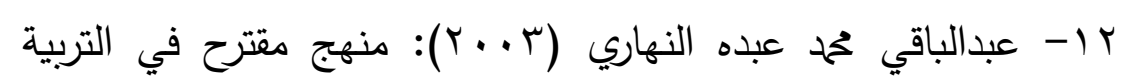

البيئية لتتمية المفاهيم والاتجاهات البيئية لدى طلبة كلية التربية

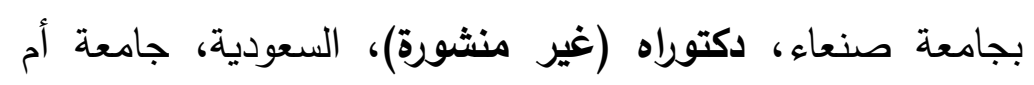

$$
\text { القرى. }
$$

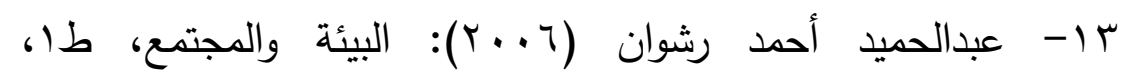
الإسكندرية، دار المعارف، 7.

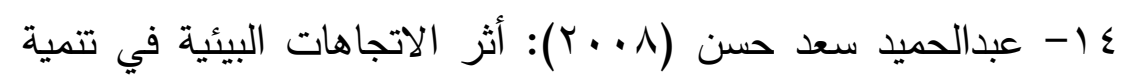
السلوك البيئي المسئول لاى طلبة كلية التربية بجامعة السلطان

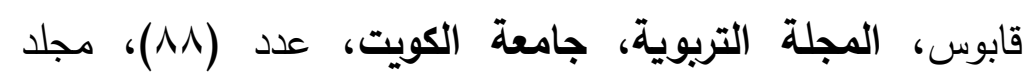

$$
\text { . } \varepsilon r-1 \Lambda ،(\cdot r r
$$

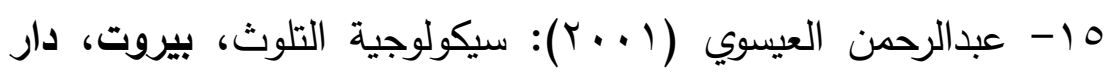

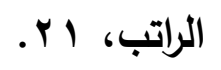


T 1 - عبدالرحمن محمد السعدني، أماني مصطفى البساط (Y + . Y): التتوير

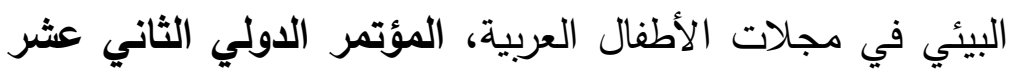

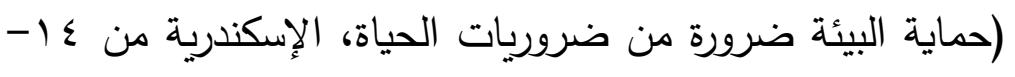

$$
\text { } 17
$$

IV المعلمين في جامعة الزرقاء الخاصة وعلاقته ببعض المتغيرات،

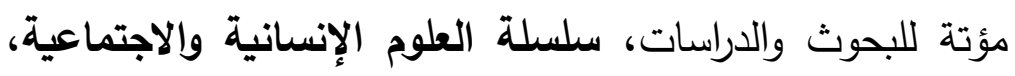

$$
. r) \leqslant-110 \text { ، r (r) ro }
$$

11 1- عبدالله سالم الزعبي (10 • ب): مستوى الوعي البيئي لدى طلبة كلية

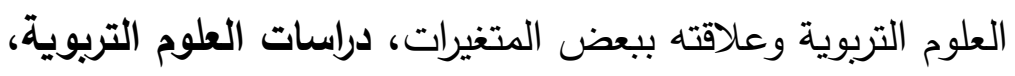

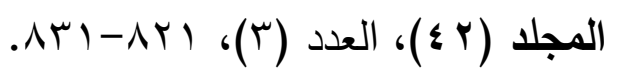

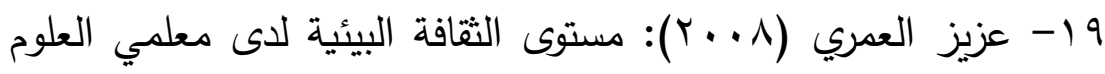
بالمرحلة الابتدائية في مدينة تبوك، ماجستير (غير منشورة)، جامعة أم القرى، السعودية، مكة المكرمة.

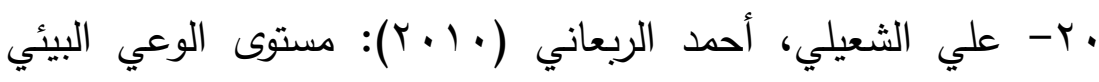
بالتغيرات المناخية لدى الطلبة المعلمين في تخصص التص العلوم

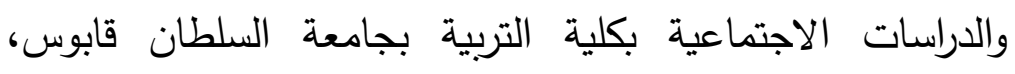

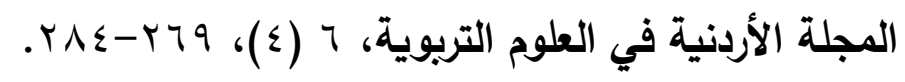

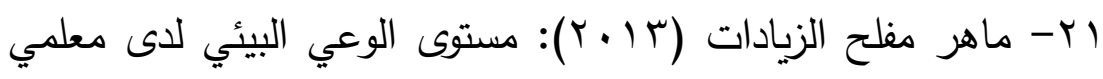

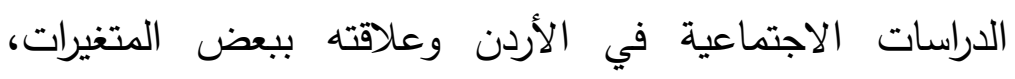

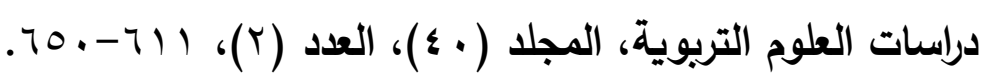

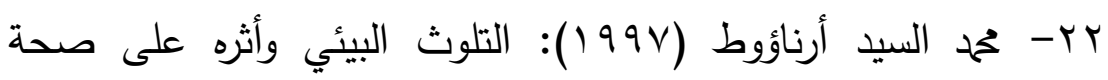

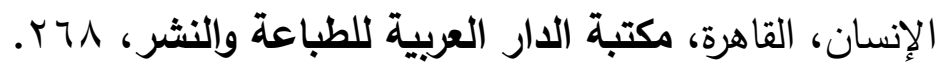

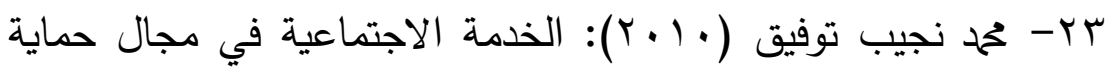

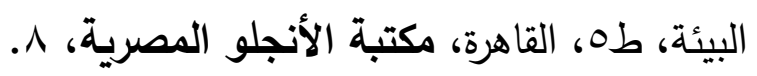




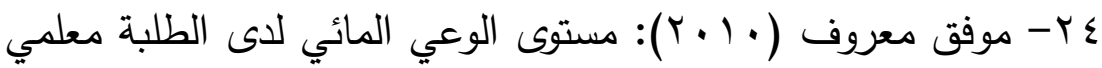

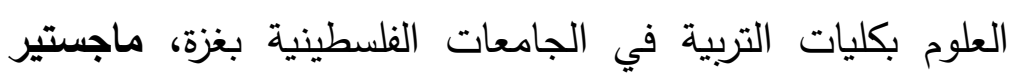
(غير منشورة)، الجامعة الإسلامية.

25 - Adora, 0. (2010): Strategies in environmental education in social studies, Environmental Education Research, Vol. (2), No.(2), 237-246.

26 - Ahuja, P. (2010) : A study of environmental awareness among B.ED. Teacher trainees of GOVT. aided and self financed colleges, International Research journal, Vol.(2), No.(1112), 28-30.

27 - Anvari, S.; Trainor,L.; Woodside, j. and levy,B. (2002): Relations among musical skills, phonological processing and early reading ability in preschool children, journal of Experimental child psychology, Vol. (83), 111-130.

28 - Astalin, P. (2011): A study of Environmental awareness among higher secondary students and some educational factors affecting it, international journal of multidisciplinary Reseach, Vol. (1), No.(7), 90-101.

29 - Bader, H. (2003): Environmental awareness and worry among high school teacher in Kuwait, The journal of the Egyptian Public Health Association, Vol. (78), No.(3+4), 319-339.

30 - Disinger, j.(2001): Education and the environmental perspectives, expectations and practice, the journal of Environmental Education, Vol . (33), No.(1), 4-11.

31 - Duvall, j. and Zint, M. (2007) : A Review of research on the effectiveness of environmental education in promoting international learning, The journal of Environmental Education, Vol.(38), No.(4), 14-24. 
32 - Ekpoh,U. and Ekpoh, I. (2011) : Assessing the Level of climate change awareness among secondary school teachers in calabar municipality, Nigeria: Implication for management effectiveness, International journal of Humanities and Social Science, Vol.(1), No.(3), 106-110.

32 - Ekpoh,U. and Ekpoh, I. (2011) : Assessing the Level of climate change awareness among secondary school teachers in calabar municipality, Nigeria: Implication for management effectiveness, International journal of Humanities and Social Science, Vol.(1), No.(3), 106-110.

33 - Forgeard, M.; Schlaug, G.; Norton, A.; Rosam, C.; Iyengar, U. and Winner, E. (2008): The Relation Between music and phonological processing in normal reading children and children with dyslexia, Music perception: An Interdisciplinary journal, Vol.(25), No. (4), 383-390.

34 - Huss, M.; Verney, j. ; Fosker , T.; Mead, N. and Goswami, U.(2011) : Music, rhythm, risetime perception and development dyslexia: perception of musical meter predicts reading and phonology, cortex, Vol. (47), 674-684.

35 - Ifeanyi, C. and Francis, C. (2000) : The Environmental and Global Security, The Environmentalist, Vol. (20), 41-48.

36 - jeronen, Elia et al. (2009) : Environmental education in finland- A case study of environmental education in nature school, published in international journal of Environmental and Science Education, Vol. (4), No. (1), january, 2009, 1-23.

37 - Klein,E. and Messitt, A. (2014): Environmental education as a model for constructivist teaching, journal of Environmental, vol.(25),No.(3), 1421. 
38 - Krishnamara, V. and Reddy, G. (2005): Environmental Education: Aims and objectives of environmental education: Importance of Environmental Education, Hyderabad: Neel Kamal Publications, PVT. Ltd.

39 - Larijani, M.(2010) : Assessment of environmental awareness among higher primary school teacher, journal of Human Ecology, Vol.(31), No.(2), 121-124.

40 - Malhotra, T. (2012) : A study of Environmental awareness among the post graduates of Kurukshetra university, International Referred Research journal, Vol.(3), No.(36), 56-58.

41 - Mckeown - Ice, R. (2000): Environmental education in the united states : A survey of preservice teacher education programs, the journal of Environmental Education, Vol.(32), No.(1), 4-11.

42 - Reason, P. (2005): Education for ecology: Science, aesthetics, spirit and ceremony, university of Bath, Uk.

43 - Rider, T. (2005): Education, Environmental attitudes and the design professions: A master thesis cornell university, U.S.A.

44 - Shobeiri, S. and prahallada, N. (2008): Environmental awareness among secondary school teachers in Iran And India, journal of environmental Science and Technology, Vol. (10), No.(36), 137-146.

45- Spencer, C. et al. (1994): Evaluating environmental induction in Nursery and Primary school, Education and Information, Vol. (3), No. (1). 
46 - Woodhouse, janice Lynn (2011) : Adult education in local environmental initiatives for Ecological and Cultural Sustainability, Doctorate Dessertation, Northern Illinois university, U.S.A. 